NBER WORKING PAPER SERIES

\title{
ECONOMIC ANALYSIS OF \\ PROPERTY LAW
}

Steven Shavell

Working Paper 9695

http://www.nber.org/papers/w9695

\section{NATIONAL BUREAU OF ECONOMIC RESEARCH 1050 Massachusetts Avenue \\ Cambridge, MA 02138 \\ May 2003}

Research support from the John M. Olin Center for Law, Economics, and Business is gratefully acknowledged. The views expressed herein are those of the authors and not necessarily those of the National Bureau of Economic Research.

(C)2003 by Steven Shavell. All rights reserved. Short sections of text not to exceed two paragraphs, may be quoted without explicit permission provided that full credit including Cnotice, is given to the source. 
Economic Analysis of Property Law

Steven Shavell

NBER Working Paper No. 9695

May 2003

JEL No. H4, K2, K11, L5

\begin{abstract}
This part deals with the basic elements of property law. I begin in chapter 7 by examining the fundamental question of what justifies the social institution of property, that is, the rationale for the rights that constitute what we commonly call ownership. I also discuss examples of the emergence of property rights.

Then I consider a number of important issues about property rights. In chapter 8 , I inquire about the division of property rights (property rights may be divided contemporaneously, over time, and according to contingency). In chapter 9, I study a variety of issues about the acquisition and transfer of property, including the discovery of unowned or lost property, registration systems for transfer of property, and the transfer of property at death. In chapter 10, I investigate "externalities" and property -- problems concerning cooperation and conflict in the use of property, together with the resolution of such problems through bargaining and legal rules. In chapter 11, I discuss public property; here I address the question of why the state should own property, and also the manner of state acquisition of property through purchase or by the exercise of powers of eminent domain.
\end{abstract}

Finally, in chapter 12, I analyze the special topic of intellectual property.

Steven Shavell

Harvard Law School

1575 Massachusetts Avenue

Hauser Hall 508

Cambridge, MA 02138

and NBER

shavell@law.harvard.edu 


\title{
Table of Contents
}

\section{Economic Analysis of Property Law}

\author{
(part of Foundations of Economic Analysis of Law)
}

\section{Chapter 7. Definition, Justification, and Emergence of Property Rights}

1. Property Rights Defined

2. Justifications for Property Rights

3. The Emergence of Property Rights

\section{Chapter 8. Division of Property Rights}

1. Division of Rights Described

2. Social Advantages and Disadvantages of Division of Possessory Rights

3. Social Advantages and Disadvantages of Separation of Possessory Rights from Rights to Transfer Possessory Rights

4. The Socially Optimal Division of Property Rights, Their Actual Division, and the Law

\section{Chapter 9. Acquisition and Transfer of Property}

1. Acquisition of Unowned Property

2. Loss and Recovery of Property

3. Sale of Property -- In General

4. Registration Systems and Sale and Theft of Property

5. Sale and Theft of Property in the Absence of a Registration System

6. Constraints on the Sale of Property Imposed by the State

7. Gifts

8. Transfer of Property at Death: Bequests

9. Control of Property after Death: The "Dead Hand"

10. Involuntary Transfer of Property: Adverse Possession

Chapter 10. Conflict and Cooperation in the Use of Property: The Problem of Externalities

1. Notion of External Effects in the Use of Property

2. Socially Optimal Resolution of External Effects

3. Resolution of Externalities Through Frictionless Bargaining

4. Why Bargaining May Not Occur and, If It Does, Why It May Fail To Result in Mutually Beneficial Agreements

5. Resolution of External Effects Through Legal Rules in the Absence of Successful Bargaining

6. Resolution of External Effects Through Legal Rules Given the Possibility of Bargaining

\section{Chapter 11. Public Property}

1. Justifications for Public Property

2. Acquisition of Property by the State: By Purchase and by Power of Eminent Domain

Chapter 12. Property Rights in Information

1. Information of Repeat Value

2. Other Types of Information

3. Information of Value as a Label 


\section{Summary Table of Contents}

\section{Foundations of Economic Analysis of Law}

(forthcoming 2003, Harvard University Press)

Chapter 1. Introduction

Part One. Accident Law

Chapter 2. Liability and Deterrence: Basic Theory

Chapter 3. Liability of Firms

Chapter 4. Extensions of the Basic Theory

Chapter 5. Liability, Risk-bearing, and Insurance

Chapter 6. Liability and Administrative Costs

Part Two. Property Law

Chapter 7. Definition, Justification, and Emergence of Property Rights

Chapter 8. Division of Property Rights

Chapter 9. Acquisition and Transfer of Property

Chapter 10. Conflict and Cooperation in the Use of Property: The Problem of Externalities

Chapter 11. Public Property

Chapter 12. Property Rights in Information

Part Three. Contract Law

Chapter 13. Overview of Contracts

Chapter 14. Contract Formation

Chapter 15. Production Contracts

Chapter 16. Other Types of Contract

Part Four. Litigation and the Legal Process

Chapter 17. Basic Theory of Litigation

Chapter 18. Extensions of the Basic Theory of Litigation

Chapter 19. General Topics on the Legal Process

Part Five. Public Law Enforcement and Criminal Law

Chapter 20. Deterrence with Monetary Sanctions

Chapter 21. Deterrence with Nonmonetary Sanctions

Chapter 22. Extensions of the Theory of Deterrence

Chapter 23. Other Functions of Sanctions: Incapacitation, Rehabilitation, Retribution

Chapter 24. Criminal Law

Part Six. General Structure of the Law

Chapter 25. The General Structure of the Law and Its Optimality

Part Seven. Welfare Economics, Morality, and the Law

Chapter 26. Welfare Economics and Morality

Chapter 27. Implications for the Analysis of Law

Chapter 28. Income Distributional Equity and the Law

$* * *$

Chapter 29. Commonly-Raised Questions about Economic Analysis of Law 


\section{Chapter 7}

\section{DEFINITION, JUSTIFICATION, AND EMERGENCE OF PROPERTY RIGHTS}

In this chapter, I first define property rights, then address the question of their justification, that is, the advantages that might be thought to explain their existence, and last discuss several instances of their emergence.

\section{Property Rights Defined}

I will use the term "property rights" to refer broadly to two subsidiary types of rights, possessory rights and rights of transfer.

1.1 Possessory rights. What are often called possessory rights allow individuals to use things and to prevent others from using them. ${ }^{1}$ A particular possessory right is a right to commit a particular act or a right to prevent others from committing a particular act. $^{2}$

On reflection, it can be seen that common property arrangements entail considerable agglomerations of possessory rights, but with certain limitations. The basic notion of ownership embraces a large bundle of possessory rights subject to exceptions. When we say that a person owns a parcel of land, we ordinarily mean that the person can do virtually as he pleases on the land (plant crops on it, build on it, leave it idle) over time and under most contingencies. Also included in the idea of ownership is the right of the owner to prevent others from using what he owns over time and in most contingencies. However, the owner's possessory rights are not absolute. If a use harms others (maintaining a compost heap that produces noxious odors), it may be proscribed; or, under certain conditions, an owner may be compelled to allow others to use his things (in an emergency, someone might be permitted to seek shelter on his land).

Likewise, under rental provisions, the renter of property generally enjoys a large swath of possessory rights, most of those associated with ownership. For example, someone who rents an apartment can use it more or less as he pleases and bar the entry of others, even generally the landlord. But there may be limitations on the renter's possessory rights that would not be faced by an owner-occupier; typically, a renter of an apartment is forbidden from making major modifications to it.

Another example worth noting is property arrangements within enterprises. When a person is working for an enterprise, he will often enjoy certain possessory rights. A person may be able to do a variety of things in the office to which he is assigned and exclude others from it under a fairly wide range of circumstances.

\footnotetext{
${ }^{1}$ The subject of the enforcement of these and other rights will be addressed generally in Part Five. Here I shall simply assume that property rights are upheld.

${ }^{2}$ A completely specified act includes in its description the place, time, and contingency under which it is committed -- for example, digging at a designated location, on Thursday at 4 PM, if it is not raining (the contingency).
} 
In strict logic, and for some purposes, it will be helpful to reduce such common property arrangements to their more basic elements, including the arrays of possessory rights that they encompass.

1.2 Rights of transfer. The other type of right associated with the notion of property rights is a right to transfer a possessory right, that is, the option of a person who holds a possessory right to give it to another person (usually, in exchange for something). Closely related, but distinct, is the right of the recipient subsequently to transfer his possessory right to another person (and for that person to do the same, and so forth). We will assume unless otherwise noted that rights to transfer possessory rights implicitly include these subsequent-order rights to transfer.

It is apparent that common property arrangements entail certain rights to transfer possessory rights. The concept of ownership incorporates not only possessory rights, but also rights to transfer these possessory rights; an owner is usually presumed to be able to sell or give away his property, in which case the acquirer obtains all the possessory rights held by the owner, as well as the rights to transfer these rights. Under rental arrangements, however, the renter of a thing may or may not enjoy the right to transfer his possessory rights to another. A person who rents an apartment may be allowed to rent to another (to "sublet"), or he may be prevented from doing this according to his rental agreement.

As a general matter, if we want to be precise about the meaning of property rights, we should describe an arrangement in terms of the entailed possessory rights and rights to transfer.

\section{Justifications for Property Rights}

2.1 The general question of justification. A time-honored and fundamental question is why there should be any property rights in things. That is, in what respects does the protection of possessory interests in things and the ability to transfer them promote social welfare, broadly construed? I now consider a list of factors suggesting that the existence of property rights fosters social welfare.

2.2 Incentives to work. It is often said that property rights provide individuals with incentives to work, and it is worth examining this argument in some detail. For this purpose, consider initially a stylized model in which individuals produce a good and in which the measure of social welfare is the utility from the good less the disutility of work. The determination of the socially optimal amount of work is plain in the model. It is best for an individual to work an additional hour if and only if the increment in utility from consuming what would be produced in that hour exceeds the disutility of work from the hour.

Example 1. Individuals can work either 0, 1, 2, or 3 hours, and each hour an individual works he produces one unit of output. The total utility he derives from output, the total disutility of work, and social welfare per individual (utility from output minus disutility from work) are as shown in Table 1. 


\begin{tabular}{|c|l|l|l|l|}
\hline \multicolumn{2}{|l|}{ Table 1: Hours, Output, and Social Welfare } \\
\hline Hours of work & Output & $\begin{array}{l}\text { Utility from } \\
\text { output }\end{array}$ & $\begin{array}{l}\text { Disutility from } \\
\text { work }\end{array}$ & Social welfare \\
\hline 0 & 0 & 0 & 0 & 0 \\
\hline 1 & 1 & 10 & 6 & 4 \\
\hline 2 & 2 & 18 & 13 & 5 \\
\hline 3 & 3 & 24 & 22 & 2 \\
\hline
\end{tabular}

Social welfare is maximized if each individual works two hours. Working the first hour is beneficial since it augments utility by 10 and involves disutility of only 6 ; working a second hour raises an individual's welfare further because it increases utility by 8 and increases disutility by only 7; but working a third hour would increase utility by only 6 and involve greater disutility of 9.//

Socially optimal amount of work is not performed in the absence of property rights. If there are no property rights, individuals will tend not to work the socially optimal amount and social welfare will be less than optimal in the model just described because of problems with individuals' incentives to work. In a situation in which property rights do not exist, an individual will take into account that his output may be taken from him. In deciding whether to work an extra hour, an individual will compare the increment in utility from consuming the additional amount of his production that he will be able to keep -- rather than the whole of the additional amount of his production -- to the disutility of work from the hour. When the individual makes this determination, he may well decide to work less than optimally because he will enjoy less utility from the smaller amount of output that he will retain for his own use. Let us illustrate this point.

Example 2. Modify Example1 by assuming that each individual will lose half of what he produces to others who can take that amount. Then each individual will choose not to work at all, for the situation facing each individual will be as follows. ${ }^{3}$

\section{Table 2: Hours and Output in the Absence of Property Rights}

\begin{tabular}{|c|l|l|l|l|}
\hline Hours of work & Retained output & $\begin{array}{l}\text { Utility from } \\
\text { output }\end{array}$ & $\begin{array}{l}\text { Disutility from } \\
\text { work }\end{array}$ & $\begin{array}{l}\text { Individual } \\
\text { welfare }\end{array}$ \\
\hline 0 & 0 & 0 & 0 & 0 \\
\hline 1 & .5 & 5 & 6 & $! 1$ \\
\hline 2 & 1 & 10 & 13 & $! 3$ \\
\hline 3 & 1.5 & 14 & 22 & $! 8$ \\
\hline
\end{tabular}

${ }^{3}$ The utilities for outputs of .5 and 1.5 are assumed to be as displayed and are consistent with the previous table. 
Here an individual will not even work the first hour because he will be able to keep and consume only .5 units of output, and therefore enjoy utility of only 5 , which is less than the disutility of work of 6 , and so forth.//

In this example, individuals decide not to work at all, so that social welfare is zero. If, however, the example is altered and individuals lose a smaller fraction of their output, they will work a positive amount. This also means that a positive amount would be taken from them, which raises two complications. First, whoever takes output will have it to consume -- in other words, what is taken will still contribute to social welfare. Second, the incentives to work of whoever takes from others have to be reexamined. But neither of these complications changes the conclusion that the amount of work and the level of social welfare will generally deviate from the optimal. ${ }^{4}$

Another point to be noted in the absence of property rights is that it is possible that individuals will choose to work more than the optimal number of hours, not less. ${ }^{5}$ Suppose that having a certain minimum amount of output to consume is important for subsistence. Then, to guarantee that he will retain this amount after others have taken some output from him, an individual might well be inclined to work more than he otherwise would. ${ }^{6}$ Although total output

\footnotetext{
${ }^{4}$ Suppose, for instance, that the individuals in the model are identical to one another and each has the opportunity not only to work and produce, but also freely to take a fraction of the output of another person. Then an individual's incentives to work will remain undesirable, for it will still be true that in deciding whether to work an extra hour, the individual will know that he will not be able to keep the full amount of what he produces in the hour.

Formally, we can show that individuals will work too little under certain assumptions. Let " be the fraction of the output that is taken, $w$ be hours of work and also output produced, $u(w)$ be utility from output consumed, where $u^{\prime}(w)>0$ and $u^{\prime \prime}(w)<0$, and $d(w)$ be disutility of work, where $d^{\prime}(w)>0$ and $d^{\prime \prime}(w)$ $>0$. It is socially optimal for $w$ to maximize $u(w) ! d(w)$, implying that the optimal $w$ satisfies $u^{\prime}(w)=$ $d^{\prime}(w)$; let $w^{*}$ be the optimal $w$. If a fraction " is taken from individuals, however, then if $w^{\mathrm{e}}$ is the work the identical individuals generally choose, each particular individual will be able to take " $w^{\mathrm{e}}$ from another. Hence, each individual will select his $w$ to maximize $u\left(" w^{\mathrm{e}}+(1 ! ") w\right) ! d(w)$, implying that $(1 !$ " $) u^{\prime}\left(" w^{\mathrm{e}}\right.$ $+(1 ! ") w)=d^{\prime}(w)$. But in equilibrium, $w=w^{\mathrm{e}}$, so that we must have $(1 ! ") u^{\prime}\left(w^{\mathrm{e}}\right)=d^{\prime}\left(w^{\mathrm{e}}\right)$. This means that $w^{\mathrm{e}}<w^{*}$ (implicit differentiation of $(1 ! ") u^{\prime}\left(w^{\mathrm{e}}\right)=d^{\prime}\left(w^{\mathrm{e}}\right)$ with respect to " shows that $w^{\mathrm{e}}$ is decreasing in ", and $w^{*}$ corresponds to " $=0$ ).
}

${ }^{5}$ This possibility, that individuals might work more in the absence of property rights than in their presence, is occasionally -- and mistakenly -- interpreted as an argument against property rights. As I am about to explain, when individuals do work more in the absence of property rights, social welfare still tends to be lower than in the presence of property rights. The issue in question is whether the absence of property rights affects work incentives in such a way as to reduce social welfare, not whether work effort and production themselves fall or rise.

${ }^{6}$ Consider the following situation.

\begin{tabular}{||l|l|l|l|l||}
\hline Hours of work & Output & Utility from output & $\begin{array}{l}\text { Disutility from } \\
\text { work }\end{array}$ & Social welfare \\
\hline 0 & 0 & 0 & 0 & 0 \\
\hline 1 & 1 & 40 & 2 & 38 \\
\hline 2 & 2 & 45 & 10 & 35 \\
\hline
\end{tabular}


will be higher when individuals in the model work more than is optimal, social welfare will tend to be lower than optimal. This is for two reasons: The hours that individuals work in excess of the optimal number may be hours for which the disutility of work is high (the disutility of work may grow as the number of hours left in the day diminishes); ${ }^{7}$ the extra output may be unevenly distributed, contributing relatively little to an individual's utility if he already has substantial output. ${ }^{8}$

Socially optimal outcome is achievable under property rights: where each individual has rights in his own output. If each individual has possessory rights in the output he produces, he will work the socially optimal amount and social welfare will be maximized. This is one of the classic arguments for the desirability of property rights. In particular, an individual with possessory rights will know that he will be able to consume what he produces and thus he will compare the utility from the output he produces by working an extra hour to the disutility of work effort. In Example 1, individuals will choose to work two hours, the optimal amount. Another way of expressing why social optimality will result is that the goal of each individual will coincide with the social goal.

Socially optimal outcome is achievable under property rights: where a supervisory entity has rights in an individual's output. A different regime in which the socially optimal outcome may result involves an entity that enjoys possessory rights in individuals' output and that can supervise individuals' work. Such a supervisory entity might, for example, be a single-person owner of a farm. If a supervisory entity can monitor individuals' work, then, through use of appropriate rewards or punishments, it may be able to ensure that they work the optimal amount. Whether a supervisory entity's incentives will lead it to choose the optimal outcome, and how a regime with supervisory entities compares to a regime with individuals as possessors of property rights in their

Notice here that an individual gains most of his utility from the first unit of output (interpreted as that necessary for subsistence) and that working one hour is socially optimal. But if individuals would lose half of what they produce, so that it would take two hours to obtain one unit of output, an individual would work two hours: his welfare would then be $40 ! 10=30$, whereas if he would work one hour, his welfare would be only $20 ! 2=18$ (assuming the utility from .5 unit of output is 20 ).

\footnotetext{
${ }^{7}$ This is the case in the example of the previous note, where the second hour of work creates output that would be worth only 5 but involves extra disutility of 8 .

${ }^{8}$ To demonstrate the latter possibility, let us assume that individuals are identical and that there is a probability $p$ that each person will lose a fraction " of his output and an equal probability of the independent event that he will obtain " of someone else's output. Then (using the notation from note 4) an individual's expected utility will be $p^{2} u\left((1 ! ") w+" w^{\mathrm{e}}\right)+(1 ! p) p u\left(w+" w^{\mathrm{e}}\right)+p(1 ! p) u((1 ! ") w)+(1$ ! $p)^{2} u(w) ! d(w)$; the terms correspond to the events that he loses " of his output and gains " of another person's, that he does not lose any of his but gains " of another person's, and so forth. Because he will select $w$ to maximize his expected utility, and because $w=w^{\mathrm{e}}$ in equilibrium, we obtain the equilibrium condition $p^{2}(1 ! ") u^{\prime}\left(w^{\mathrm{e}}\right)+(1 ! p) p u^{\prime}\left((1+") w^{\mathrm{e}}\right)+$

$(1 ! ")(1 ! p) p u^{\prime}\left((1 ! ") w^{\mathrm{e}}\right)+(1 ! p)^{2} u^{\prime}\left(w^{\mathrm{e}}\right)=d^{\prime}\left(w^{\mathrm{e}}\right)$. Now the third term on the left side of this condition can be arbitrarily higher than $u^{\prime}\left(w^{\mathrm{e}}\right)$, for $(1 ! ") w^{\mathrm{e}}<w^{\mathrm{e}}$. Hence, the left side may exceed $d^{\prime}\left(w^{*}\right)$, implying that $w^{\mathrm{e}}>w^{*}$ is possible; that is, the equilibrium may be such that individuals work more and produce more than is optimal. They are also worse off than in the optimal situation. To see explicitly why this is so, note that, as is readily shown, if they work $w^{\mathrm{e}}$ and retain their entire output for sure, individuals are better off than in the risky situation; but we know that when they retain their output, they are better off working $w^{*}$ than $w^{\mathrm{e}}$.
} 
output, are, of course, different questions. The point here is simply that it is possible for the optimal outcome to be achieved if a supervisor has information about individuals' work effort and possessory rights in output.

Comments. (a) The conclusions just discussed about property rights and incentives to work carry over to more general and realistic settings (as will the conclusions about the other advantages of property rights to be discussed). In particular, in an economy with many kinds of goods and money as a medium of exchange, an individual's incentive to work will not inhere in his being able to consume the literal product of his labor. Rather, his incentive to work will involve his being able to consume the various goods purchased with his money wages. But this difference does not alter the point that an individual's incentives to work will tend toward the desirable under property rights and will tend to be suboptimal in their absence.

(b) In modern industrialized countries, the majority of individuals are motivated to work not because they consume or sell the output they produce, but rather because of the incentives and salary structure established by supervisory entities where they are employed. The individuals who have property rights in their own output are restricted mainly to certain farmers, artisans, shopowners, and independent professionals.

(c) In extreme instances in which property rights break down, we observe that little productive work is done. During civil wars and other episodes of great upheaval, productive work generally ceases. (Instead, people devote themselves to protecting what they have, and some engage in looting.)

2.3. Incentives to maintain and improve things. An essentially similar justification for property rights is that they are associated with incentives to maintain and improve things. If we reinterpret the model from the last section and assume that the result of work effort is the maintenance or improvement of durable things (as when individuals apply oil to machines or fertilize farm land), we may say that it is socially optimal for an individual to work an extra hour if the utility gained from maintenance and improvements exceeds the disutility of work. Further, this outcome will not occur in the absence of property rights; when durable things may be taken from individuals, they will not benefit from improving them (if a machine would be taken from an individual, he will not have an incentive to maintain it well). When, however, individuals hold possessory rights in durable things, they will have an optimal motive to improve the things because they will possess the things in the future and therefore be able to enjoy the gains from maintenance and improvements. Likewise, if there is a supervisory entity that can observe individual behavior, the supervisor can induce individuals to work optimally to maintain and improve things.

Comments. (a) Suppose that we take into account the possibility that durable things will be transferred in the future, for example, that farmland will change hands when the possessor becomes too old to continue to work. Then the socially optimal amount of effort to improve durable things will reflect the future use of things by new possessors as well as present ones; the socially desirable amount of fertilization of farmland will reflect the enhancement in its productivity for both current and future users. Moreover, the socially optimal improvement in durable things will be promoted not only by possessory rights, but also by rights to transfer things. Notably, possessors will often transfer things by selling them and sales prices will generally reflect improvements made in things. Because present owners will anticipate this, they will be led to make 
appropriate improvements for the advantage of future owners. The present owner of farmland will fertilize it for the benefit of future owners because that will allow him to sell the land to them at a higher price.

(b) Both forms of incentives to maintain and improve durable things, those deriving from ownership and those associated with a supervisory regime, seem important in reality. Individuals own many things, ranging from their clothing and other personal articles, to electronic equipment, automobiles, and real estate, and because they own such things, they are naturally led to take care of them. Where durable things are not owned but are rented (or are used by employees of enterprises), the present possessors need inducement to take into proper account the interests of future possessors. This is accomplished generally by use of maintenance requirements (to fertilize leased farmland), obligations to allow others to maintain things (to admit a landlord into an apartment to make repairs), and penalties for harm done (for damaging a rented vehicle).

(c) At the same time, we observe problems with the care of durable things when no one owns them or when there are substantial difficulties in monitoring the behavior of users of the things. For example, public parks often are treated irresponsibly (or are vandalized), the reason being that an individual will not generally be able to benefit personally in the future from any effort that he makes to maintain the park (if a person cleans a picnic table, he will probably not profit from that in the future because he will be unlikely to use that particular table again, or at least not before someone else does).

2.4 Incentives to transfer things. An additional advantage of property rights is that they foster the beneficial transfer of things. Let us now consider a model in which there are several types of goods. Then there are both direct and indirect reasons why it will be socially desirable for goods to be transferred among people.

The direct advantage of transfer of goods, that is, of trade, is that it raises the utilities of those who engage in it. This may be because the preferences of individuals differ. If a person who possesses parcel of land $\mathrm{X}$ and prefers parcel $\mathrm{Y}$ makes a trade with a person who possesses $\mathrm{Y}$ but prefers $\mathrm{X}$, both will be made better off by the exchange. Trade may also raise the utility of individuals who have similar, or even identical, preferences, because they may wish to consume a mix of different types of goods but possess only one or only several types of goods prior to trade. Suppose one person possesses two apples and no bananas, another possesses two bananas and no apples, and each would prefer to consume one piece of each fruit than two pieces of the same fruit. Then each person will be made better off by trading one piece of fruit for a piece of the other fruit.

In addition, the ability to trade enhances social welfare indirectly because it allows the use of efficient methods of production. Efficient methods of production take advantage of specialization and of agglomerations of individuals who devote themselves to making just one or several related goods. But this means that the allocation of goods immediately after they are produced is far from what is best for purposes of consumption; the individuals at a factory who produce thousands of units of some good cannot consume that good alone. The transfer and trade of produced goods enables each individual to consume many different types of goods.

It is clear that if only possessory rights exist, optimality will not be achieved because things that exist will not be traded. Individuals will produce solely for personal consumption rather than collectively organize and employ efficient production methods. 
If, however, individuals enjoy rights to transfer what they produce as well as possessory rights, then an optimal outcome is achievable. Mutually beneficial trades can in principle be consummated and, because this possibility will be anticipated, individuals will be willing to produce things that they would not want to consume but that they can trade to their advantage. Thus, efficient production will be promoted. Likewise, if supervisory entities have possessory as well as rights to transfer things, an optimal outcome is achievable. This presumes, however, that the supervisor has the necessary information, including in particular information about individuals' preferences.

Comments. (a) In the discussion of trade, mention has not been made of intermediate goods, that is, goods that are used in the production of other goods. The transferability of these intermediate goods is important to optimality. Were the transfer of intermediate goods hampered, enterprises would have to manufacture their own (automobile manufacturers would have to make their own computers, their own steel), which would be inefficient.

(b) We see in fact that both trade by individuals who enjoy rights of transfer and the command of supervisors help to achieve optimality. With regard to the former, the sale of personal property is obviously illustrative, as are transactions between enterprises in capitalist countries. With regard to the latter, transfers of equipment and also of output at different stages of production are typically governed by the command of superiors within an enterprise. Another example was the transfer of goods between state enterprises in centrally planned economies.

(c) We also see that when the right to transfer does not exist, or is enjoyed by a supervisor who does not exercise it well, outcomes are not socially desirable. When rights to crop-growing land are governed by the classical usufruct -- under which a person enjoys possessory rights in the land as long as he uses it but cannot sell it to another -- it is often observed that the land is used too intensively because the possessor has no future interest in caring for it. When rights to apartments are determined by the assignment of a social authority, instances often arise in which some families would be happy to trade apartments with each other (because, for example, they would then each live nearer to where they work) but are not allowed to make an exchange. When the transfer of goods in an economy is carried out according to the dictates of central planners, inefficiencies abound, with many potentially mutually beneficial trades not being carried out.

2.5 Avoidance of dispute and of efforts to protect or to take things. Disputes, which may involve physical conflict, and efforts devoted to protecting things or to taking things from others, are socially undesirable in themselves because they may result in harm and because they do not result in the production of things, only in their possible reallocation. In the absence of property rights, individuals will often find it rational to devote effort and resources to taking things from others, leading to disputes, and individuals will also find it rational to devote time and resources protecting their things from being taken. These undesirable outcomes will be avoided if the state stands ready to prevent the taking of things; in the ideal, the guarantee of property rights by the state will remove the motive to take or to protect things, and also the occurence of dispute.

Comments. (a) The problems that may arise when property rights are not well protected are rampant in certain parts of present-day Russia, South America, and Africa. Moreover, even in countries where the state makes a substantial effort to safeguard 
property, many individuals are engaged in the enterprise of theft, large sums are devoted to protecting property, and harm to individuals frequently comes about during robbery.

(b) There are two indirect but potentially important costs associated with lack of enforcement of property rights, in addition to the efforts expended to carry out theft and to preventing theft. First, things may be damaged when they are taken (when a radio is stolen from an automobile, the thief may break the automobile's window and damage the radio as well). Second, individuals may alter the types of things they use or produce in favor of what is most easily protected rather than what would best suit them (a farmer might grow crops rather than raise cattle, because the cattle could be stolen when grazing, even though the cattle would be more valuable to raise).

2.6 Protection against risk. Another advantage of property rights is that they provide individuals with protection against risk, which is socially valuable due to individuals' general risk aversion. The most obvious way that property rights afford such protection is that the protection of property rights means that individuals' holdings will not be stolen by others. Moreover, the system of property rights allows for insurance and risk-sharing arrangements, and thus for protection against a whole range of risks, those due to the uncertainties of nature (crop loss due to pests, floods), technological uncertainty (malfunction of products), and market uncertainty. On reflection, it is evident that property rights enable insurance and risk-sharing arrangements, for they cannot be made in the absence of possessory rights and rights of transfer.

2.7 Achievement of a desired distribution of wealth. Associated with any given measure of social welfare will be a socially optimal distribution of the available wealth, one that maximizes social welfare. In the absence of property rights, however, the distribution of wealth would be unlikely to tend toward the optimal, as it will be determined by the ability of individuals to take things from one another, to protect what they have, and by chance elements. By contrast, under a regime of property rights any desired distribution of wealth is achievable in principle, for the state may redistribute wealth and the new distribution will be maintained due to enforcement of property rights. ${ }^{9}$

Comments. (a) In fact, the problem of social welfare maximization involves not just the distribution of an available quantity of wealth, but also the production of wealth. And efforts to redistribute wealth in order to achieve a desired distribution generally influence incentives to produce wealth. ${ }^{10}$ Notably, if the amount that an individual must surrender in taxes to the state rises with his wealth or income, his incentive to work will often be compromised. This problem generally renders achievement of the ideal distribution of wealth infeasible, but it is plain that there is great scope for improvement over the distribution that would result without a system of property rights.

(b) The advantage of property rights under discussion is obviously a potential one, as the actual distribution of wealth depends on the political system and may depart substantially from a notion of the ideal. The point here is simply that without property

\footnotetext{
${ }^{9}$ This advantage of property rights is different from that concerning protection against risk, for individuals will be protected against risk under a regime of property rights regardless of the distribution of wealth.

${ }^{10}$ This subject is discussed in section 2 of chapter 28 .
} 
rights, the distribution of wealth is virtually certain to deviate greatly from the ideal (and the quantity of wealth available to be distributed will be small).

\subsection{Cautionary remark: The foregoing are justifications for some form of} property rights -- not necessarily for private property. If the advantages of property rights are sufficiently great, they will warrant the existence of some form of the rights. But arguments have not been given that support any specific form of property rights, in particular, for a regime of private property, wherein things generally are owned (and can be sold) by private parties, as opposed to the state. The benefits of property rights may often be enjoyed under very different property rights regimes. Notably, in a socialist state, just as in a capitalist one, the protection of possessory rights results in avoidance of dispute and of effort to take or to safeguard things; further, incentives to work in a socialist enterprise, just as in a capitalist one, may be fostered through use of a salary structure that rewards good behavior, even though individuals do not own their output; and so forth. The question of the circumstances in which a private property regime versus a socialist or another property rights regime is best is obviously significantly more complex than that of the justification for property rights per se and is beyond our scope. ${ }^{11}$

Note on the literature. The justification for property rights was of particular interest to seventeenth and eighteenth century political theorists, notably Hobbes, Locke, Hume, Blackstone, and Bentham (although the basis of property rights has been the object of scholarly inquiry from the earliest times ${ }^{12}$ ). These writers generally stress that in the absence of protection of possessory rights, individuals would take things from one another and disputes would arise, and the writers usually note that the motive to work would be compromised. They often mention also the advantages of trade in things, but they appear to see this more as a consequence of the existence of property rights than as an aspect of their justification. ${ }^{13}$ Today, most literature on property rights is concerned not with their basic justification, but rather with their most desirable character. ${ }^{14}$

\footnotetext{
${ }^{11}$ There is, of course, a vast and now highly elaborated literature on the virtues of private property and the price system versus central planning and socialism. For accessible introductions to and commentaries on this literature, see, for example, Heilbroner 1987, Kowalik 1987, and Shleifer 1998.

${ }^{12}$ There is a long history of writing on property rights, dating at least from Greek and Roman times. For example, Aristotle observes in his Politics that incentives may suffer when property is not private. For a critical chronology of the idea of property, see generally Schlatter 1951.

${ }^{13}$ Hobbes ([1651] 1958) stressed that in the absence of a state to protect things, there would be perpetual violence and no industry because of uncertainty of return; see especially part I, chapter 13. Locke 9 [1689] 1988) did not emphasize that property rights promote work effort. The core of his justification for property rights was that when a person devotes labor effort to produce something, it is only fair that he thereby acquires a property right in it; see Second Treatise, chapter 5. Hume ([1739] 1992) discussed the state's establishment of property rights as necessary to prevent individuals from taking from one another, but was not explicit about incentives to produce; he did, though, mention the value of trade; see book 3 , part 2, sections 2 and 4. Blackstone ([1765-1769] 1992) saw property rights protection as valuable because it averted disputes and furnished incentives to produce; he also noted the beneficial nature of trade; see book 2, chapter 1. Bentham ([1802] 1987) focused on the incentives created by property rights and mentioned as well the virtues of trade; see Principles of the Civil Code, part I, chapters 7, 8, and 10, and pt. II, chapter 2.

${ }^{14}$ However, Ellickson 1993 discusses the justification for property rights in land. Also, there are empirical studies of the general benefits of property rights; see the survey Besley 1998 and, for specific
} 


\section{The Emergence of Property Rights}

3.1 In general. We would expect property rights to emerge from a background of no rights, or poorly established rights, when the various advantages of property rights come to outweigh the costs of instituting and maintaining the rights. Property rights will be likely to arise in these circumstances because, if a substantial proportion of the population recognizes that it will be better off, or probably so, under a regime with property rights, individual or collective pressures will be brought to bear to develop them. ${ }^{15}$

3.2 Examples. A number of examples of the establishment of property rights illustrate their advantages.

(a) Rights in land during the California Gold Rush. When gold was discovered in California in 1848, property rights in land and minerals were largely undetermined, as the territory had just been acquired from Mexico, the population of the region was low, and, in any case, there were virtually no authorities to enforce law. After a short time, however, the gold-bearing area of California found itself divided into districts. In each district, men had made an explicit agreement governing property rights. Their compacts typically stated in detail how land was to be assigned and how theft and other infractions of rules were to be sanctioned (often by the loss of the violator's land or gold).

Why did the gold-seekers enter into these bargains? To obtain gold, individuals had to expend effort and make investments of one type or another. For instance, excavations had to be undertaken and sluices had to be constructed in which to separate gold from dirt. These tasks would not have been performed, and relatively little gold would have been collected, if individuals could not be reasonably confident that their gold would not be stolen and that the land on which they dug a ditch or on which they had built a sluice would not subsequently be taken over and benefit others. Moreover, the agreements were designed to prevent violence (in fact, there was little) and to reduce the need for each person to spend valuable time protecting his land. These advantages of property rights were recognized as mutual by the men who made the compacts in this quite dramatic instance of the emergence of property rights. ${ }^{16}$

(b) Rights in land on the Labrador Peninsula during the fur trade. At the time of the development of the fur trade on the Labrador Peninsula in North America, certain Indian tribes established a system of property rights in land, where none previously existed. An owner's territory was often marked off by identifiable blazes on trees and proprietorship included retaliation against trespassers. The explanation that has been suggested for this system of rights is that without the rights, overly intensive hunting of fur bearing animals (especially beaver) would have depleted the animal stock. With property rights, owners of land had incentives to husband their animal resources (for example, by sparing the young, and rotating the area of their land on which they trapped animals), because they would later be able to enjoy the benefits of having a larger stock.

examples, Alston et al.1996, Besley 1995, and Feder and Feeny 1991.

${ }^{15}$ Literature on the emergence of property rights is reviewed in Libecap 1986; see also related work of Bailey 1998 and Rose 1998.

${ }^{16}$ The development of property rights during the California Gold Rush is well documented and is interpreted from the point of view of economics in Libecap 1989 and Umbeck 1981. 
Before the advent of the fur trade, Indians had no reason to obtain furs in numbers beyond the small quantity required for their own use. Thus, there was no danger of depletion of the animal stock and, as a corollary, no need for property rights in land. ${ }^{17}$ (It is not clear, though, why the Indians did not make collective agreements to limit hunting rather than establish property rights.18)

(c) Rights to the resources of the sea: fisheries, oil, and minerals from the seabed. For most of history, there were no property rights in the ocean's fisheries because fish were in inexhaustible supply for all practical purposes. However, certain fisheries came under strain with the introduction of trawler fleets in the late nineteenth century, and fish populations are under significantly greater pressure today because of the increased scale of, and the modern methods employed in, fishing (factory fleets, mileslong nets, electronic detection of fish). In response to the need to preserve the fisheries, countries have developed, through a series of treaties, property rights in the fish found in their coastal waters; at present, a country enjoys such rights in an Exclusive Economic Zone (EEZ) extending 200 miles from its coastline. This gives a country a natural incentive not to deplete its fisheries because it will then enjoy a greater catch in the future, provided that the fish in question do not tend to swim outside the EEZ.

Likewise there were no property rights established for oil and minerals from the sea-bed until it became apparent, around the end of the second World War, that extraction might be commercially viable. Today, coastal countries have property rights to the resources of the sea-bed within the EEZ, which gives them (or, more precisely, companies granted licenses by them) a motive to explore, develop technology for extraction, and then to exploit oil and mineral resources (to date, principally manganese nodules). Outside the EEZ, property rights to the sea-bed will be partial, governed often by an international authority according to a complex provision of a treaty on the law of the sea. ${ }^{19}$

(d) Rights to the electromagnetic spectrum. With the invention of the radio and other means of wireless communication, the electromagnetic spectrum -- the medium through which electromagnetic signals travel -- became valuable and property rights in it emerged. The main reason is that if two parties simultaneously attempt to transmit signals in the same area over the same frequency, their signals interfere with each other resulting in garbled signals. In the early days of radio, this problem prompted the government to pass the 1927 Radio Act (and in 1934 to establish the Federal Communications Commission), under which it allocated exclusive rights to broadcast over particular ranges of the spectrum at particular times in particular areas. These property rights in the

\footnotetext{
${ }^{17}$ See Demsetz 1967.

${ }^{18}$ This advantage of property rights must have outweighed the costs of enforcing the rights. It is not clear what these costs were. It is unlikely that the Indians actively policed the borders of their lands, for that would have been inordinately expensive. Perhaps it was sufficient for a land owner to monitor the small area near his beaver lodges for strange traps and, if such traps were discovered, to lie in wait for interlopers.

${ }^{19}$ For a brief description of the development of property rights in ocean resources, see Biblowit 1991, 79-81. See also Eckert 1979, Hanneson 1991, Scott 1988, and Sweeney, Tollison, and Willett 1974 for economically oriented analysis of the subject. On the law of the sea treaty, see Agreement Relating to the Implementation of Part XI of the United Nations Convention On the Law of the Sea, with Annex, July $28,1994$.
} 
spectrum generally took the form of nontransferable licenses of limited duration that might be renewed. Inability to transfer licenses and the cost and other disadvantages of the licensing and renewal process has led over the years to dissatisfaction with the allocation of the spectrum. Recently, lotteries and auctions have begun to be employed to allocate rights to parts of the spectrum, where these rights have limited transferability. ${ }^{20}$

(e) Rights to extraterrestrial bodies and outer space. One can expect that as uses for extraterrestrial bodies and for outer space become apparent, property rights in them will be established. There is now a "Moon Treaty" that commits signatories to establish an international regime to govern the exploitation of the natural resources of the moon (but postpones allocation of property rights). ${ }^{21}$ Also of note is discussion of (and some claims for) property rights to the geostationary orbit, the band of space 22,300 miles above the equator where satellites travel at the same speed as that at which the earth rotates and therefore maintain a fixed position relative to the earth. This is the most valuable orbit for communications satellites, yet the orbit is a scarce resource, principally because of electronic interference between satellites that are too close to one another. ${ }^{22}$

${ }^{20}$ See Coase 1959, De Vany et al. 1969, and, more recently, Andrews 1995, McAfee and McMillan 1996, McMillan 1994, and Settani 1994.

${ }^{21}$ Agreement Governing the Activities of States on the Moon and Other Celestial Bodies, Dec. 18, 1979, art. 11(5), 18 I.L.M. 1434.

${ }^{22}$ See Kosmo 1988, Roberts 2000, and Staple 1986. 


\section{Chapter 8}

\section{DIVISION OF PROPERTY RIGHTS}

Having considered the general reasons for the existence of property rights, I now examine a number of topics about property rights, beginning in this brief chapter with the advantages and disadvantages of their division. ${ }^{23}$

\section{Division of Rights Described}

The bundle of property rights in a thing may be partitioned in a variety of ways: into various rights that are enjoyed contemporaneously; into rights that are enjoyed only under certain contingencies; into rights that are enjoyed only at certain times. Further, possessory rights and rights to transfer them may be separated from each other. Consider the following examples of division of property rights.

(a) An owner of land may not hold complete possessory rights, in that others may enjoy an easement, that is, the contemporaneous right of passage upon his land, such as along a path or on a private road. Others may also have the right, known as a profit, to take something from the land, such as timber, oil, or minerals.

(b) The provisions of a will may stipulate that the disposition of property will depend upon various contingencies, such as whether grandchildren have been born, whether a child is still alive, or whether a person has obtained an education.

(c) The common rental arrangement constitutes a division of property rights over time, in which many of the rights are held by the renter during the rental period, but not before or after that period.

(d) The sale of property or its donation are occasions at which all rights associated with ownership pass to the buyer or recipient from that moment on.

(e) Under the trust relationship, the trustee holds title to property for the benefit of another. The beneficiary may enjoy the use of property but generally will not have the right to sell or transfer it, so that possessory rights and rights to transfer are divided. For instance, an orphaned child may live in a house but an adult trustee, such as a relative, may decide whether or not to sell it.

\section{Social Advantages and Disadvantages of Division of Possessory Rights}

The division of possessory rights may be socially valuable when different parties derive different benefits from them because, other things being equal, gains can then be achieved if rights are allocated to those who obtain the most from them. This will be so, for instance, if the absentee owner of forest land gives hikers the right to pass through his property or if the owner of a home at a summer resort rents it to someone during the winter when the owner would not much want to use it.

There are several types of disadvantages of division of possessory rights, or of too fine a division of the rights. The first concerns the observation that certain minimal transportation and related costs must be borne in order to enjoy possessory rights in a thing. To benefit from use of land (to hike on it, to harvest timber from it), one must generally travel to the land and perhaps convey equipment to it. These costs are not worth

\footnotetext{
${ }^{23}$ For an economically-oriented survey of division of property rights, see Stake 2000.
} 
bearing if the rights enjoyed are too limited (no one would make a long trip in order to hike along a mere fifty foot path).

A second disadvantage of division of possessory rights is that division may lead to the chance of more than one individual wishing to exercise the same rights and thus of disputes. If many individuals have the right to use a person's backyard swimming pool at different times, the odds of different people wishing to use the pool simultaneously will increase. Although this difficulty should not arise if the division of property rights is unambiguous, as a practical matter that may not be so (watches may disagree).

A third disadvantage of division of possessory rights is that one person's use may conflict with another's, that is, give rise to a detrimental externality. ${ }^{24}$ If a farmer gives an easement for right of passage on his land to someone, this person may, in exercising his right, trample the farmer's crops. These problems would not arise if possessory rights could be completely specified and enforced, for then the right to engage in the problematic behavior would not be granted: The farmer would not give the person with the easement the right to trample his crops. But to determine whether a person with an easement does or does not trample the crops might be difficult (perhaps he could claim that animals trampled the crops). Hence, in effect, giving a person an easement may mean that the person is obtaining also the right to trample crops.

A closely related disadvantage of division of possessory rights is that it may result in the failure to obtain benefits from the coordinated use of property; one person with rights may not do things that could aid another in his use of property because the first obtains no gain for himself from doing so. If a person has the right to use a farmer's land as pasture for his cattle, he could help the farmer by distributing manure so as to efficiently fertilize the farmer's land; but he might not do so because he may see no real gain in it. (By contrast, if the farmer grazes his own animals, he will naturally have the motive to use manure appropriately to fertilize his land.) As with the previously mentioned disadvantage of conflicting use, this disadvantage would not arise if possessory rights were completely specified and enforced, for then beneficial actions, like distributing manure, could be required.

Another disadvantage of division of rights arises when the division is long-lasting -- as an easement allowing passage over land may be -- and the property is sold. At that time, the cost of the transaction will rise somewhat, because the buyer will need to understand the nature of the division of rights (or will wish to investigate the possibility that others have a right in the property of which he is not aware).

\section{Social Advantages and Disadvantages of Separation of Possessory Rights from the Rights to Transfer Possessory Rights}

One would suppose that it is typically socially desirable for possessory rights and the rights to transfer them to be held by the same party, as the usual expectation is that the holder of possessory rights has both the knowledge and the motive to make good decisions about the transfer of the rights. The holder of possessory rights will typically have the requisite knowledge to decide about transfer because he will be familiar with the characteristics of the thing and will naturally know its value to himself. And he will generally have a socially desirable incentive to decide whether to transfer a possessory right because he will lose the benefit of his possessory right if and only if he decides to

\footnotetext{
${ }^{24}$ On externalities, see generally chapter 10 .
} 
transfer it, and will gain from whatever is given in the transfer.

There are, however, circumstances in which separation of rights to transfer possessory rights from the possessory rights themselves is beneficial. One such circumstance arises when the holder of the possessory rights does not have the knowledge or the intellectual ability to decide about transfer, such as when a child owns property and an adult trustee has the right to decide whether to sell the property because he can make better decisions than the child could. Another major circumstance in which separation of possessory rights and rights of transfer may be beneficial occurs when the holder of possessory rights does not have a proper incentive to transfer them. For example, suppose that Alpha rents a room in Beta's house. Alpha would not have the motive to consider appropriately the character of another tenant (such as whether he would make noise), so that it may be best for Alpha not to have the right to sublet his room. ${ }^{25}$

\section{The Socially Optimal Division of Property Rights, Their Actual Division, and the Law}

It will be socially desirable for property rights to be divided when, but only when, the accompanying advantages outweigh the disadvantages.

One would expect the actual division of property rights by private parties generally to reflect the socially optimal division. The fundamental reason is that when the transfer of certain rights would be socially desirable, there will typically exist a mutually beneficial private exchange involving the rights. If, for example, a landowner is not equipped to cut down his timber and someone else is, there will be a price at which the landowner will be willing to sell his timber rights and the other person will be willing to purchase them.

Furthermore, the law tends to aid the division of property rights that parties wish. Individuals are generally able to divide property rights as they please by means of contracts. Thus, the landowner might arrange for another party to enjoy timber rights during a specified period according to a contract. Also, individuals are often able to effect mutually desirable division of property rights, and over long periods, through recognized devices of property law, including, as mentioned, easements, profits, and trusts. However, the law places various limitations on division of property rights. The general forms of property rights that individuals are permitted to hold are restricted. ${ }^{26}$ For instance, time shares in real estate were not an allowed form of property until relatively recently. Some commentators suggest that certain such limitations are socially desirable because they simplify sales transactions ${ }^{27}$ or because they prevent excessive fragmentation

\footnotetext{
${ }^{25}$ This example may be expressed generally. Division of possessory rights may, as discussed above, be associated with problems of conflicting use and of coordination. If so, it may be beneficial not to allow a holder of some of the rights to transfer them to another because this may worsen the problems.

${ }^{26}$ See Rudden 1987, who also emphasizes that restrictions on the form of property rights present a puzzle for economic thinking because they apparently hinder desirable division of rights.

${ }^{27}$ Sales transactions might be eased by a limitation in property rights because, as noted in section 2, a buyer would then not have to interpret a new form of property right, or would not worry about or investigate the possibility of a hidden interest in the property that he is buying. Thus, if time shares are not allowed, a buyer of property need not concern himself with their meaning or ascertain whether some
} 
of property that would not be cured by private consolidation. ${ }^{28}$ But these views do not seem persuasive as presently articulated. ${ }^{29}$ In some particular cases, though, limitations on division of rights have a fairly clear justification. For example, consider zoning rules that prevent lot size from falling below a prescribed minimum. Small lots may be disliked by individuals in a neighborhood because they lead to congestion and reduce greenery for all to enjoy. If so, and if it would be difficult for the many individuals living in a neighborhood to contract with each other to keep lot sizes from being too small, regulation of lot size would be necessary to accomplish their common goal.

unknown person has a time share in his property. This view is discussed by Rudden 1987 and versions of it are developed and advanced by Merrill and Smith 2000 and by Hansmann and Kraakman 2002.

${ }^{28}$ If property is too fragmented, for instance, if too many time shares are sold, such that it would be more efficient for them to be consolidated and there to be one owner of real estate, the argument is that such consolidation might not come about through private purchase of the time shares. Hence, the law might prevent such danger by proscribing fragmentation in the first place. This possibility is also discussed by Rudden 1987 and is endorsed by Heller 1999.

${ }^{29}$ Several arguments suggest that the goal of simplifying sales transactions does not justify legal limits on division of rights, at least not in an obvious way. First, if an owner of property divides rights, such as by selling time shares, and this makes the property more expensive to sell (and for a buyer later to resell), then the price the owner will obtain for the property when he comes to sell it will fall as a consequence. Therefore, the owner has a natural reason to take the effect of division of rights on transactions costs into account. However, the argument is sometimes made that the owner does not have a reason to take into account the possibility that transactions in property other than his might be impeded -the latter may happen because his division of rights will contribute to general worry among buyers about hidden interests in their property. This problem, if significant, seemingly could be met by either of two types of legal rules that do not bar individuals from dividing property rights if that is what they wish: (a) a rule under which a division of property rights is not enforced unless the division is made explicit in the sales documents (then there could be no concern about hidden interests); or (b) a rule under which a division of property rights is not enforced unless the division has been entered into a registry, and possibly a fee has been paid for so doing (to induce those who obtain the rights to take into account the cost that others will bear in checking the registry).

Regarding the inability of private parties to consolidate property if it is excessively fragmented, one wonders why consolidation by private parties would not usually occur (why for example a person would not ordinarily succeed in purchasing different individuals' time shares if an apartment is more valuable when lived in year round by a single person). A satisfactory answer to this basic question has not been provided, even though it is possible that in some situations problems in bargaining might retard or prevent beneficial private consolidation. 


\section{Chapter 9}

\section{ACQUISITION AND TRANSFER OF PROPERTY}

In this chapter, I consider the acquisition and transfer of property, an issue that is important because most property changes hands at least once (in a modern economy, it has to be sold by the producer to consumers). I begin with the acquisition of previously unowned property and with the related topic of the acquisition of lost or mislaid property. I next examine the more common ways of acquiring property, through its transfer by sale, by gift, or by bequest. Then I discuss state-imposed constraints on the sale of property, and last, involuntary transfer of property through so-called adverse possession.

\section{Acquisition of Unowned Property}

1.1 Introduction. Here I inquire about the incentives of a single party, and then of multiple parties, to find previously unowned things, such as fish in the sea or wild animals, or oil or mineral deposits. ${ }^{30}$ (Acquisition of things never previously owned is sometimes called original acquisition.) The measure of social welfare will be the net expected value of things, that is, the probability of finding them multiplied by their value, minus the costs of search effort. I will first consider the simple situation of acquisition by a single individual and then the more complicated and realistic situation involving multiple parties.

1.2 Acquisition by a single individual. Let me first describe socially optimal behavior. Consider a situation in which a single individual has the opportunity to invest effort or resources to discover a thing. It will be socially desirable for the individual to make an investment when the investment would increase the expected return by more than its cost. Thus, if an undersea mineral deposit is worth 1,000 and an exploration effort would increase the likelihood of finding it by 10 per cent, the expected value of the effort would be 100, so the effort ought to be taken if and only if its cost is less than 100 .

Finders-keepers rule leads to optimality. It is clear that an individual will invest socially optimally provided that he will obtain the full value of the thing if he discovers it. Consequently, the finders-keepers rule -- under which the finder is deemed to be the owner of anything that he has found -- will lead a finder to act desirably to locate things. ${ }^{31}$ In contrast, a rule that accords a finder only part of the value of what he discovers leads to inadequate incentives to find things.

\footnotetext{
${ }^{30}$ Most of what is said in this section will apply also to abandoned property, on which see section 2 below.

${ }^{31}$ An exception to the point of this paragraph concerns unowned currency. Here the socially optimal effort to devote to finding it is zero, for there is no social value of currency: The state can print more currency at negligible cost. However, the value of currency to an individual is hardly zero; individuals will be willing to make substantial investments to obtain lost currency. Thus, perhaps, it would not be desirable to grant a person ownership of currency if, say, it was in the safe of a ship that was lost at sea and the person would mount an expensive effort to recover the currency.
} 
1.3 Acquisition by multiple individuals. In this case, the description of socially optimal behavior involves a complication. When an individual searches for a thing, the increase in the probability that the individual in particular will find the thing typically exceeds the increase in the total probability of discovery -- the probability that some individual will find the thing. The reason is that the person may search in places that others would have examined in any event, so that the increase in the particular person's likelihood of finding the thing will often come at the expense of others' likelihood of finding the thing. This factor needs to be taken into account in determining whether it is socially desirable for an individual to devote effort to search, for it is only the increase in the total probability of success that is relevant in deciding whether a given individual's effort is socially justified.

Example 1. Suppose that if A alone searches for some thing, the odds of his discovering it will be 10 per cent; and if B joins A, the odds of B finding it will be 4 per cent and the odds of A finding it will fall to 7 per cent because $B$ will be looking in some of the places A would have. Thus, if B searches along with A, the overall probability of discovery will rise by only 1 per cent -- that is, by $4 \%+7 \% ! 10 \%-$ not by 4 per cent. ${ }^{32}$ Accordingly, the 1 per cent increase in the total probability of discovery is what is relevant for calculating whether it is socially desirable for $B$ to search. If the value of the thing sought is 1,000 , the cost of search for A is 15 and the cost of search for B is 20 , then A alone should search, for B's cost exceeds the increase of 10 (namely, $1 \% \mathrm{H} 1,000$ ) in the expected total return that he would bring about. ${ }^{33} / /$

As a general matter, it is socially worthwhile for an individual to search, or to make a greater effort to search, only if the cost of so doing is warranted by the expected increase in the total probability of finding the thing, which equals the increase in his probability of finding the thing minus the reduction in others' probability of doing the same. ${ }^{34}$

Finders-keepers rule results in excessive search. If whoever discovers a thing will own it, then incentives to search will generally depart from the optimal and there will be a tendency toward socially excessive search activity. The reason is that a person's incentive to engage in search derives from the likelihood that he, specifically, will find the thing, whereas, as just mentioned, his search will tend to lower the chance that others will find the thing. Thus, the individual's personal return from search under the finderskeepers rule will exceed the social return, and as it is his personal return that will

\footnotetext{
${ }^{32}$ I assume that A and B do not simultaneously discover the thing; thus the probability that one of the two discovers the thing is simply the sum of 4 per cent and 7 per cent.

${ }^{33}$ More precisely, if A alone searches, the net expected return is $10 \% \mathrm{H} 1,000 ! 15=85$; and if A and $\mathrm{B}$ search, the net expected return is $11 \% \mathrm{H} 1,000$ ! $15 ! 20=75$; thus A alone ought to search.

${ }^{34}$ To amplify, suppose that the per-person cost of search is $c$, that $x$ is the number of people who search, and that $p(x)$ is the probability each person has individually of finding a thing worth $v$. Note that the total probability that the thing will be found is $x p(x)$ (suppose that people will never find the thing simultaneously). Assume that $p^{\prime}(x)<0$ for the reasons discussed in text (notably, others will search where a given person might have) and that $p^{\prime \prime}(x)>0$. The social objective is for $x$ to maximize the social surplus, $x p(x) v ! c x$, meaning that the optimal $x$ (treated as continuously variable) satisfies $p(x) v+x p^{\prime}(x) v=c$. That is, individuals should engage in search until the expected gain $p(x) v$ less the reduction in others' gain $x p^{\prime}(x) v$ equals the cost $c$. Denote the optimal $x$ by $x^{*}$.
} 
motivate him to engage in search, he will often search more than is socially desirable. In the preceding example, the rule giving ownership to a finder will result in B joining A in searching, even though this is not socially desirable: B will obtain an expected return of 40 as against his cost of 20; B will not take into account that A's expected return will drop by 30 when B searches as well. ${ }^{35}$

Comments. (a) Qualifications: The point that search may be socially excessive bears several qualifications. First, it may be that different parties happen to search in different areas, so that their efforts are not competitive; if so, the private return and the social return will be the same, and search by each party will be optimal. Second, and related, parties may sometimes cooperate and agree to divide their areas of search into mutually exclusive regions; in this case too, search by each party will be optimal. Third, if one person's search activity would convey information to others about the possible location of a thing, then search effort could be less than socially desirable: An individual might refrain from investing in search because he anticipates being joined by others, diluting his return, or he might limit his efforts in order to conceal them from others (work only at night in order to escape notice).

(b) Reality of the phenomenon of excessive search: Despite the foregoing qualifications, it seems clear that in a variety of instances too much effort is expended in trying to find things. A well known case in point is fishing activity. It is a commonplace that the quantity of fish taken could be caught by a smaller fleet. Relatedly, investment in equipment for fishing (powerful engines for beating other vessels to a site, sonar for detecting fish) has arguably been excessive; cheaper methods would be sufficient to produce present yields. ${ }^{36}$ Similarly, efforts to discover and extract oil have sometimes been unwarranted. For example, in the East Texas oil fields, over half of all the wells drilled as late as the 1930 s were said to have been unnecessary. ${ }^{37}$

Possible remedies to the problem of excessive search. One response to the problem of excessive search activity under the finders-keepers rule is to reduce the return to discovery by granting only partial ownership to finders or by imposing taxes on what is found. ${ }^{38}$

Another remedy is for the state to control directly the volume of search activity (the number of fishermen, the length of the fishing season), their methods of search

\footnotetext{
${ }^{35}$ In the situation described in the previous note, it can be seen that too many individuals search. An individual will search as long as his expected return $p(x) v$ is at least $c$, so that the condition determining $x$ is $p(x) v=c$; call the $x$ so determined $x^{* *}$. It is apparent that $x^{* *}>x^{*}$, since $x^{*}$ satisfies $p(x) v=c ! x p^{\prime}(x) v>$ $c$. For a survey of the extensive economic literature on the possible inefficiencies under the finders-keepers rule, and its relation to law, see Lueck 1998.

${ }^{36} \mathrm{~A}$ dramatic example of this is that so much effort and equipment has been devoted to beating competitors to catch herring in Alaska that I was told on a visit that the season may last less than one hour. It would obviously be socially preferable for the herring to be caught more cheaply over a longer period of time. On the inefficiencies of investment and excessiveness of effort devoted to fishing, see, for example, Libecap and Johnson 1982.

${ }^{37}$ See Ely 1938, 1233.

${ }^{38}$ However, a tax will lead to inadequate levels of search effort if searchers have cooperated and divided the territory into mutually exclusive regions.
} 
(allowable net sizes, types of vessels), or the quantity of their recoveries. The chief problem with this, as with any regulatory approach, concerns the quality of the state's information about proper regulation and the bluntness of its rules (regulating only the number of fishermen does not result in selection of those best able to fish).

An additional approach is for the state to sell or to grant some party an exclusive right to search. For example, the state could sell the right to search for oil in an offshore area. This would tend to cure problems of search incentives because the purchaser of the right would then be motivated to choose the optimal number of searchers and to coordinate their actions; the purchaser's motive would be to maximize the total expected return minus the total costs of all hired searchers.

It should be noted, though, that when search activity and discovery is not observed by the state, the situation is, de facto, identical to that when finders obtain ownership of what they discover, and no remedy is possible.

1.4 The law. The character of the law regarding the rights of finders of things depends importantly on what the things are -- notably, whether they are fish, game, oil, or undersea mineral deposits. ${ }^{39}$ To an important degree, finders are given title to what they discover, but they also are often restricted in various ways by the remedies just mentioned to the problem of excessive search effort. ${ }^{40}$ Those who catch fish at sea and those who kill game in hunting areas usually are deemed to be proper owners, but limits on the quantity of fish and of game that may be taken, the times when they may be taken, and who may engage in search for them, are commonly imposed. ${ }^{41}$

In the early days of oil exploration and recovery, those who obtained oil were given ownership of it, regardless of whose land the oil had lain under. Over time, however, various regulations curtailing quantities taken and methods of recovery emerged, and now in many jurisdictions the race to extract oil is prevented by unitization schemes, under which all owners of land over an oil reservoir are required to join into a single unit for the purpose of developing their oil. ${ }^{42}$ Offshore oil exploration is governed differently. The state typically sells the right to search and produce oil in a given offshore area. $^{43}$

The right to minerals on the ocean floor used to be enjoyed by whoever found them, but according to an international agreement, different areas of the ocean have been allocated across countries, ${ }^{44}$ and the countries will presumably sell or grant the right to search for minerals to private parties.

\footnotetext{
${ }^{39}$ See generally Lueck $1998,137-41$, in addition to the references cited in notes $12-15$.

${ }^{40}$ The motive for using these remedies is not just to control excessive search effort. The remedies may also be employed to prevent the closely related problem of excessive depletion of stocks (in the case of fish and wildlife) or to raise revenue for the state.

${ }^{41}$ See Brown 1975, 13-23, Bean 1983, and Lund 1980.

${ }^{42}$ See, for example, Williams and Meyers 2001, chap. 9.

${ }^{43}$ See, for example, Jones 1984 and Wiygul 1992.

${ }^{44}$ See U.N. Convention on the Law of the Sea 1982.
} 


\section{Loss and Recovery of Property}

2.1 Introduction. The subject of the loss and the subsequent recovery of property involves the incentives of original owners to prevent loss of their property and then, if property is lost, the incentives of original owners or of others to recover the property. Both types of incentives are influenced by whether the law allows original owners to retain ownership in property that has been lost or instead accords ownership to finders.

\subsection{Socially optimal effort to prevent loss of property and to recover lost}

property. Our social welfare criterion will continue to be the expected value of property minus the costs of effort, but now effort will include steps taken to prevent loss as well as the expected effort expended to recover lost property. It will be convenient to consider first socially optimal recovery effort and second, socially optimal effort to prevent loss.

Observe that once property is lost, the social welfare criterion reduces to just the expected value of property minus the cost of recovery effort, so that it is socially optimal to devote effort to recovery if and only if its cost is less than the expected return. Thus, the description of socially optimal recovery effort is identical to that of socially optimal search effort for unowned property, as discussed above in section 1.

Now consider socially optimal effort to prevent loss in the first place. This level of effort will reflect the point that, should a loss occur, there may be a subsequent recovery and hence no social loss ultimately suffered. Suppose that a stray cow worth 1,000 would, after recovery effort of 10 , be found with probability 40 per cent, and in that case no social loss would be suffered. ${ }^{45}$ Then the expected social loss from the straying of a cow would equal only $60 \% \mathrm{H} 1,000$ or 600 , not 1,000; and adding this to the cost 10 of recovery effort, we obtain 610 as the expected social costs associated with a stray. Thus, fencing in a cow to prevent it from straying will be socially desirable if and only if fencing costs less than 610 . Fencing would not be worthwhile if it costs, say, 800 , even though that is less than the 1,000 value of the cow; a cost of 800 would be worth bearing only if a stray cow would definitely be lost, not if it would be found with probability 40 per cent. As in this illustration, the socially relevant consequence of an initial loss of property is not the entire value of the property, but rather a smaller adjusted loss -- equal to the probability of failure of someone to recover the property multiplied by its value, plus the cost of (optimal) recovery effort. Therefore, effort to prevent loss will be socially justified only to the extent that it reduces the chance of this adjusted loss, and thus will be desirable less often when there is a chance to recover lost property than when there is no such chance. $^{46}$

\footnotetext{
${ }^{45}$ I assume for simplicity that lost cattle would be worth the same amount to any person who finds them. In general, however, a lost thing might be worth a different amount (often a lesser amount) to a finder than to the original owner. The effects of this consideration will be obvious to the reader.

${ }^{46}$ To express what has been said in this section formally, suppose that $y$ is effort to prevent loss, $q(y)$ is the probability of loss, where $q \mathrm{~N}(y)<0$ and $q \mathrm{Q}(y)>0, x$ is recovery effort, $p(x)$ is the probability of success in recovery, where $p(x)>0$ and $p Q x)<0$, and $v$ is the value of the property. The social object is to maximize the expected value of property minus expected effort, or equivalently, to minimize expected effort plus loss of value, namely, to minimize $y+q(y)[x+(1 ! p(x)) v]$. The optimal $x$ clearly minimizes the term in brackets, so satisfies $p(x) v=1$, assuming as I shall that the optimal $x$, denoted $x^{*}$, is positive. The optimal $y$, denoted $y^{*}$, satisfies $\left.! q \mathrm{~N} y\right)\left[x^{*}+\left(1 ! p\left(x^{*}\right) v\right]=1\right.$, the marginal reduction in the expected adjusted loss equals the marginal cost of prevention effort, 1. The optimal adjusted loss $x^{*}+\left(1 ! p\left(x^{*}\right)\right) v$ is less than $v$, for as $x^{*}$ minimizes $x+(1 ! p(x)) v$ over $x$, we know that $x^{*}+\left(1 ! p\left(x^{*}\right)\right) v<0+(1 ! p(0)) v \# v$.
} 


\subsection{Situations in which original owners have the opportunity to exercise} recovery effort or to hire others for that purpose. In many circumstances, original owners have at least as good an opportunity as others to find property that they have lost or to engage other individuals to do so. Original owners will often have this opportunity because they will be aware of when and approximately where they lost their property (such as where a ship went down, or approximately where a watch was mislaid). In such situations, let us consider the outcomes under the two legal regimes concerning ownership of recovered property.

Original ownership rule. It is evident that the outcome under the rule whereby original owners retain ownership in lost property will be socially desirable. Recovery effort will tend to be optimal because the original owner will retain ownership of what he finds. In particular, there will be no problem of excessive incentives to search, for no one will engage in search unless hired by the owner, and he will direct their efforts so that they are not working competitively and engaging in duplicative activities.

Also, effort to prevent loss from occurring will tend to be optimal; original owners will not invest excessively in preventing loss. Because original owners will anticipate that they will retain ownership rights if they recover their lost property, they will properly view a loss in adjusted terms and exercise the socially correct degree of effort to prevent loss. Because a cattle owner will know that he will retain property rights in found strays, he will treat straying as less serious than certain losses of cattle; accordingly, he will not invest socially excessively to prevent straying. ${ }^{47}$

Finders-keepers rule. By contrast, the outcome under the finders-keepers rule is socially less desirable. Under this rule, original owners and other parties might invest excessively in search effort to be first to find lost property.

Furthermore, original owners will tend to exercise excessive effort to prevent loss because, if they lose their property and it is recovered by someone else, they will not retain ownership of it. That is, under the finders-keepers rule, the original owner will treat a recovery by another party as a full loss to himself, even though for society there will be no loss; he will thus see a loss as exceeding the socially relevant, lower, adjusted loss. If a stray would never be recovered by him but would be recovered by others with a probability of 40 per cent, then the owner will regard a stray as a certain loss. Hence, he will invest in fencing whenever the cost is less than 1,000, such as when its cost is 800 , rather than only when the cost is less than $610 .^{48}$

Comparison of rules. In the situations in which original owners have a good opportunity to engage in recovery effort, allowing original owners to retain ownership rights to property that they have lost is the better rule. Under the original ownership rule, there is no problem of a wasteful race to find property once it is lost, and there also is no problem of original owners investing excessively to prevent loss in the first place.

\footnotetext{
${ }^{47}$ In terms of the analysis in the preceding note, the original owner will himself seek to minimize $y+$ $q(y)[x+(1 ! p(x)) v]$, so will choose $x^{*}$ and $y^{*}$.

${ }^{48}$ To amplify, assume for simplicity that the original owner will never be the one to recover his lost property. Then the owner will choose y to minimize $y+q(y) v$, so his choice of $y$ will be determined by the condition $! q^{\prime}(y) v=1$; let this $y$ be denoted $y^{* *}$. Because $v>x^{*}+\left(1 ! p\left(x^{*}\right)\right) v$, as explained in note 18 , we have $y^{* *}>y^{*}$.
} 
It should be observed that the possibility that original owners would be induced to take excessive care to prevent loss under the finders-keepers rule is of substantial importance in many settings, for the likelihood of recovery by others might be significant. The example of straying animals fits in this regard, for the odds of someone other than the owner finding a stray would often be high. Thus, were property rights not to remain with the owners of strays, owners might invest significantly in fencing where that would not be socially justified. Or, imagine that if a person leaves a personal article, such as a watch, someplace and another individual finds it, that the finder automatically becomes the owner of it. Then people would arguably be led to take excessive care not to leave personal articles about, even temporarily.

\subsection{Situations in which original owners do not have good opportunities to} exercise recovery effort. Let us now consider the many situations in which original owners do not have the best, or any practical, opportunity to exercise recovery effort. These include cases in which original owners have essentially no idea where they lost their property, so they would not know where to search for it. For expositional purposes, let us assume that the original owners have no opportunity to recover property themselves, and that others will have such opportunity.

Original ownership rule. Given our assumptions, the outcome under the original ownership rule leaves no incentive for other parties to recover lost property. ${ }^{49}$ Thus, property that is lost will not be recovered. Also, the owner's effort to prevent loss will be excessive because a loss for him will be a loss for sure.

Finders-keepers rule. If those who find lost property can keep it, then they will have an incentive to recover it; a single individual will have optimal incentives, and multiple parties will have excessive incentives. An owner's effort to prevent loss will be excessive because, for him, the chance of recovery will be zero.

Comparison of rules. The finders-keepers rule is superior. Under this rule, unlike under the original ownership rule, there is some recovery of lost property. Under both rules, original owners have identical (and excessive) incentives to prevent loss. Thus, the difference between the rules is that some lost property is recovered under the finderskeepers rule.

Although the finders-keepers rule is superior, as just noted, it suffers from the problem that original owners have excessive incentives to prevent loss. A type of rule that is superior to a finders-keepers rule and also to the original ownership rule is an original ownership rule combined with a mandatory reward paid by the owner to the finder. This hybrid rule has the attractive feature that it furnishes incentives to nonowners to recover lost property -- because they receive rewards -- and it also mitigates the problem of excessive loss prevention efforts by owners -- because they retain ownership in lost property. The precise way in which such a rule would influence behavior would depend on the formula for the reward. ${ }^{50}$

\footnotetext{
${ }^{49}$ However, some individuals may be altruistic, especially in a rescue situation, and make a recovery effort for that reason. Another reason that individuals might make a recovery effort in the presence of the original ownership rule is that there may be a chance that they will obtain ownership of what they find if the owners cannot be identified (see below) or if the things they find have been abandoned.

${ }^{50}$ If the reward is a simple fraction of the value of the recovered thing, the higher the reward fraction, the greater the incentive for recovery, which is desirable, but the more excessive is the incentive of original
} 
2.5 Comments. To round out our discussion, let us consider several other relevant issues.

(a) Abandoned property. The finders-keepers rule has appeal in regard to abandoned property, given the above analysis, assuming that abandonment tends to occur when original owners are not able to accomplish recovery (the situation in section 2.4). Moreover, abandonment may signal that the owner attaches relatively low value to the property, which also argues in favor of the finders-keepers rule.

(b) Adventitiously discovered property. Things that are found in the normal course of individuals' activities (such as a watch that a person finds lying on his seat on a bus) are things that would be found regardless of the legal rule concerning lost things. Thus, there is no need to create incentives to find such things (the watch is going to be found on the bus seat whatever the legal rule). Consequently, there is no need for the finderskeepers rule to be employed, and it is best for original owners to retain property rights in adventitiously found things, in order that they do not invest excessively in prevention effort.

(c) Identification of original owners of property. It has been implicitly assumed that when the best rule favors original owners, they can be identified, but often, of course, they cannot. In this regard, a desirable rule is one that requires finders to make reasonable efforts to determine the identity of original owners (such as by reporting finds to the police) and that gives title to finders if the owners cannot be located after a stipulated period. This rule also has the virtue that it stimulates original owners to mark their property as their own. Furthermore, it provides finders with some incentive to search for and/or bring into their possession things that it would be wasteful for no one to use.

(d) Care of property. Some types of lost property must be cared for in order to be preserved, a notable example being stray livestock. In such cases, it is desirable for finders who take possession of things to make reasonable efforts to maintain the things. Finders will be inclined to do this, or not disinclined, if they are compensated appropriately by the original owners if they are identified, so that a rule mandating such compensation is desirable.

(e) Enforceability of original owners' rights. Athough it has been supposed that there is no difficulty in enforcing legal rules, there is obviously a problem in enforcing original owners' rights, for things will sometimes be found when no witnesses are present and can be used by finders without their being discovered. To the degree that this is so, the de facto rule is the finders-keepers rule.

2.6 Law concerning property rights in lost, mislaid, and abandoned property. As a general matter, owners of property retain rights in things that they have lost or mislaid. ${ }^{51}$ Finders of such property are not usually entitled to a reward but are due reimbursement for reasonable expenses of securing and caring for found property. ${ }^{52}$

owners to prevent loss. If the reward depends on the optimal recovery effort, it can be shown to lead to optimal behavior for both types of party, and likewise if the reward is paid by the state to the finder.

\footnotetext{
${ }^{51}$ See Brown 1975, sections 3.1, 3.4, and 3.5.

${ }^{52}$ For example, those who find strays are allowed reimbursement for the expenses incurred in keeping them (if they can find the animals' owners); see St. Julian 1995, section 56. On the duty to reimburse
} 
However, finders are entitled to rewards based on value under maritime law, and often as well according to the codes in civil law countries. ${ }^{53}$ When a finder does not know the identity of the original owner, many jurisdictions provide for finders to follow procedures allowing original owners to come forward to claim their property within a time limit, after which finders gain title to discovered property. ${ }^{54}$ (Complications about who gains ownership may arise, though, where the thing is found on the property of a third party. ${ }^{55}$ ) Rights to treasure trove, that is, secreted money, gold, and silver whose owner is ancient or unknown, is ordinarily granted to the finder. ${ }^{56}$

Abandoned things generally become the property of finders (complications may arise, again, where abandoned things are found on the property of third parties). ${ }^{57}$ This includes shipwrecks abandoned at sea; according to maritime law, they become the property of finders. But title to abandoned shipwrecks embedded in territorial waters sometimes goes to the state in which they are discovered. ${ }^{58}$

\section{Sale of Property -- In General}

3.1 Reasons for sale. Let us now turn to the most common way in which a party acquires title to property: through its sale. At various times, it will be desirable for property to be sold, for two basic reasons. First, efficient production requires that firms

finders for reasonable expenses of securing and keeping found property, see generally Brown 1975, section 3.5. It should be added that statutes sometimes provide for rewards also to be paid, as Brown notes.

\footnotetext{
${ }^{53}$ Under maritime law, anyone who takes into his possession a ship lost at sea or its cargo is entitled to a reward that lies within the equitable powers of the courts, with the amount not exceeding the benefit to the owner; see generally Dietz 2000, sections 66-69. On rewards in civil law countries, see, for example, the description of the German situation in Dukeminier and Krier 1998, 115.

${ }^{54}$ See Brown 1975, section 3.5, and Dukeminier and Krier 1998, 116.

${ }^{55}$ The owner of land on which a thing is found is often called the owner of the locus in quo or simply the locus owner. If the finder was trespassing, he is generally denied title as against the locus owner, but when the finder is an invitee or licensee of the locus owner, the authorities are divided as to who obtains title. Additionally, importance may be attached to the legal distinction between lost property -- that which is inadvertently parted with, through negligence or oversight -- and mislaid property -- that which has been intentionally set aside or hidden, and then forgotten. When property is mislaid, rights to it are more often granted to the locus owner than when property is lost. See Brown 1975, sections 3.2 and 3.4. Also, when things found are embedded in or attached to the soil, title is generally given to the locus owner; see Corpus Juris Secundum 1961, 36A: 421-24.
}

\footnotetext{
${ }^{56}$ The finder usually obtains title against the owner of the locus in quo (sometimes even if the finder was trespassing). Historically, however, treasure trove reverted to the Crown, and in most foreign countries, rights to treasure trove are divided between the finder and the locus owner. See Dukeminier and Krier 1998, 112-13, and Izuel 1991, 1665-75.

${ }^{57}$ The state also enjoys the power to claim apparently abandoned property under certain circumstances. On abandonment, see for example, Gabel 1994.

${ }^{58}$ In the Abandoned Shipwreck Act of 1987, 43 U.S.C. sections 2101-2106 (1988), the United States effectively grants title to a shipwreck to the state in whose waters the shipwreck is located. Most states following the passage of the Act claimed title to embedded shipwrecks but failed to develop adequate regulatory schemes, leading to incidents of vandalism and misuse. See Stevens 1992 and Foster 2000.
} 
exchange intermediate products with each other and that final products be exchanged with ultimate consumers. Second, changing needs for durable property, notably for land and equipment, leads to exchange of such property.

3.2 Problems surrounding sale: legitimacy of seller's claim of ownership; agreements concerning deferred exchange. A basic issue arising whenever property is sold concerns the legitimacy of the seller's claim of ownership, for the property might have been stolen, or improperly obtained, by the seller or by another party who held the property before the seller acquired it. This issue will be discussed in the next two sections of the chapter.

Another problem surrounding sale of property is that the parties may want to make advance agreements for their exchanges. Advance agreements are often desired by parties because, on one hand, it is inconvenient for them to make exchanges immediately, but, on the other, they want to be able to plan on the basis that exchanges will be made. For example, a person may be unable to move immediately into a home that he wants to purchase in a different city because he has to settle his affairs where he now lives and arrange for shipment of household goods, but at the same time wants to be able to plan on moving to the new home, to enroll children in school, purchase appropriate furniture, and so forth. The subject of ensuring that agreements for deferred exchange are honored when it is appropriate will be dealt with in the part of this book on contract.

\section{Registration Systems and Sale and Theft of Property}

4.1 Registration system defined. Let us now consider an important method for establishing the identity of property owners. Under a registration system a list is maintained of items of property, each uniquely identified and associated with the name of its owner. When there is a sale of registered property, the acquirer's name is recorded as the new owner. Under this system, if anyone desires to know the identity of the owner of a particular item of property in the registry, he need only check the registry, because the person whose name is in the registry is deemed to be the owner. Further, it is assumed that if an item of property listed in the registry is stolen from its owner and later discovered, it will be returned to the owner.

4.2 Costs and requirements of a registration system. For a registration system to function, certain expenses must be incurred and requirements met. First, the registration system's records must be maintained. Second, individuals must communicate with the registry when they make a transaction. Third, each piece of property must be uniquely identified. Land is, of course, identified by its geographical boundaries.

Moveables such as automobiles or aircraft are typically identified by their serial numbers as well as by their physical description (model and make), and animals, such as cattle and horses, may identified by their brands and/or their physical description.

\subsection{Principal virtues of a registration system: promotes sales transactions;} discourages theft. An advantage of registration systems is that they may ease sale and resale of things by assuring buyers of the validity of sellers' claims of ownership. In the absence of a registration system, uncertainty as to the validity of ownership might cause a wary buyer not to purchase. Alternatively, this uncertainty might cause the buyer to spend greater effort investigating the validity of ownership than would be necessary if there were a registry. 
Furthermore, the existence of a registration system discourages theft in two major ways. ${ }^{59}$ First, thieves face a higher risk of conviction if they steal registered property, for if discovered with such property, they cannot claim that they own it. If a thief is discovered in possession of an automobile that is registered in someone else's name, he cannot claim that it is his, whereas a thief found to have unregistered property, such as raw diamonds, might be able successfully to deny that the diamonds are owned by someone else.

Second, the value of stolen property to a thief is lowered by the existence of a registration system. If a thief plans to use stolen property himself, its value to him will be diminished by the chance it will be discovered and taken away and that he will be punished. If a thief plans to sell stolen property, the existence of a registry may lower the price he will be able to obtain because the buyer can determine that the property is stolen by consulting the registry, because its value to the buyer may be diminished by the chance of its discovery, and because the buyer in turn may face difficulty in reselling the property.

4.4 Additional advantages of registration systems. Registration systems have several other advantages. First, because a registry allows owners to establish their ownership to lenders easily, their ability to use their property as collateral for loans is enhanced, as is their ability to insure it. Second, the state may use a registry to identify owners of valuable property for the purpose of imposing taxes. Third, the state may use a registry to identify owners of property (especially moving vehicles) in order to enforce safety regulations.

\subsection{Social desirability of registration systems versus private incentives to} establish and use them. Society will find use of a registration system advantageous if its costs are outweighed by its various benefits. However, private incentives to establish and use registration systems may deviate from social incentives to do so.

In particular, three of the social advantages of a registry will tend not to be counted as advantages by a private person contemplating incurring the expense of entering his item in a registry. A person will ordinarily not consider deterrence of theft as a benefit from placing his particular item of property in a registry: Deterrence will usually be affected by whether or not the mass of individuals use a registry, not by any one individual's decision about using it. ${ }^{60}$ In consequence, an individual will be inclined to obtain a free ride from the deterrence created by others who use a registry; he will not want to spend his own time and effort to register his property to promote deterrence. Also, an individual obviously will not credit an enhanced ability of the state to collect taxes or to enforce safety regulation as a benefit of his own use of a registry.

\footnotetext{
${ }^{59}$ The reason that discouraging theft is socially advantageous is principally what was mentioned in section 2 of chapter 7, as an advantage of protecting property rights: that the possibility of theft leads individuals to expend effort preventing theft and also induces some individuals to devote effort to carrying out theft; both types of effort are socially sterile.

${ }^{60}$ This will be so if potential thieves have only statistical knowledge of owners' use of the registry, that is, if thieves do not know in advance of carrying out a theft whether a particular owner has had his property registered. While that would seem usually to be the case, it would not always be so. For example, if cattle thieves live in a locality and would thus know which ranchers brand their cattle and which not, then a particular rancher's decision to brand his cattle would indeed have a deterrent effect on theft, so he would take it into account in his calculus whether or not to brand.
} 
An individual may, though, want to use a registry for three reasons. The first two have been mentioned: He may anticipate reselling his property, which might be made easier by his having registered it, and he may want to be able to borrow against his property or to insure it. The third reason is that if a person's property is stolen, the probability of its recovery will be higher if it has been registered. If these private reasons to use a registry (the first two of which are also social reasons) are not enough to induce individuals to use a registry and the use of a registry is socially desirable, it will be best for the state to establish a registry and require its use. ${ }^{61}$

4.6 Comments. (a) Property for which registries are likely to be socially desirable: durables of high value, especially real estate and vehicles. Registries are more likely to be socially valuable for property of high value for two basic reasons. First, many of the benefits of registries increase with the value of property. This is true of the fostering of sales transactions (the higher the value of property, the higher the surplus from a transaction is likely to be for the buyer and for the seller), of deterrence of theft (the higher the value of property, the more parties will spend protecting it and trying to take it, so the greater the benefits from deterrence of theft), of the ability to borrow against and insure property, and of the ability of the state to raise tax revenues. Second, the costs associated with registries, being essentially bookkeeping costs, seem to be largely independent of the value of registered property. Thus, as a general matter, we would expect the benefits of registries to outweigh their costs more often for high value property than for low.

Further, because durable property is often sold and resold, the benefit of promoting sales transactions is greater than for other property. Accordingly, we might well suppose that registries are often socially desirable for real estate and for certain other types of valuable durables. One category of valuable durable property that is often sold, and for which registries appear desirable, is patents and trademarks. Indeed, because this property is abstract rather than physical and cannot be possessed, registries have a special advantage. $^{62}$

There are additional reasons why we might expect registries to be socially desirable for cars, boats, and aircraft. Namely, because these things are used for transportation and may cause accidents, the advantages to the state in terms of enforcing safety regulation may be substantial. Also, because these things are used for transportation, they are used in public areas, which is to say, in circumstances where the validity of ownership claims can readily be verified by law enforcement officers through a registration system. (The same is true about real estate, which by its nature cannot be concealed.)

\footnotetext{
${ }^{61}$ One suspects that the social reasons for use of a registry generally outweigh the private ones. However, it is possible that parties would use a registration system when that is socially undesirable. Suppose, for instance, that there is no social benefit from a registration system because it does not create deterrence (the expected ease of theft might outweigh expected sanctions despite the existence of the system) nor does it have other social benefits. Yet registration might still have private benefits because some stolen goods will be recovered if there is a registry. Thus, a registry might be set up even though it is not socially desirable. Such a case seems more theoretical than real.

${ }^{62}$ The only obvious alternative to a registry would be a system in which a certificate is issued and the possessor of the certificate is deemed to be the holder of abstract property.
} 
(b) Property for which registries is not likely to be socially desirable. Contrast the situation with regard to the types of property just discussed to that with respect to radios, televisions, and similar items. As noted, the costs of registration systems will tend to be as high for property of low value as for property of significant value, but the benefits of registration systems will tend to be correlated with the value of the goods and thus to be less for lower value goods. Further, goods such as radios and televisions, although of some durability, are not as likely to be resold as are more valuable durable goods, reducing the transaction-related benefit of registries. Also, many of the lower value goods under discussion are ordinarily used within domiciles; thus the likelihood that illegal possession of such goods would be detected were there a registry is smaller. Moreover, there is not a strong reason for the state to regulate safety in the use of these goods. Hence, the likelihood that registries for such goods would be socially desirable appears to be low relative to that for real estate and valuable durables. Another category of goods for which registries are not likely to be desirable are those for which unique identification is difficult or costly relative to their value. Such goods include things whose appearance would be marred by the imprinting of a serial number or identifying mark, as well as many fungible goods, for instance, wheat and diamonds.

4.7 Actual use of registries. Ownership of land is recorded by the state in registries or similar systems, and although not necessarily required, recording is strongly encouraged. ${ }^{63}$ Use of registries is mandatory for automobiles and motorcycles, aircraft, and boats over a certain size. ${ }^{64}$ Additionally, cattle and other animals are frequently branded, with the brands being recorded in registries or generally understood; branding of animals is often mandatory but sometimes is voluntary. ${ }^{65}$ Patents, copyrights, trademarks, and various security interests in property are also registered. ${ }^{66}$ Fairly well known works of art may often be viewed as implicitly registered because their true owners are commonly known. (If a person steals the Mona Lisa from the Louvre, he

\footnotetext{
${ }^{63}$ In the United States, individuals generally enter real estate transactions into a recording system; a buyer is induced to record his transaction because, if he does not and the seller sells the same property to another party who does record his transaction, this second party will gain title (the first will only be able to sue the seller for money damages). Recording systems are not identical to the registration systems described in this section, for the party listed as title holder in the recording system may not in fact be the title holder, and the recording system does not reliably list all those who have interests in property. Eleven states do have registration systems, though their use is not required. See Stoebuck and Whitman 2000, 86997, 923-30. In Europe, use of registration systems is more common; see McCormack 1992, 70. For economic analysis of recording systems versus registration systems, see Miceli 1998.

${ }^{64}$ On registration of automobiles and motorcycles, see Bassano et al. 1997, section 55; on aircraft, see Philbin 1997, section 30; and on boats, see Zakolski 1997, sections 23-24.

${ }^{65}$ More than thirty states have enacted some type of branding law, applying usually to cattle, horses, mules, and asses. In the West, branding is usually mandatory but elsewhere it may be optional. See Meyer 1990, and see also St. Julian 1995, sections 8-9. Use of brands is ancient (the Egyptians practiced branding); on the history of branding, see August 1993, 466-74.

${ }^{66}$ On the registration of patents, copyrights, and trademarks, see, for example, Flinn 2001, 2-10, 2-23, 2 $24,2-42,2-43,2-44$. On registration of security interests in property, see for example, Clark and Clark 2001, vol. 1, 1-13, 1-14, 2-118, 2-119, 2-120.
} 
cannot resell it and hope that it will not be recognized as stolen. ${ }^{67}$ ) Use of registries for other types of property is infrequent.

\section{Sale and Theft of Property in the Absence of a Registration System}

5.1 Meaning of the absence of a registration system. Let us assume now that there is no registry in which the lawful owners of property are recorded. This is the case with most goods; as just discussed, the actual use of registries is relatively limited. Unregistered goods may have no identifying marks or labels on them; this is typically true of common household goods, food, clothing, and jewelry, for instance. When such goods are in a person's possession or offered for sale, there will often be no easy way to determine whether the goods had previously been stolen or impermissibly obtained. It is also possible that unregistered goods do have an identifying label, notably, a manufacturer's serial number, as is the case with much electronic equipment for example. An owner of such goods could attempt to maintain proof of ownership, such as by recording the serial number of his property on a bill of sale. ${ }^{68}$

5.2 Two legal approaches concerning ownership: bona fide purchase rule; original ownership rule. There are two basic approaches that the law may take in defining legal ownership when there is a sale in the absence of a registration system. One is to deem a purchaser to be the owner if, at the time of the exchange, he believed that the property was not previously wrongly acquired and he could not readily determine otherwise. This rule will be called the bona fide purchase rule because the purchaser believes the exchange to be bona fide. Under the other approach that the law may adopt, a purchaser must surrender a thing to a previous owner if the latter can establish that the thing was illegitimately taken from him. This rule will be called the original ownership rule.

5.3 Bona fide purchase rule fails to discourage theft and sale of stolen goods. Under the bona fide purchase rule, an owner will be in the unfortunate position that, unless a thief is caught in the act of theft, the owner will be unlikely to recover what has been taken from him. This is true, virtually by definition, of all goods for which owners do not have proof of ownership; if, after a thief steals my pen, I happen to see a person with what appears to be my pen (perhaps I recognize scratches on it), how do I establish this? Even if an owner does have proof of his ownership, it may well be difficult to prove that a person in possession was the thief or was not a bona fide purchaser. If I see a person riding my bicycle, for which I have a bill of sale recording the serial number, and I wish to reclaim it, I need to demonstrate either that that person stole it or that he purchased it from some other party knowing that it was stolen.

Next, consider the situation of a thief. As just discussed, thieves will know that if they are not caught in the actual act of theft, they will be relatively unlikely to be caught.

\footnotetext{
${ }^{67}$ This undoubtedly reduces the problem of theft of well known works. For art not widely known, however, the analogy does not hold; without there being a registry in art works, a person who steals, say, a statuette made by an undistinguished Renaissance sculptor might be able to pass it off without much difficulty.

${ }^{68} \mathrm{I}$ am assuming that the manufacturer does not maintain (much less mandate) a list of current owners of its product. In fact, even original purchasers often do not register their property with the manufacturer. Otherwise, the situation might resemble that under a registration system.
} 
Moreover, thieves will anticipate that if they attempt to sell what they have stolen -something they will want to do if they do not wish to use stolen items themselves -- sales will often be relatively easy to make appear bona fide. The latter is true because buyers will have little interest in proving that they are making purchases from thieves; rather buyers' self-interest is socially perverse, to overlook theft so that they can consummate purchases at advantageous prices and become the legal owners of goods. Further, a buyer's ability to determine whether a good was stolen by the seller will often be poor. If the thief claims the property is his, or if he produces a document that he says is a bill of sale, the buyer might not be able to check the veracity of the document very easily. Also, to impose a substantial burden on buyers to investigate the claims of sellers before sales are considered bona fide would disturb trade.

For these various reasons, it appears that the bona fide purchase rule dilutes deterrence of theft. Theft has to be discouraged primarily by the possibility of catching thieves in the act. ${ }^{69}$

5.4 Original ownership rule discourages theft and sale of stolen goods. The original ownership rule has contrasting effects on the sale of stolen goods and theft. First, an owner of a thing will have a positive incentive under this rule to obtain proof of ownership, for that will be of potential benefit to him after a theft, as he will be able to recover his property if he can locate it even if it has been sold by the thief to an unknowing third party.

Further, because owners may possess proof of ownership and may be able to recover their stolen property, thieves will find stolen property less valuable and not be able to obtain as much for it in sales as they otherwise would. The reduction in sales price will reflect the likelihood that goods are stolen, and it will be in buyers' interests to determine whether goods are stolen.

5.5 Conclusion: original ownership rule may be superior. Because thieves will find stolen property less valuable, theft will be discouraged more under the original ownership rule than under the bona fide purchase rule. This suggests that the original ownership rule is the superior rule. However, when one takes into account the transactions costs of exchange under the two rules (see paragraph (b) in the next section), it is conceivable that the bona fide purchase rule would turn out to be superior.

5.6 Comments. (a) Limited effect of the choice of rule on theft. Although the original ownership rule should lead to greater deterrence of theft, its effect on theft appears to be limited by two considerations. First, original owners may not be led to obtain proof of ownership because of the certain costs of so doing and the uncertain nature of the benefits. This is especially true of goods that do not come with serial numbers. Second, even if original owners do have proof of ownership, it will frequently be difficult for them to locate stolen goods.

(b) Argument that the original ownership rule undesirably encumbers trade. It is sometimes thought that the original ownership rule might unduly curtail trade because buyers would be subject to uncertainty about sellers' ownership rights and thus of their own, or else because buyers would have to expend great effort assuring themselves that sellers have good title. This view is oversimple, however. Buyers' uncertainty will often

\footnotetext{
${ }^{69}$ This is not to deny that law enforcement agencies can succeed in such strategies as employing undercover agents to prove that certain buyers ("fences") knowingly buy stolen goods.
} 
be modest or insignificant because the likelihood that goods were stolen will be small, because, as just discussed above, original owners will not take the trouble to maintain proof of ownership, and because original owners often will not know where to look for their property. For these reasons, buyers often will not rationally expend much effort to verify sellers' title. Trade therefore will not be generally impeded under the original ownership rule. It will be impeded mainly when the fraction of stolen articles is great, which is also when it is probably socially desirable that trade be impeded. ${ }^{70}$

5.7 The law. In the United States, the original ownership rule generally applies, although there are a variety of limitations to it under which a bona fide purchaser gains title over the original owner. ${ }^{71}$ In Europe, the bona fide purchaser rule is more commonly employed, though with certain exceptions. ${ }^{72}$ Historically, both types of rule have governed. $^{73}$

\section{Constraints on the Sale of Property Imposed by the State}

Having discussed the sale of property in the last two sections, let us now turn to consider briefly justifications for state intervention in sales.

6.1 Intervention to correct external effects. One basic justification for the state to impose a constraint on the sale of property is that this may help to solve a problem of harmful external effects (on external effects, see generally chapter 10). If the sale of property would result, directly or indirectly, in harm to people not involved in the transaction itself, then discouraging sales may be socially beneficial. Such state intervention may be helpful in solving problems with external effects because alternative methods, such as the use of liability, may not function perfectly or may be more difficult to employ. Let us consider several types of intervention.

(a) Banning sales. An extreme form of intervention is the outright ban of sales of certain types of property. For example, the sale of certain classes of firearms is proscribed, the justification being that the harmful external effect of their sale is that purchasers might use the weapons to hurt someone and/or to carry out crimes. A drawback of prohibiting sales is that there may be legitimate, non-harm producing uses of the firearms. This disadvantage depends on the type of firearm; for hunting rifles it would be more significant than for, say, machine guns.

A type of good for which a ban on sales has, perhaps, the strongest justification is one that is used solely for circumventing the law, and thus one that contributes to the doing of harm and for which there is no social disadvantage to a ban. An example is the

\footnotetext{
${ }^{70}$ In addition to the points made in this paragraph, it may be noted that some buyers might expend effort to discern which goods are stolen, and that this may only divert sellers to other buyers. To that extent, buyers' efforts to determine which goods are stolen might contribute little to deterrence and may constitute a social waste.

${ }^{71}$ For example, if the original owner is induced by fraud to sell property to a person and this person sells to a bona fide purchaser, the purchaser will gain title as against the original owner. See generally Brown 1975, chapter 9, and Thomas 1994, section 13.

${ }^{72}$ See Prott and O’Keefe 1995, 367-97.

${ }^{73}$ See the economically oriented analysis of the two rules in Baird and Jackson 1984, Levmore 1987, and Weinberg 1980.
} 
radar detector, which is used only for detecting the presence of police looking for speeders; if speeding is assumed to be socially undesirable, then radar detectors are undesirable because they reduce the likelihood of penalties for speeding.

In such cases where a ban on sales seems appealing, the justification for this categorical prohibition must rest on a comparison with other legal approaches to control harmful external effects. For firearms and radar detectors, for example, it might be that a ban is superior to other methods of control, for once these goods have been sold, it is difficult for the state to monitor their use and the harm done with them.

(b) Restrictions on the type of purchase. The state may intervene not by banning the sale of a product, but rather by restricting sales to certain classes of purchasers unlikely to use the property in the wrong way. Thus, the sale of firearms may be limited to private police, to shooting clubs, and so forth. The state may also intervene by restricting the type of purchase. For example, zoning laws may mandate minimum lot size, which implicitly alters the ambience of a neighborhood by increasing the amount of greenery, the wealth of residents, and the like.

(c) Limitations on privately-imposed constraints on sale. Private parties may themselves wish to place constraints on the sale of property, and sometimes this will cause harmful external effects. For example, an individual might want to prevent sale of land to persons of particular religions or races, and that might create social harm. If so, it could be desirable to prevent these constraints on sale.

6.2 Intervention to remedy problems of lack of information. A second general justification for state intervention in sales is to cure a problem of lack of information on the part of a participant in the sale, in order to effect a type of transaction more closely in line with what would have been consummated had parties been informed.

An example is that certain drugs cannot be sold except according to physician prescription. Without restrictions on sale, a person who does not understand which drugs to use might use the wrong one, a drug that the person would not have used if he or she had expert medical advice.

This line of reasoning overlooks two possibilities, however. First, a potential purchaser whose knowledge of a good is incomplete might well realize this deficiency and seek more information. A person who does not understand the properties of a drug might contact a physician or pharmacist to determine when it would be safe and helpful to take the drug. Second, the state might supply potential purchasers of goods with information. They might be informed of basic characteristics of goods on labels, for example, and be told to consult an expert if the characteristics are too complicated to state succinctly. If people are able to understand such information, its provision by the government would appear to be a superior solution to intervention against sale.

6.3 Intervention for paternalistic reasons. Another justification often mentioned for intervention is paternalism, meaning that the state has a desire for individuals not to consume certain goods, at least under particular conditions. Sometimes, though, paternalism reflects an external effect. For example, society's efforts to curb consumption of alcohol may be due to the fact thatif people drink to excess, others can be harmed. It may also be the case that paternalism reflects a problem of lack of information. For instance, if minors are not allowed to purchase cigarettes, the justification may be that they are not old enough properly to evaluate the health risks of smoking. However, paternalism is occasionally not readily viewed as reflecting 
externalities or lack of information, but rather as a desire of society to override the preferences of others. For example, the view that adults who understand the risks of failure to wear seat-belts in cars should be required to do so may in part be a product of true paternalism. $^{74}$

\section{Gifts}

7.1 Gifts and their motivation. Gifts are an important form of transfer of property, especially when one takes into account the size of bequests. ${ }^{75}$ A major motivation for giving a gift is pure altruism: The donor cares about the well-being of the donee; that is, the donor obtains utility from the utility of the donee. This is frequently the case with gifts given to family members or to friends and may extend to the wider population and to organizations.

There are, however, a variety of reasons for gift-giving apart from altruism. One is that the act of giving itself may supply utility to the donor, independently of the degree of satisfaction it renders the donee. ${ }^{76}$ Another is that a gift may produce expressions of appreciation or affection from the donee, or respect from those who learn of the gift (as might be true when the community is informed that a person has made a substantial gift to a symphony orchestra); thus, the gift is somewhat like a sale that is accompanied by receipt of a service (the expressions of appreciation). In addition, a gift may provide a signal about the donor that results in behavior that he considers valuable. ${ }^{77}$

7.2 Desirability of state encouragement of gifts. A general reason exists for the state to support the giving of gifts and in principle to subsidize them: Because donors do not take the value of gifts to donees into full account, but that should be done from the perspective of promoting social welfare, donors may give too little, and the subsidy of gifts may therefore be desirable. Consider the case where altruism is the motivation for gifts (the point largely applies as well with respect to the other motivations for giftgiving). Suppose that if A were to give a gift to B, A would obtain an altruistic benefit of 35 , that B himself would obtain a benefit of 70 from the gift, but that the gift would cost A 40 owing to the consumption he would forgo. Individual A therefore would not give the gift, as the altruistic benefit to him of 35 is outweighed by the cost to him of 40 . However, it is socially desirable for the gift to be given, assuming a sum-of-utilities

\footnotetext{
${ }^{74}$ Still, in strict logic, it might often be said that a species of external effect is at issue when individuals in society want to override a person's preferences, such as a person's preference for driving without a seatbelt: The externality is the disutility that individuals in society experience when some persons act on their preferences (drive without seatbelts).

${ }^{75}$ For example, Gale and Scholz 1994, 152-54, estimate that intended giving amounts to 17 per cent of individuals' net worth, and that annual bequests constitute almost 1 per cent of net worth. Also, charitable giving accounts for slightly over 2 per cent of household income; see Statistical Abstract of the United States 2001, table 559, p. 360.

${ }^{76}$ The utility from giving itself is sometimes described as a "warm glow"; see Andreoni 1990.

${ }^{77}$ If I give a generous gift to my rather new employee, this may signal that I am pleased with his performance and am likely to continue to employ him, for why else would I have made the investment in the gift? This may inure to my benefit, for the employee will be more likely to work hard and less likely to search for another position.
} 
measure of social welfare; for if the gift is given, the net change in welfare will be positive, $35+70 ! 40=65$. A subsidy for gift-giving could induce A to give the gift, and therefore might be socially advantageous. ${ }^{78}$

There are also specific reasons for the state to support gifts to certain organizations. Notably, if an organization is furnishing a public good (see section 1 of chapter 11), providing a benefit to society generally that cannot be provided by the private sector, then one way to finance it is by encouraging those who would give for whatever reason to give more, by subsidizing giving. Thus, a university, which provides public goods of a sort, could be financed in part by state encouragement of gifts.

\section{Transfer of Property at Death: Bequests}

8.1 Transfer at death an important event. A bequest is the transfer of property upon the death of an individual, the so-called testator, according to his wishes. Bequests are a significant form of transfer of property; at least 30 per cent of the total wealth of individuals in this country is acquired through bequests.

The principal aim in this section is to explain why bequests are made. In other words, why do individuals neither consume nor give away their entire wealth during their lives? ${ }^{80}$ (Gifts made while a person is alive are known as inter vivos gifts because they are made between living persons.) As will be seen, the answer to this question is not selfevident. After exploring this question, I will comment on wills and on legal policy regarding bequests.

8.2 Altruism and uncertainty about donees. Altruism is a reason for a person to give property away, but it does not furnish an explanation for why a person should give his property away in a bequest rather than when he is alive. After all, if a person makes a gift when he is alive, the donee can make earlier use of it for some good purpose (for example, to obtain a college education) or at least plan his actions better knowing that he has the gift in hand. In either case, the advantage to the donee will indirectly benefit the

\footnotetext{
${ }^{78}$ The argument of this paragraph is made by Kaplow 1995. To explain, let $u(y)$ be the utility of wealth y of the donor, $v(w)$ the utility of wealth $w$ of the donee, and " $v(w)$ the utility the donor derives from the donee's utility, where " $>0$ represents the strength of altruism and $u$ and $v$ are increasing and concave in wealth. The donor chooses a gift $x$ to maximize $u(y ! x)+" v(w+x)$, so that he will give a positive gift if $u \mathrm{~N}(y)>$ " $v(\mathrm{~N} w)$, and if he gives a positive gift, it will be determined by $u \mathrm{~N}(y ! x)=" v(w+x)$. Assuming that the measure of social welfare is the sum of the donor's and donee's utilities, $x$ ought to maximize $u(y$ ! $x)+" v(w+x)+v(w+x)=u(y ! x)+(1+") v(w+x)$, so that the socially optimal gift, if positive, is determined by $u \mathrm{~N} y ! x)=(1+") v(w+x)$, which implies that the socially optimal gift exceeds the size that the donor will give. Because a donor gives a smaller gift than is socially optimal, it can be shown that a subsidy raised by a lump sum tax raises social welfare, where the state is unable to base the tax on who is a potential donor and who is a potential donee (this might be difficult for the state to determine and, if observable, would allow the state to achieve its object directly).

${ }^{79}$ See Gale and Scholz 1994, 147.

${ }^{80}$ For a useful and wide-ranging survey of the economic literature on bequests (dealing with accidental bequests, as described below, and with other issues in addition to altruism), see Kotlikoff 1988; see also Kotlikoff 2001. On gifts made during a person's life, and the choice between such gifts and bequests, issues on which somewhat less attention has been devoted, see, for example, Cox 1987, Gale and Scholz 1994, and Altonji, Hayashi, and Kotlikoff 1997.
} 
donor because of his altruism (and perhaps this is why the dollar value of inter vivos gifts is estimated to exceed that of bequests ${ }^{81}$ ).

However, uncertainty about donees can explain why altruists may defer gift giving, possibly until death. A donor may be uncertain about the needs of a potential donee (whether a relative will turn out to have a need for money may depend on his or her marriage, health, and employment) or about the character of a potential donee. The qualities and circumstances of people are revealed over time, so that a donor may not want to give a gift unless he has gathered as much evidence about the need or the character of a potential donee as possible. Closely related, a donor may not know to which person or organization he will want to give property. For example, a donor may imagine that some worthy cause may arise and reveal itself to him in the future (who could have imagined the AIDS epidemic before it materialized?). Thus, the donor may want to preserve his options in order to modify his plans about who should receive his property until he has died.

8.3 Uncertainty about length of life: accidental bequests. A second reason why property may be transferred only upon a person's death involves uncertainty over the length of one's life. If a person is uncertain how long he will live, he will want to keep enough wealth in his possession to support himself if he should be lucky enough to live longer than he expects. That, in turn, means that when he dies, he will die with property. Thus, bequests will result from the "accident" of death; this event will make a person's wealth available to be passed on to a donee. ${ }^{82}$ Note that this reason for transmission of property at death applies even if a person does not have an altruistic motive.

The existence of a well-functioning annuities market, however, substantially qualifies the argument that individuals must hold property until death to assure themselves necessary support if they live unexpectedly long. Under an annuity contract, an individual pays a premium and in exchange receives a stream of income for as long as he lives, but for no longer.

A risk-averse person who is earning little or no income may find an annuity an attractive way to expend his wealth because it allows him to assure himself income for consumption no matter how long he lives. Indeed, if annuity contracts are actuarially fair, a risk-averse individual should want to invest much of his wealth in annuities, other things being equal. ${ }^{83}$ And, by definition, the more an individual invests in annuities, the less wealth he will have in his possession when he dies; if he were to invest everything in annuities, he would die penniless and make no bequest. Hence, the significance of uncertainty over length of life as an explanation for the holding of wealth at the time of death, and thus for transmission of wealth at death, is reduced to the extent that individuals purchase annuities.

\footnotetext{
${ }^{81}$ See Cox 1987, 511.

${ }^{82}$ On uncertainty about length of life as an explanation for bequests, see, for example, Abel 1985, Davies 1981, and Hurd 1989.

${ }^{83} \mathrm{~A}$ risk-averse person would in principle want to invest all of his wealth in an annuity if it were actuarially fair, he did not have a bequest motive, and he were not subject to other uncertainties that will be mentioned in the text. On the theory of annuities and life insurance, see the early paper by Yaari 1965, and for a relevant empirical study, see Bernheim 1991.
} 
A person might not want to invest too heavily in annuities, though, even if he has no desire to make a bequest (obviously, if he does want to make a bequest, he will retain wealth for that purpose). This is because of uncertainty about his future needs and tastes. For example, he may not know how much he will want to spend if his health declines (will he want full-time nursing care?), or whether he will want to travel or buy a home at another location. If a person commits all his funds to an annuity, he will have less freedom to increase his expenditures. To gain this freedom, he may rationally elect to retain a share of his wealth rather than devote it entirely toward annuities. ${ }^{84}$

8.4 Life insurance. Uncertainty about the length of one's lifetime can also lead a person to purchase life insurance, and therefore lead to his passing on wealth in the form of life insurance proceeds at the time of his death. In particular, a person who is earning a wage that he would spend in part on a donee for whom he has altruistic feelings may rationally purchase life insurance, if sold at approximately actuarially fair rates and the donee is risk-averse. ${ }^{85}$ The amount of coverage the donor purchases will reflect the income the donee would lose due to the donor's death. Note that this reason why a donee may obtain wealth when a donor dies applies even though the donor may be certain of the amount of wealth that he wants to give to the donee; the donor cannot give his future stream of earnings to the donee now, but he can purchase life insurance and name the donee as the beneficiary.

8.5 Control over the behavior of children. Individuals often want children (or others) to give them care and attention, especially during their later years of life. It is occasionally argued that to foster this behavior, an individual can make a child's inheritance conditional on his providing a requisite degree of attention. ${ }^{86}$ A parent might say, or might make it understood, that a child's inheritance depends on his being attentive, that otherwise he will be disinherited or his inheritance will be considerably reduced. A problem with this argument, however, is that if a parent desires attention, it is not obvious why the parent cannot "purchase" it through gifts during the parent's lifetime (such as through large Christmas presents or loans for the education of grandchildren). ${ }^{87}$ Thus, the desire of parents to influence the behavior of children does not by itself convincingly explain why parents would retain wealth until their deaths.

\footnotetext{
${ }^{84}$ Several other reasons that a person may not want to invest in annuities should be mentioned. One is that annuity income is subject to income taxation at ordinary rates, whereas income from investments may be subject only to lower capital gains rates. Another is that annuity payments may not be actuarially fair due to administrative costs and adverse selection. (Adverse selection refers to the fact that purchase of annuities by the relatively healthy and long-lived reduces the annual annuity payment that companies can make. This renders annuity contracts actuarially unfair for the less healthy.) An additional reason is that a family's financial arrangements may mimic annuities. Notably, when husband and wife bequeath their assets to each other, the surviving spouse in effect obtains a kind of annuity. On the latter, see Kotlikoff and Spivak 1981.

${ }^{85}$ On the theory of life insurance, see Yaari 1965.

${ }^{86}$ See Bernheim, Shleifer, and Summers 1985.

${ }^{87}$ Indeed, if the desire for attention and his own personal consumption were all that a parent cared about and the parent's date of death were known in advance, the parent would have no reason not to expend his entire wealth on attention and on personal consumption; the parent would retain no wealth at death because this would represent a waste of assets.
} 
Nevertheless, the desire to affect the behavior of children reinforces other arguments that have been given for individuals to retain wealth until death. Notably, parents may want to retain wealth until their deaths because of continuing uncertainty about the needs of potential donees, and, independently, various uncertainties may lead parents to limit annuity purchases. As a by-product, they can obtain enhanced control over the provision of care and attention by their children.

8.6 Taxation. Tax considerations may favor giving property after death. For example, under the U.S. tax code, securities given after death have their "basis" increased, making them more valuable to donees than if the securities had been given as a gift before death. ${ }^{88}$

8.7 The will: the legal instrument for effecting transfer of property at death. General reasons have been offered above for why an individual may possess property at death and want to pass it on. The will is the instrument through which such an individual can direct the disposition of his property. A will is a document specifying the recipients of a person's property upon death.

Several characteristics of wills deserve comment. First, wills often contain conditional provisions. The reason is that certain contingencies (such as the needs of children) may affect the amount the writer of the will would like the donee to receive or the identity of preferred donees.

Second, and related, is that wills are often modified. Changes to wills are made because of the occurrence of contingencies that alter the writer's wishes. Yet one might ask why the occurrence of such contingencies should lead to modification of a will, for the writer could have obviated the need to modify his will by providing for the occurrence of the contingencies in the will. Sometimes, however, this is not feasible because the occurrence of the contingency cannot be verified by a court. For instance, the quality of an elderly parent's relationship with a child (revealed by such behavior as whether the child pays visits to the parent) may be difficult for courts to determine. If so, a provision in a will stating that the child's inheritance should be reduced if the child treats his or her parents poorly would be unworkable. Thus, the parent must change his will in order to alter the allocation to the child. A second reason why a person may modify a will is simply that the writer did not include a contingency in the will because, at the time the will was written, the contingency was unlikely or because it was not even contemplated. (The rationality of not including certain provisions in contracts, of which a will is a special example, is taken up generally in section 4 of chapter 13.)

Third, writers sometimes want to make wills irrevocable. One reason is that the donee can then rely on receipt of the gift, and therefore it will have greater value to him. For example, a child who expects an inheritance can invest his own funds in a promising business enterprise. The increased value of the gift bequest will inure to the benefit of the

\footnotetext{
${ }^{88}$ See Section 102(a) of the Federal Income Tax Code, specifying that bequests are excluded from the income of the donee, and Section 1014, stating that the tax basis of property acquired by inheritance becomes the market value of the property at the date of the testator's death. Section 1014 means that property that has appreciated in value over the testator's lifetime will be treated as having been acquired by the donee at its appreciated value at the time of the testator $=\mathrm{s}$ death. Thus, if land purchased for $\$ 10,000$ by the testator and worth $\$ 100,000$ at his death is subsequently sold by the donee for $\$ 105,000$, the latter will owe taxes only on $\$ 5,000$-- the difference between his sale price and his basis of $\$ 100,000$-- not on the gain of $\$ 105,000 ! \$ 10,000=\$ 95,000$.
} 
writer of the will owing to his altruism. ${ }^{89}$ A second reason for making a will irrevocable is that a writer may fear that he will later become incompetent (but not be so judged by a court) and act against his own best interests.

8.8 Policy in respect to inheritance. ${ }^{90}$ Should society intervene in private decisions to bequeath property? In an important sense, bequeathing property is simply one way of using property. And therefore, society should not interfere with bequests for the same general reasons that it is undesirable for society to constrain the use of property. Namely, this tends to reduce individuals' utility directly (a person will derive less utility from property if he wants to bequeath it but is prevented from doing so) and also lowers their incentives to work (a person will not work as hard to accumulate property if he cannot then bequeath it as he pleases).

It might be argued, however, that externalities (see chapter 10) are relevant to inheritance. One might say that allowing families to retain large amounts of wealth detracts from social cohesion because it allows elites to sustain themselves. If so, the state might find some justification (apart from raising revenue) for imposing taxes on inheritance. ${ }^{91}$

Another externality of concern is that a spouse or dependent child who does not inherit wealth may receive public support (in the form of general welfare payments, education, or health care). A person might reduce or exclude his or her allocation to a spouse or children, depending on public support to take up the slack. This externality might justify a stipulation that some minimum fraction of property be given to spouses and children. An additional factor that could justify a state-imposed guarantee of a minimum inheritance for spouses and children is that, had the family members made a contract, it would have specified such support. For example, a contract between a wife who does not work and a husband who does might have stated that half the family's assets would be inherited by her if the husband predeceased her. ${ }^{92}$

The donor's inability to make a sound decision might also be suggested as a rationale for state control of bequests; in the late stages of life, an individual's judgment is often impaired.

It should be noted, however, that legal policies controlling inheritance can be partially circumvented by increases in inter vivos gifts. For example, were a law to

\footnotetext{
${ }^{89}$ See section 2 of chapter 16 on donative contracts for further discussion.

${ }^{90}$ This section deals mainly with the power of individuals to control the distribution of property at the time of their death. The next major section considers the issue of the power of individuals to control the distribution and use of their property after their death.

${ }^{91}$ To amplify, the rationale for such taxes cannot be solely to prevent a person from acquiring wealth. Were that the social goal, it would be best and most directly accomplished through a tax on wealth; there would be no need for an inheritance tax per se (and an inheritance tax would not prevent the living from accumulating excessive wealth); this type of argument is emphasized by Tullock 1971. The rationale for an inheritance tax must be that the retention of wealth by particular families across generations is deemed a social problem.

${ }^{92}$ Why a husband and a wife might not make a contract about the disposition of assets at death is another, somewhat problematic question. It is sometimes suggested that doing so might be inconsistent with the trust and mutuality of confidence bound up in the marital relationship.
} 
require that half a person's property pass to the person's spouse and children, the person could transfer much of his wealth to an alternative preferred donee during his life. The person would be unlikely to do this with all of his wealth, however: There must be some value to the person of retaining wealth until death, for he would otherwise already have given all of his wealth to the preferred donee.

8.9 The law. Individuals generally have great freedom to designate to whom their property will pass at death, but most countries stipulate that a decedent's spouse (and sometimes his or her children) receives a minimum share, ${ }^{93}$ and restrictions on inter vivos gifts are also frequently imposed to guarantee that these minimum shares will not have been diluted before testators die. ${ }^{94}$ Wills may generally be altered whenever the writer desires, unless the writer is found to be incompetent, and the ability of a writer to make a will irrevocable is circumscribed or non-existent. ${ }^{95}$ Property given at death is generally taxed at high rates, but only if it surpasses a threshold level. ${ }^{96}$

\section{Control of Property after Death: The "Dead Hand"}

9.1 Question of concern: Should the power of the "dead hand" -- the power to control property after a person's death -- be constrained ? $^{97}$ The issue to be considered here is whether or not it is socially desirable for there to be limits on the power of individuals to exercise control over property after their deaths. For example, should a person be able to prescribe that his wealth accumulate for two centuries and then be given to his descendants, that his land be forever set aside as a memorial to his cat, or that his art collection be kept on permanent display at a named museum? ${ }^{98}$

\subsection{Why individuals might or might not want to control property after their}

death. It should first be said that individuals often would rationally elect not to control property after their deaths. An altruistic donor generally will be best off if he leaves a

\footnotetext{
${ }^{93}$ Almost every American jurisdiction allows the surviving spouse to claim a statutory portion (generally, from one-third to one-half) of the decedent's estate. In Germany and France, the law is similar; in Britain the spouse obtains maintenance and certain other benefits as decided by the court. See, for example, Glendon 1989, 238-51.

${ }^{94}$ See, for example, Langbein and Waggoner 1987, 303-17.

${ }^{95}$ See Waggoner et al. 1991, 531.

${ }^{96}$ At present, the first $\$ 1,000,000$ of a bequest is excluded from taxation (this amount will rise to $\$ 2,000,000$ by 2006); I.R.C. Section 2010 (2002). The tax rate then applies, rising from 18 per cent to 50 per cent; I.R.C. Section 2001 (2002).

${ }^{97}$ Although the power of a donor to control property after his demise is today often called the power of the dead hand, the term "dead hand" originally referred to the donee, notably, to a religious corporation that had been granted land. One speculation for this usage is that religious corporations that held land were early excused from the tenurial obligation to supply knight service, so it was as if there were only dead hands available to provide this form of military assistance. See Simes 1955, 2 -3.

${ }^{98}$ In these examples, and in general in this section, I will be discussing the control of property substantially after a person's death, not merely in the period right after death that is necessary to settle and implement a will providing for the disposition of assets to parties who are then free to use and to sell or transfer the property as they wish.
} 
beneficiary free to use and to dispose of property as the beneficiary sees fit, for in that way the beneficiary can most raise his own welfare, which will inure to the donor's benefit. If I give wealth to a child and the child can use this wealth as the child desires as the future unfolds in its unpredictable ways, the child will be better off, and thus so will I be, anticipating this, given that I care about the child's well-being.

Nevertheless, a donor might want to control the use of property after his death for several major reasons. One is that, although the donor is altruistic, he does not believe that the donee will use property so as to raise his utility; an example is a donee who is too young to make wise decisions for himself. A second reason is that future events might determine who the preferred donee will be. For instance, the donor might want to give wealth to a child only if that child eventually has children. Another reason that a person might wish to control property after his death is that he has a direct desire to do this, that is, the donor derives utility from the knowledge that the property will be used as he wishes, and not because that will serve to advance the utility of some other persons who will be alive and about whom the donor cares. The donor who specifies that land be set aside to memorialize his cat might fit in this category, and possibly also the donor who wishes paintings to be displayed in exactly the way he specifies (rather than where and in the manner that future viewers would prefer).

9.3 General argument favoring dead hand control of property. Just as it was observed in section 8.8 that bequeathing property is simply one way of using property, so too is controlling property after one's death merely a way of using property. And as such, a benchmark for thought is that society should not interfere with parties' desires to control property after their deaths. Otherwise, individuals' utility from property will be reduced and their incentives to work will be diminished.

9.4 Incorrect arguments against dead hand control of property. One argument that is often offered in favor of interfering with dead hand control of property seems problematic. Namely, as the dead cannot enjoy utility, it would be socially wasteful, a folly, for the dead to control property, interfere with its use, to the detriment of those who are living. ${ }^{99}$ This argument fails to reflect two points. First, individuals who desire dead hand control will in fact suffer utility losses when they are alive, assuming that they anticipate that property will not be used in the way they want when they are dead. Thus a social policy of ignoring the wishes of the dead will in fact hurt certain individuals when they are alive. Second, the detriment to the living due to dead hand control of property is not ignored by a person who wants dead hand control, but rather is taken into at least implicit account by such a person. For example, if a person sets aside land as a memorial to his cat, he pays a price for the land (or gives up selling the land if it already is in his possession), and this price embodies the value of the land to individuals in the future. (The price of any asset impounds all future values.) Thus, the decision of a person to control property after death involves a weighing of the utility of such control against the price, which represents its alternative value to others into the future. Accordingly, the decision of the person seems just as appropriate from a social standpoint as essentially any decision a person makes about consumption, ${ }^{100}$ such as whether to purchase a tank of gasoline to run his automobile. ${ }^{101}$

\footnotetext{
${ }^{99}$ See, for example, the summary of this point of view in Simes and Smith 1956, 10-11, and see also Stoebuck and Whitman 2000, 120.

${ }^{100} \mathrm{I}$ am here referring to one of the basic conclusions of microeconomic theory, that consumption
} 
Another argument against dead hand control that is sometimes encountered is that the benefits to the dead of controlling property decline with the passage of time and at some point are outweighed by the interests of the living. ${ }^{102}$ This argument, however, is incomplete as stated, for it does not take into account that donors themselves are led to compare their benefits as a function of the period of time over which they exercise dead hand control with the corresponding costs to individuals who will be alive later. This is because a person will in principle have to pay more for dead hand control the longer he wishes to exercise it. For instance, a person who wishes land that he owns to be set aside to memorialize his cat for only one year after his death will not have to pay much for this -- he will be able to sell the land for most of its market value. But a person who wishes the land to be set aside for ten years before it can be sold will have to pay much more -for he will not be able to sell the land for nearly as much. Thus, a person will set aside the land for ten years rather than for one year only if the extra benefit he derives therefrom is worth the extra cost (this extra cost reflecting the value to others of the use of the land for the additional nine years). In other words, donors who wish to exercise dead hand control engage in the very type of weighing that the argument at issue suggests is socially desirable; hence, more must be said to justify interference with the decisions that donors make about dead hand control.

9.5 Valid arguments against dead hand control of property. Despite the foregoing, a number of justifications for interfering with dead hand control of property can be identified.

One concerns the cost and impracticality of making highly refined arrangements for dead hand control of property, under which control would be relaxed in various contingencies and at certain times. For example, a person who stipulates that his paintings should always be shown in a particular way at a named museum might in fact prefer that his paintings be shown at another museum if the named museum's patronage falls substantially (perhaps because of shifts in population over time) or if new ways of displaying paintings come into existence that he had not contemplated during his lifetime. Or a person who wants land permanently set aside as a memorial to his cat might in fact prefer that the memorial shift to another location if the land becomes very valuable at some time after a century has passed or if a new and graphic way to memorialize the cat becomes possible (suppose DNA from the cat can be used to clone it). For individuals to make highly detailed plans for the control of property after death, however, would often be irrational, as the cost of making a detailed provision is borne with certainty, whereas the benefit is discounted by the often extremely small likelihood of the occurrence of a

decisions based on price have a desirable social character, given the underlying distribution of wealth, if markets are competitive and complete. See, for example, Feldman 1987.

\footnotetext{
${ }^{101}$ Indeed, when a person uses gasoline, he denies it to all future generations. Thus, using gasoline is very similar to tying up land forever. Hence, if one regards decisions to use gasoline based on its price to be socially reasonable and good (since people will then use gasoline when its value exceeds its social cost), so too should one regard decisions of persons to tie up land forever to be socially reasonable and good. (The main difference is that land, if tied up, can always be taken back by a future generation, but not so gasoline that is burned. This difference is inessential to the present point, but does have significance, as I will discuss in section 9.6.)

${ }^{102}$ See, for example, Ellickson 1986.
} 
contingency and perhaps by its remoteness in time. Moreover, many kinds of future outcomes would not even be contemplated by a person when making provisions for the control of property (the cat lover might have made the provisions before DNA was discovered and the possibilities of cloning were conceived). If, then, the plans that are made for the control of property after death are not reflective of the true detailed plans that would have been made if the individuals had the time and ability to consider all details, the state's modification of their plans may sometimes be justified as an attempt to carry out their true plans. ${ }^{103}$

An observation that reinforces this argument for legal intervention in dead hand control is that, of course, the dead cannot be told of difficulties that arise and cannot give permission to alter the terms of their arrangements. Therefore, it is not inconsistent for society to modify or override dead hand arrangements to control use of property but not to intervene generally with use of property during a person's lifetime, when bargaining with a person is possible (if a person now alive is using land as a memorial to his dead cat and the land becomes very valuable, he can be asked and perhaps convinced to sell it). An additional justification for staying dead hand control of property arises when the specified use of property causes harmful external effects. A classic example is a requirement that only individuals of a certain race or religion use property, such as land set aside as a park. The external effect here is that the restriction may increase feelings of separateness in the population at large and generally contribute to social friction. When dead hand control of property generates externalities, state intervention may be warranted.

A third possible justification for restricting the dead hand is inherent inequality in the wealth of the present generation versus that of future generations. By virtue of its priority in time, the present generation owns the whole of the earth and all the things on it. This means that the present generation has the ability to control property more than is socially desirable, presuming the measure of social welfare accords substantial weight to future generations. ${ }^{104}$ Thus, in order to preserve intergenerational equity, limiting the ability of the present generation to control property after their death may be socially desirable.

9.6 Why we would expect the state to prevent dead hand control of property, independently of the social desirability of such policy. Quite apart from whether or not there exists sound social justification for the state to prevent dead hand control of property, we would predict that the state will intervene for a simple reason: The generation that is alive always enjoys the power to use property that the dead would have

\footnotetext{
${ }^{103}$ There is, on reflection, no conflict between the point of this paragraph and the general point, referred to in the last section, that decisions based on market prices will lead to socially desirable results. The reconciliation of the two points is that the optimality of outcomes based on the market is premised on markets being complete. The interpretation of complete markets for land is separate markets for the use of land not only at each future time, but also under each future contingency. Were such markets to exist, the person who wants to control land for the use of his cat would make separate purchase decisions about land for the memorial to the cat for each future year and for each possible value the land might have. But such markets do not exist, for essentially the reasons discussed in the text.

${ }^{104}$ For example, those alive today might care very little about the well-being of individuals ten generations in the future, but a social welfare measure might accord similar weight to the well-being of individuals ten generations in the future as it does to the well being of the present generation.
} 
wanted to control and certainly has an interest in doing so. This is especially true when the dead are at least a generation removed from the present generation, which is to say, when the present generation feels few personal bonds to them.

9.7 The law. The law constrains the power of the dead to control property in a number of ways. First, courts can refuse to enforce conditions in bequests and trusts if they are deemed unreasonable or if they unduly constrain the ability of beneficiaries to sell property. Courts can, under the cy pres doctrine, refuse to enforce unreasonable or obsolescent conditions in charitable bequests or trusts, and hold that administrators substitute a related purpose for the original one. Also, courts can refuse to enforce certain types of restrictive covenants when they offend a public interest. Furthermore, according to the so-called rule against perpetuities, donors are barred from making bequests that will not necessarily vest in a donee until long into the future (for instance, a barred condition would be: to my first descendant who is elected to Congress). In effect, the rule against perpetuities prevents a certain kind of dead hand control of property for more than a limited time. ${ }^{105}$

\section{Involuntary Transfer of Property: Adverse Possession}

10.1 Adverse possession defined. Adverse possession is a situation in which a person who is not the owner of land takes possession of and uses land continuously, without permission, and openly, for at least a prescribed length of time, such as ten years. The rule of adverse possession gives legal title to the land to the adverse possessor (subject to certain additional conditions). ${ }^{106}$ Thus, the rule effectively authorizes involuntary transfer of property. ${ }^{107}$

The rule will be considered in three contexts: when someone contemplates using land that he knows is not his; when a person contemplates using land that he is not sure is his because boundary lines are uncertain; and when a person is buying land and is not sure of the validity of the seller's title. ${ }^{108}$

10.2 Use of land that a person knows is not his. In some situations, a person contemplates using land that he knows belongs to someone else. For example, a farmer might consider growing crops on vacant land owned by a large, abutting ranch or by a railroad. In such cases, the question arises whether the rule of adverse possession might be socially desirable because it functions to transfer land from an idle to a productive state. $^{109}$ The answer seems to be no. On one hand, idle land sometimes is really serving a

\footnotetext{
${ }^{105}$ On the law just described, see, for example, Stoebuck and Whitman 2000, 118-45, 471.

${ }^{106}$ For a description of the rule, see for example, Stoebuck and Whitman 2000, 853-60. A closely related rule of prescription states that a person will acquire not possession of land, but instead rights to use it in certain ways (such as to walk along a path) if the uses have occurred over a stipulated period and meet the other requirements of adverse possession; see, for example, Stoebuck and Whitman 2000, 451-57.

Prescription will not be explicitly addressed in this section, but analogous points to those to be made here apply to it.

${ }^{107}$ Whereas this rule allows involuntary transfer of land between individuals, another rule allows involuntary transfer of land to the state. This will be discussed in section 2 of chapter 11.

${ }^{108}$ For surveys of economic analysis of adverse possession, see Bouckaert and Depoorter 2000 and Netter 1998.

${ }^{109}$ This possibility is frequently mentioned; see, for example, Ballantine 1918, 135, Stoebuck and Whitman 2000, 860, and Cooter and Ulen 1995, 132.
} 
useful purpose, as will be noted. On the other, a person wishing to use land can rent it or buy it, so that the rule of adverse possession is not necessary to achieve a change in its use. Furthermore, the rule can result in social waste.

To amplify, there are good reasons why an owner of land would want to keep it idle. A rancher may want to keep land in its natural state for animals to graze upon, a developer may wish to leave his land untouched because he is planning to build on it in the future, and an environmentalist owner may desire to maintain land in its pristine condition for the benefit of wildlife. Thus, the idle state of land may in fact be associated with a higher value than the state in which an adverse possessor would put the land.

Second, if the owner does not value his idle land as much as other parties do, he can lease the land or sell it. If the owner has not chosen to do this, the likelihood is that the value to him of keeping the land idle is greater than the alternative value of the land to others. Moreover, one assumes that the potential adverse possessor either knows who the owner is -- the adverse possessor usually knows the identity of his neighbors, and if land recording systems or registries exist, the adverse possessor can readily determine ownership -- and can fairly easily locate him, so that the adverse possessor can bargain for lease or purchase of the land that he contemplates using. The farmer thinking about growing crops on railroad land can always contact the railroad and see if a mutually satisfactory deal can be made. Hence, it is hardly necessary for society to resort to the rule of adverse possession to foster the transfer of land to productive use; that can be done via the normal routes of lease or sale of land.

Third, the rule of adverse possession may lead to socially wasteful consequences. The rule may induce owners of land, such as the railroad, to fence their property and monitor it to prevent adverse possession. Also, the rule may induce adverse possessors to invest resources inappropriately (for instance, growing crops that have little economic value) in order to acquire land. This point aside, if adverse possessors proceed to use land and are subsequently discovered and forced to withdraw, their efforts may be largely wasted, and if they succeed, they may interfere with more valuable uses of the land.

Despite the foregoing, it should be remarked that the requirements of the rule of adverse possession are such that it will normally be easy for an owner of land to detect incursions: The land must be used continuously for a period measured in years, and the use must be open, not surreptitious. In consequence, the ability of adverse possessors to succeed in taking someone else's land by using it is small and the waste of resources is ordinarily limited.

10.3 Use of land when boundaries are uncertain. A different circumstance in which the rule of adverse possession may apply arises because of uncertainty about boundaries. ${ }^{110}$ For example, a person may not know whether the garage he is building will encroach on his neighbor's land because he is unsure of the boundary line. The rule of adverse possession is sometimes suggested to be socially beneficial in this context because it alleviates problems of mistake: A person who turns out to have built on another party's land will not have to alter his structure when that would be socially wasteful. If a person builds a garage that turns out to encroach by six inches on his neighbor's land, it would probably be wasteful for the person to incur a large expense to move the garage off his neighbor's property. However, this argument favoring the rule of adverse possession overlooks the possibility that bargaining would result in avoidance of

\footnotetext{
${ }^{110}$ For economic analysis of this issue, see Miceli and Sirmans 1995.
} 
undesirable outcomes. If the garage is more costly to move than the extra six inches of land is worth to the neighbor, the two individuals will often arrive at an agreement under which the garage will not be moved. ${ }^{111}$

Moreover, the argument favoring the rule of adverse possession fails to take into account possible disadvantages regarding investments in land, similar to those mentioned in the previous section. For instance, the rule might encourage individuals to invest wastefully (extend the garage when that serves no real purpose) in order to gain ownership of more land. Therefore, the argument favoring the rule of adverse possession does not have clear appeal.

10.4 Sale of land when seller's title is not clear. Under the rule of adverse possession, sale of land is often said to be simplified because a buyer need only do the following to assure himself that the seller has good title to land: determine that the seller has himself lived continuously on the land for the period necessary to gain title through adverse possession. ${ }^{112}$ If that is so, then even if there were another individual who previously had some claim to the land, that person would no longer have a valid claim; thus the seller would, by application of the rule of adverse possession, have the valid claim. By contrast, were there no rule of adverse possession, a purchaser would in principle have to check into the infinite past to assure himself that no one other than the seller had good claims. This would be expensive and tend to impede the sale of land.

10.5 Historical origins of the rule of adverse possession. The rule of adverse possession apparently owes its origins to the advantage just discussed in section 10.4, namely, the motive to reduce transactions costs and to ease the settlement of disputes ver land ownership. ${ }^{113}$ The original act in England, from which the law of adverse possession in Anglo-American law derives, set a particular year (1189, the beginning of the reign of Richard I) as the point from which a person had to use land to obtain title through adverse possession. Eventually, the rule was changed so that a person had to use land for a certain number of years to obtain title through adverse possession. Today, it is doubtful that the rule of adverse possession lowers the costs of land sales because ownership of land is noted in recording systems or in registries. ${ }^{114}$

\footnotetext{
${ }^{111}$ Of course, problems in bargaining might lead to impasse and to the garage being moved. To ameliorate this problem, it is not necessary to accord the encroaching party ownership in land, as under the rule of adverse possession, but rather only to grant the party the right of use for a limited time, such as the normal lifespan of a garage.

${ }^{112}$ This point is emphasized by most commentators on adverse possession; see, for example, Ballantine 1918 and Netter 1998.

${ }^{113}$ Ballantine 1918,135 , emphasizes that its central rationale is quieting title and correcting errors in conveyancing. The preamble to an early English statute allowing adverse possession is explicit about the statute's purpose, stating that to be "the avoiding of Suits" and the "quieting of Men's Estates." See 21 Jac. ch. 16 (1623). It is also suggested that the feature of Roman law, usucapio, which operated in ways similar to adverse possession, was intended to cure defects in title and conveyancing; see, for example, Nicholas $1962,122$.
}

${ }^{114}$ See Ballantine 1918 on the history of adverse possession and on the point that with registries and recording systems for land, the rule is not needed to facilitate transactions. 


\section{Chapter 10}

\section{CONFLICT AND COOPERATION IN THE USE OF PROPERTY: THE PROBLEM OF EXTERNALITIES}

This chapter deals with various issues of conflict and cooperation in relation to the use of property. The plan of the chapter is first to describe how the behavior of a person in using property may influence the welfare of others, then to explain the ideal resolution of such effects, and subsequently to examine their resolution through bargaining and through legal rules.

\section{Notion of External Effects in the Use of Property}

1.1 General definition. One party's action will be said to have an external effect - or to create an externality ${ }^{115}$-- if it influences, or may influence with a probability, the well-being of another person, in comparison to some standard of reference. ${ }^{116}$ When I speak of external effects here, I shall be referring in the main to those associated with property rights, that is, to external effects due to actions that are allowed given a person's property rights, where the effects are experienced by other individuals given their own property rights. ${ }^{117}$

Externalities vary along a variety of dimensions. They may be beneficial for, or detrimental to, the affected party. They may occur contemporaneously with actions taken or result in the future; and they may ariseonly under certain contingencies. Moreover, they may affect one, several, or many parties. Let us consider several classic examples of externalities.

(a) Nuisance. When a person disturbs his neighbors by making noise, producing foul odors, allowing a misbehaving pet to roam free, and the like, he is commonly said to be creating a nuisance. This species of external effect is detrimental, often contemporaneous (noise is immediately disturbing), and commonly affects a small number of individuals.

(b) Pollution. When a firm discharges a substance into a body of water or into the air, it reduces the utility of others who use the water or breathe the air. This external effect is detrimental, may occur contemporaneously or in the future, and frequently involves many victims.

\footnotetext{
${ }^{115}$ According to Coase 1988, 23, the term “externality” was apparently coined in Samuelson 1958.

${ }^{116}$ It may be helpful to state the definition formally. Consider two parties, a potential generator $\mathrm{G}$ of an external effect, and a potential recipient $\mathrm{R}$ (victim or beneficiary) of the effect, and a reference situation described by a reference act $a$ of $\mathrm{G}$ and possibly other factors pertaining to him and to $\mathrm{R}$. In the reference situation, $\mathrm{R}$ will have a reference level of expected utility $\operatorname{ER}(a)$. Another act $a^{\prime}$ of $\mathrm{G}$ is said to have an external effect on $\mathrm{R}$, relative to the reference situation, if $\operatorname{ER}\left(a^{\prime}\right)$ is unequal to $\operatorname{ER}(a)$.

${ }^{117}$ I shall exclude from consideration externalities associated with transactions in markets, for example, the harm a person causes other buyers of a commodity if he increases its price through his purchases. On the subject of such pecuniary externalities, see, for example, Laffont 1987b.
} 
(c) Dangerous, risk-creating behavior. A party may act in a way that does not cause harm for sure but only in particular circumstances. Thus a firm may let sludge accumulate in a retaining area and there may be a chance -- if there is an earthquake, for instance -- that the material will burst forth and do harm to neighboring property. Dangerous, risk-producing behavior is behavior that causes damage under certain contingencies.

(d) Use of a common resource. Access to a resource such as pasture, a lake, or a reservoir of oil, may sometimes be enjoyed by many individuals. In such cases, one person's use of the resource may harm others, usually by depleting or causing damage to the resource. This effect is detrimental to others, sometimes contemporaneous and sometimes not, and affects multiple parties.

(e) Salutary behavior. A person's actions may occasionally help not only him but others as well, as when an apiarist's bees help to pollinate a nearby farmer's fruit trees, when one person's spraying to kill mosquitoes also rids his neighbors of the pests, or when a person beautifies his land to the advantage of others as well. These externalities are beneficial and may affect several or multiple parties.

(f) Treatment of rental property. When a person rents farmland, he may reduce its usefulness by abusing it, letting it erode, and so forth; he may also increase its future value by fertilization or by rotation of crops. When a person rents a dwelling or a movable good, such as an automobile, again he can affect the future utility of the property by the care that he exercises in using it and maintaining it. In these cases, the external effect is a future one, can be detrimental or beneficial, and usually affects one or a small number of parties.

1.2 Comments. (a) For there to be an external effect when a person takes a particular action, it must be the case that a different party possesses relevant property rights so as to be affected. Thus, making noise late at night creates a nuisance only if there are other individuals who have rights in nearby land. If I mistreat an automobile that I will own until it is scrapped, there will be no external effect on future holders of rights to my automobile since there will be no future holders; all effects will be internal, on me.

(b) If the standard of reference mentioned in the definition of external effect changes, this may influence whether or not an act has an external effect and its description. For instance, if in the reference situation I am quiet, then my act of making noise would be said to create a detrimental external effect, whereas if in the reference situation I am noisy, then my being noisy would not be said to create an external effect, and if I keep quiet, this act would be described as having a beneficial external effect.

(c) Whether we tend to call an externality harmful or beneficial depends on what we are likely to assume, if only implicitly, about the standard of reference. We are inclined to say that building a compost heap that gives off foul odors is harmful because we are likely to assume that the standard of reference is that individuals do not engage in composting and that all enjoy clean air. And we are likely to say that an apiarist's freeing of bees to pollinate his neighbor's fruit trees is beneficial because the standard of reference is that people do not keep bees.

(d) An externality need not be associated with a physical invasion. If, for instance, I erect an unsightly building, this may easily cause displeasure to neighbors despite the absence of any physical change to their property. Indeed, it could be that even though 
others see no indication of it, their mere knowledge that I am doing something on my property (practicing a disfavored religion) will affect their well-being.

\section{Socially Optimal Resolution of External Effects}

2.1 In general. Behavior that maximizes social welfare will reflect possible external effects associated with the use of property. Specifically, it will be socially desirable for individuals to engage less often in acts that cause detrimental external effects than is in their immediate self-interest, and to engage more often in acts that engender external benefits than is in their self-interest.

2.2 Socially optimal resolution of externalities in a simple model. Consider a model in which the social goal is to maximize the sum of parties' utilities. Then it is optimal for an act to be committed if and only if its utility to the actor together with its external effect on the utility of others is, on net, positive.

In a simple version of this model, one party -- a potential injurer -- can prevent harm to a second party -- the potential victim -- if the former takes a precaution, which will involve a cost and therefore lower his utility. The precaution might be installing a smoke arrestor or putting a compost heap in a location where it will not create odors bothersome to others. In this model, it is desirable for the injurer to take the precaution if and only if its cost is less than the harm that would be prevented, for that will minimize losses to the two parties (or equivalently, maximize the sum of their utilities). Thus, if a smoke arrestor costs 30 to install and would prevent harm of 50, it would be optimal to install.

2.3 Comment on the reciprocal nature of external effects. As was mentioned in section 1.2(a), externalities are reciprocal in that a party must be present to be the victim (or the beneficiary) of an external effect; otherwise there will be no external effect. ${ }^{118}$ This feature of external effects can readily be incorporated into the simple model considered above. For example, in the illustration of the smoke arrestor, suppose that the victim has the option to move to another location where he would be free from harm, but moving would involve a cost of 10 . Then it would be optimal for the victim to move to this other location: Because there would then be no reason for the injurer to take the precaution to avoid causing harm, he could save 30, whereas the victim would bear a cost of only 10 . This example should serve to illustrate that the reciprocal nature of externalities can readily be analyzed and does not pose any conceptual difficulties. ${ }^{119}$

\subsection{Comment on the conditional nature of the problem of the socially optimal} resolution of external effects. As it is usually expressed, the problem of optimally resolving externalities is not the same as the complete problem of maximization of social welfare, because the externality problem usually involves implicit assumptions about the assignment of property rights. In the externality problem involving pollution, for example, we took as given that the victim would suffer harm from smoke and asked whether installing the smoke arrestor would raise social welfare. But a complete solution to the social welfare maximization problem would not presume that the assignment of

${ }^{118}$ The reciprocal nature of externalities was emphasized by Coase 1960, 2, 12-13.

\footnotetext{
${ }^{119}$ Nevertheless, it now seems to be part of academic folklore that the reciprocal aspect of externalities creates a fundamental theoretical challenge.
} 
property rights is what it is. Instead, the complete solution would allow, among other elements, for a reassignment of property rights when that would be optimal. In the example above, this might involve the transfer of the victim to another location; as noted, that might lead to an increase in social welfare because it would mean that the injurer would not have to take a precaution. More generally, the positions of parties who are affected by external effects are determined by assumptions pertaining to a whole array of property rights; thus, the optimal resolution of externality problems, as usually phrased, must be regarded as a problem of partial social welfare maximization.

2.5 Examples of optimal resolution of externalities. With the definition of optimality of section 2.2 in mind, let us consider the general nature of socially optimal arrangements regarding externalities in the examples noted in section 2.3.

(a) Nuisance, pollution, and dangerous behavior. An action to ameliorate or eliminate a nuisance will be socially desirable when the cost of the action is less than the additional harm that would otherwise be caused. Thus, it will be socially advantageous for a factory to eliminate noxious odors if the cost of so doing -- associated with a change in the production process or with the purchase of a device to remove the odors -- is less than the harm to the people living nearby. And similarly with a pollutant, or with some dangerous act.

One aspect of optimal behavior may involve not the amelioration or elimination of the harm through the exercise of some precaution, but rather reduction or cessation of the activity that generates it. It may be optimal for a factory not to operate, for example, if it is very expensive to reduce the harm done and the benefit from its operations is small. Likewise, an aspect of optimal behavior may involve the potential victim of harm moving to another location, where he would not be exposed to harm. Similarly, optimal behavior may involve the victim taking steps to reduce harms, such as installing air filters or noise proofing.

(b) Salutary behavior. An act with beneficial consequences for another will be socially optimal when its cost, if any, is lower than its value to the person undertaking it and to others beneficially affected. Thus, spraying mosquitoes will be optimal when its cost is less than the sum of the benefits to the person spraying and to his neighbors.

(c) Use of a common resource. The use of a common resource by an individual will be socially desirable when and only when the benefits to him exceed the harm done to others. Thus, it will be socially desirable for a person to graze his animals in common areas when and only when the animals yield a benefit to him exceeding the harm they cause by denying other animals pasturage, by contributing to erosion, and so forth. Likewise, it will be socially desirable for a person to catch fish or to trap animals when and only when their value to him outweighs any reduction in the value of the future stock resulting from loss of fish or animals that would have reproduced - notably, if their numbers are too rapidly reduced, there will not be sufficient reproduction to maintain the population. Similarly, it will be optimal for a person to withdraw oil from a pool when and only when its value to him exceeds any increase in future costs of extraction. (When oil is obtained, it may cause underlying gas and water pressure to fall, increasing the 
costs of future extraction because, for instance, water may have to be pumped underground to force up remaining oil.) $)^{120}$

(d) Treatment of rental property. Treatment of rental property will be optimal if and only if the treatment benefits the renter more than it harms the owner in the future. Thus, it will probably not be optimal for a renter to make major modifications in an apartment if they would impose a large cost on future users. Suppose, for instance, that the renter wants to remove an interior wall to make one large room from two smaller rooms, but that future users would be likely to want the two smaller rooms. However, it may be optimal for a person who is renting an apartment to modify it in minor ways, such as by hanging pictures on the walls, since these may benefit the renter by more than they will harm the owner in the future. (The owner will probably have to repaint in any case, and at the that time it would be cheap for him to do any necessary replastering to repair damage from picture hanging.) It may also be optimal for certain things to be done during the rental period if they benefit the owner in the future more than they harm the renter. Many types of maintenance (fixing a slow leak that will cause damage only over time) have this character.

\section{Resolution of Externalities Through Frictionless Bargaining}

In this section, I will briefly discuss the resolution of external effects through bargaining among the involved parties, assuming that bargaining is a costless and invariably successful process. In following sections, however, I will examine costs of bargaining and obstacles to it, and then the resolution of external effects through the use of legal rules.

\subsection{The assumption of frictionless bargaining: that bargains are made} whenever a mutually beneficial agreement exists. Our present assumption is that bargaining will take place, and that a mutually beneficial agreement about externalities will be concluded, whenever such an agreement exists in principle. In the situation involving the smoke arrestor, the parties will each be better off if the injurer agrees to take the precaution at a cost of 30 in exchange for payment of, say, 35 by the victim; for then the injurer's utility will be augmented by 5 and the victim's utility will be raised by 15 because he will avoid harm of 50 . Hence, our assumption is that such an agreement will be made. (Note also that if the victim's harm from the smoke would be only 25 , there would be no mutually beneficial agreement possible and the injurer would not take the precaution. ${ }^{121}$ )

The statement that a mutually beneficial agreement will be made whenever one exists -- given the assumption that nothing will prevent parties from reaching this kind of agreement -- is one version of the Coase Theorem, and is an immediate tautology. ${ }^{122}$

\footnotetext{
${ }^{120}$ The point of this paragraph is closely related to that made in section 1.3 of chapter 9 on the excessive incentives to search under the finders-keepers rule when there are multiple parties who might look for unowned property.

${ }^{121}$ To see that there is no mutually beneficial change possible in this case, observe that for the injurer to be willing to take the precaution, he must be paid at least 30 by the victim. But the victim would be willing to pay at most 25 to be free from harm.

${ }^{122}$ This version of the theorem is sometimes expressed by saying that a mutually beneficial outcome will be achieved in the absence of transaction costs, where the latter are interpreted to be any
} 


\subsection{Mutually beneficial agreements exist whenever the sum of parties'}

utilities can be raised. In the case of the smoke arrestor, a mutually beneficial agreement exists to install the arrestor whenever that change would raise the sum of the parties' utilities. That such mutually beneficial agreements generally exist between the generator of an externality and the affected party whenever the agreements would raise the sum of their utilities can be explained as follows. Figuratively, when a change raises the sum of the two parties' utilities, it raises the size of the pie available to be shared by them. And if the size of the pie can be increased, plainly there must exist some way of dividing it that will make each of the parties better off than he would have been with only his slice of the original, smaller pie. That is, there must exist some agreement between the generator of the externality and the affected party under which each is made better off. ${ }^{123}$

3.3 Social welfare maximization and frictionless bargaining. It follows from the above that the sum of utilities measure of social welfare will be maximized through frictionless bargaining despite the presence of externalities. Specifically, if the sum of their utilities is not maximized when parties act in their self-interest, then there exist mutually beneficial agreements calling for changes that maximize the sum of their utilities, and these agreements will be concluded through bargaining.

However, frictionless bargaining does not necessarily lead to maximization of social welfare if wealth is not distributed in a socially desirable way. Suppose, for example, that a party does not possess wealth sufficient to pay for a socially desirable change in another party's behavior. If the wealth of the victim of smoke is less than 30 , he will not be able to pay the injurer enough to induce him to install the smoke arrestor even though this is socially desirable. ${ }^{124}$ (Note here that the outcome in which the victim suffers from the smoke is not dominated by a mutually beneficial arrangement, for there is no feasible arrangement that is better in the eyes of both parties than the existing one; the victim's lack of wealth makes the outcome in which he pays the injurer enough to purchase the smoke arrestor infeasible.) However, even if bargaining does not result in the social welfare optimum, bargaining can only improve social welfare by raising the

hindrances to bargaining -- whether literally costs of bargaining, or instead other obstacles, notably, asymmetries of information between bargaining parties (to be discussed below). The version of the Coase Theorem under discussion is sometimes called the efficiency version because it says that the outcome will be (Pareto) efficient, a synonym for mutually beneficial. Another version of the Coase Theorem, the invariance version, will be discussed in section 6 below. See Coase 1960 and De Meza 1998.

${ }^{123}$ The point can be expressed algebraically as follows. Let $x_{1}$ and $y_{1}$ be the levels of utility of the generator of the externality and the other party, respectively, in an initial situation and $x_{2}$ and $y_{2}$ be their levels of utility in a second situation with a higher sum of utilities, that is, $x_{2}+y_{2}>x_{1}+y_{1}$. Assume, however, that the generator would be better off in the initial situation than in the second in the absence of an agreement, in other words, $x_{1}>x_{2}$. (Otherwise, the first party would have made the change, whereas our supposition is that the change has not been made.) Then a mutually beneficial agreement can clearly be constructed: If the generator is compensated for making the change by at least $x_{1} ! x_{2}$ he will be willing to make an agreement. The other party gains $y_{2} ! y_{1}$ in the second situation, and this exceeds $x_{1} ! x_{2}$ (for $x_{2}+y_{2}$ $\left.>x_{1}+y_{1}\right)$; hence he will be willing to pay enough to the generator to induce him to agree to the change.

${ }^{124}$ This point does not conflict with the demonstration of the previous footnote. It was shown there that the second party would be willing to make a payment sufficient to induce the first to alter the situation, but it was implicitly assumed that the second party had the wealth sufficient to do that. 
well-being of the parties involved in bargaining (assuming that all parties affected by the externality participate in the bargain and understand its nature).

3.4 Markets and the resolution of externalities. We have been discussing so far how external effects may be mitigated through bargaining between a single generator of an external effect and identified potentially affected parties, such as neighbors. A related possibility is the resolution of external effects through the bargains that are effectively made between unrelated parties when a competitive market in an externality arises. For instance, instead of an apiarist bargaining with a particular neighboring farmer about whether he will release his bees into that farmer's orchard to foster pollination, we can envision the apiarist transacting in a market and transporting bees to any farmer who purchases bee services.

Where such a market exists, all mutually beneficial changes will automatically come about, owing to the standard argument concerning behavior in the presence of markets. To illustrate, suppose that the price for bee services is 5 . Then any apiarist who can supply bee services at a cost less than 5 will do so, and any farmer who places a greater value than 5 on bee services will purchase them; this means that there is no unexhausted opportunity for mutually beneficial trade, namely, trade between an apiarist who can supply bee services at a cost of less than 5 and a farmer who values them more highly than $5 .{ }^{125}$

3.5 Actual resolution of externalities through bargaining. It is a commonplace that parties often make bargains in order to resolve nuisances or other externalities. For example, a person might pay his neighbor to plant a screen of bushes around an unsightly garbage area so that the person can enjoy a better view (or he might simply ask his neighbor to do so, implicitly in return for his acting in similar ways vis-à-vis his neighbor in the future); a restaurant might pay nearby residents for the right to remain open late, when the residents have the right to insist that it be closed; a person might sell a part of his land with a restriction that prevents a harmful use (such as a business use); a group of individuals using a common resource (such as a grazing area) might agree to preserve it (not overgraze it). ${ }^{126}$ Additionally, some experimental evidence suggests that, at least when the number of parties is small, individuals will often conclude mutually beneficial agreements to settle externality problems. ${ }^{127}$ It is also evident that when parties are in a contractual relationship, they will frequently include terms in their contracts to resolve externalities. Thus, when a person rents land, real estate, or equipment, the contracts will generally specify that he cannot make major modifications to them or cause them to deteriorate (which would, as discussed, harm owners). Organized markets that resolve externalities are unusual (for reasons to be explained in section 4.5), but they do exist, and one well-known example concerns bees. ${ }^{128}$

${ }^{125}$ On the general notion that the establishment of markets in certain goods or services, here bee services, can cure externality problems see, for example, Arrow 1969 and Laffont $1987 \mathrm{~b}$.

${ }^{126}$ On the general subject of arrangements to ameliorate externalities made by parties using a common resource, see Libecap 1989 and Ostrom 2000.

${ }^{127}$ See, for example, Hoffman and Spitzer 1982, and Croson and Johnston 2000.

${ }^{128}$ This highly developed market is characterized by farmers paying apiarists for rental of bees during the pollination season, and, after that season, by apiarists paying farmers for use of their land 


\section{Why Bargaining May Not Occur and, If It Does, Why It May Fail to Result in Mutually Beneficial Agreements}

It is evident from experience that (a) bargaining does not always occur when a mutually beneficial agreement exists, and that (b) even when bargaining does occur, it may not be successful. Why this should be so is addressed in this section.

4.1 Factors explaining why bargaining may not occur when mutually beneficial agreements exist. At the most general level, the explanation for why bargaining may not occur (as opposed to occurring but then not succeeding) when mutually beneficial agreements exist is that the costs of bargaining -- including the costs of coming together and the time and effort devoted to the bargaining process itself -outweigh the expected benefits. We can list particular factors bearing on the occurrence or lack of occurrence of bargaining.

(a) Proximity of parties. If the concerned parties are not physically proximate, bargaining may be difficult to arrange. For example, a person may be at the point of deciding whether to erect a fence, which his neighbor might find objectionable, but his neighbor may be away, making it impractical for him to discuss an alternative, possibly superior agreement (such as sharing the higher cost of planting a screen of trees instead of a fence).

(b) Number of parties. If the number of involved parties is large, then their ability to all come together for the purpose of bargaining may be small, for difficulties of coordination tend to rise with the number of parties. In addition, the motivation of parties to bargain may diminish as their number increases. If, for example, each person in a neighborhood believes that he can depend on others to engage in bargaining for an agreement that will benefit him, such as for a factory to stop blowing its whistle early in the morning, then no one, or too few, will participate in bargaining with the factory to obtain an agreement. This problem of free-riding on others' efforts may be acute if the benefits that would be gained from bargaining are individually small.

(c) Lack of knowledge of external effects. Clearly, if a person who would suffer a loss or experience a benefit does not have prior knowledge of this, he will be unlikely to engage in bargaining. If I live near a factory and do not know that I am at risk of developing cancer from its discharges, then I will hardly bargain for a change in its behavior.

(d) Probability of bargaining failure. If a party believes that there is a substantial chance that bargaining will not lead to a successful outcome, then this will tend to dissuade him from engaging in bargaining at the outset. (As will be explained in the next section, if a party is imperfectly informed about the other side's costs or benefits, or if the other side has poor information about the first party's costs or benefits, the chances of failure to reach agreement in bargaining rise.)

4.2 Examples. Several contexts in which external effects exist may be reviewed in the light of the above factors to see whether they help to explain why bargaining does or does not usually occur.

because bees' consumption of nectar raises honey production; see Cheung 1973. See also section 5.2 below on the market in rights to pollute. 
(a) Accidents between strangers. Bargaining is unlikely to help ameliorate the risk of the typical type of accident between strangers, such as that involving automobiles. Indeed, the very notion of bargaining between possible injurers and possible victims in such contexts seems fanciful, and on reflection it is evident why. The potentially involved parties, being strangers, are typically not in a sufficiently proximate relationship to bargain with each other about their behavior. Moreover, the benefit from bargaining between particular parties would be small, because of the unlikelihood that this or that pair of strangers would be involved in an accident.

(b) Pollution caused by firms. Here, we may imagine quite readily some situations in which bargaining would be likely to occur and others in which it would not be. Bargaining might well occur in situations where the number of people affected by pollution is small, the harm each sustains is substantial, and they are well aware of it. However, bargaining would tend not to occur if the pollution affects many individuals but each by only a small amount, or, apart from this, if the victims do not recognize the source of the pollution or even that they are suffering from it. (c) Nuisance between neighbors. In this type of case bargaining would often occur. If my neighbor owns a dog that chews up my flower garden, then there will be no obstacle to bargaining posed by lack of proximity; I should not ordinarily find it difficult to get together with my neighbor. Also, we may well both know what the problem is. Hence, if a mutually beneficial agreement is feasible (because, for example, it is evident that my neighbor could fairly easily restrain his dog or to teach it not to chew up my flowers), bargaining might occur (setting aside the effect that an argument or emotionalism might have on the willingness of neighbors to negotiate about such a nuisance).

(d) Rental agreement. When parties have come together to bargain over rental, the marginal cost to them of bargaining over a potential externality problem will typically be small, so that, as remarked above, they will tend to include terms in rental agreements to resolve the problem. When a person rents a room in someone's home, for instance, we would often expect there to be bargaining about noise and other possible disturbances during the rental period and terms governing them in the rental contract.

4.3 Even if bargaining occurs and a mutually beneficial agreement exists, it may not be reached due to asymmetry of information. Suppose that bargaining does occur, that the bargaining process is not costly, and that a mutually beneficial agreement exists. Will such an agreement come to pass? We know that in fact success is not guaranteed, and as economists emphasize, the theoretical explanation involves asymmetric information between parties that leads to miscalculations in bargaining and failure to agree.

Example 1. Let us return to the situation involving the smoke arrestor that would cost the injurer 30 but would eliminate smoke and thus harm of 50. Here, as discussed, a mutually beneficial agreement exists: If the victim pays the injurer any amount between 30 and 50 for him to install the arrestor, the victim and the injurer will each be made better off.

Consider a simple bargaining process under which one of the parties, the victim for concreteness, makes a single, take-it-or-leave-it offer to the injurer. Assume first that the victim has perfect information about the cost to the injurer of the arrestor. Then the victim knows that if he offers any amount over 30, the injurer will accept this. Hence, there will definitely be an agreement; the victim will offer an amount just over 30 (such 
as 31) and the injurer will rationally accept. This illustrates that where one side's information about the other side is perfect, there will tend to be an agreement when a mutually beneficial agreement exists.

Now assume instead that the victim does not know for sure the cost to the injurer of the smoke arrestor. Specifically, suppose that the victim thinks that there are two possibilities: The cost of the arrestor might be 20 , with probability 80 per cent, and it might be 30 , with probability 20 per cent. Then if the victim offers just over 20 , he believes that his offer will be accepted with probability 80 per cent and that his offer will be rejected with probability 20 per cent -- in which case he will suffer harm of 50 . Hence, his expected losses will be approximately $80 \% \mathrm{H} 20+$

$20 \% \mathrm{H} 50$ or 26 . If he offers just over 30 , it is true that his offer will be accepted for sure, but his costs will be about 30, exceeding 26 . His best offer is therefore just over 20, and there will be no bargain, because in fact we are supposing that the cost of the precaution to the injurer is $30 .{ }^{129} / /$

Thus, we see that, due to lack of precise knowledge of the other side's situation, a person in bargaining may rationally offer an amount that he is aware might be refused, in order to gain the best for himself in an expected sense.

Imperfection of information may concern not only costs of precautions, as in Example 1, but also the magnitude of externalities and the costs of bargaining itself. The latter should not be overlooked as a source of bargaining failure. If, for instance, one side mistakenly thinks that the other side's cost of bargaining is low and that he will continue for another round, the first side may not make a sufficiently good offer before the second side withdraws. More generally, virtually any kind of asymmetry of information can produce a probability of failure to agree even when mutually beneficial agreements exist.

\subsection{Evidence that parties who bargain may fail to reach mutually beneficial} outcomes. Ample evidence exists of the possibility that parties who bargain may not succeed in reaching a mutually beneficial agreement. There are many instances of nuisance where remedial action could have been taken at a lesser cost than the harm yet where the bargaining process broke down. ${ }^{130}$ More broadly, the fact that parties often go to trial rather than settle, that employees strike rather than settle, that wars are fought after breakdowns in negotiations, all bespeak parties' failure to agree to mutually beneficial outcomes. ${ }^{131}$

\subsection{Comment on the unlikelihood of markets for the resolution of}

externalities. It was mentioned above, in section 3.4, that externalities might be resolved through market transactions rather than through bargaining between identified parties. Why in theory are market resolutions of externality problems unlikely? (They are unusual in fact, as we noted.)

A precondition for a market to exist is that each seller be able to transact with whichever buyer he chooses. That happens to be possible with respect to the pollination

${ }^{129}$ If there were a population of injurers, 80 per cent of whom faced costs of 20 for smoke arrestors and 20 per cent of whom faced costs of 30 , then 20 per cent of the time there would be no bargain, even though in all cases a mutually beneficial bargain exists.

\footnotetext{
${ }^{130}$ For instance, W. Farnsworth 1999 finds no cases of bargaining in a study of nuisance disputes.

${ }^{131}$ See the survey Kennan and Wilson 1993 and the references cited therein.
} 
services of bees; a particular apiarist can provide his bees' services to the farmer he selects by transporting his bees to that farmer's land. For many external effects, however, a seller cannot transact with any buyer whom he chooses -- he can transact only with a particular buyer -- and a market therefore cannot occur. For example, if I landscape my yard, I will benefit only my close-by neighbors (and myself); I cannot transport the vision of my yard to any other buyer who desires beautified surroundings (in contrast to the apiarist who can transport his bees to any farmer who wants them). Likewise, if I make noise or if I maintain a compost heap, this will cause a nuisance only for my neighbors, not for a distant person who would wish to sell me the right to be the victim of a nuisance. In such cases, therefore, the only way that voluntary resolution of externalities can come about is through bargaining between just the two, or the small number of, parties who are effectively stuck with each other. ${ }^{132}$

Additionally, for some external effects there is another reason why a market may not be possible to establish. Notably, some externalities affect many parties simultaneously, as with general air pollution: When a factory spews smoke into the atmosphere, it harms the population in the area generally. Here there cannot be a market in which one individual victim sells rights to allow his property to be polluted and another individual does not. (Although there cannot be a market in which victims independently sell rights allowing themselves to be polluted, the state can decide to allow pollution and create a market in which polluters purchase rights to pollute. See section 5.2 below.)

\section{Resolution of External Effects Through Legal Rules in the Absence of Successful Bargaining}

Assume for simplicity in this section that parties do not bargain, or do not bargain successfully, because of the various obstacles discussed above. Instead, parties act in a self-interested way and, other things being equal, do not take into account how their actions influence others. ${ }^{133}$ Legal rules, however, can alter their behavior desirably. ${ }^{134}$

5.1 Types of legal rules for controlling externalities. There are a variety of legal rules that can be used to control external effects, an important group of which are now described.

${ }^{132}$ Even if the preconditions for a market to exist hold -- individual generators of an externality can purchase rights to cause harm from individual victims (or sell their services to individual beneficiaries) there may remain a problem with existence of competitive equilibrium. As Starrett 1972 emphasizes, if, for example, the price of the right to pollute is positive, a potential victim would have an incentive to sell an extraordinary, potentially infinite, number of these rights to polluters -- for he can then always move away from his property and become rich through his sale of rights. This means that at any positive price, an infinite number of rights to pollute would be offered, preventing the market for rights from coming into equilibrium.

${ }^{133}$ Here and below I will emphasize harmful external effects for simplicity; for the most part, the case of beneficial external effects is analogous.

${ }^{134}$ I do not consider how informal social sanctions, such as reputational harm, may affect parties' behavior. For a notable treatment of this subject, see Ellickson 1991. See also the discussion of morality in chapter 26 below. 
Under direct regulation, the state constrains the set of acts that would otherwise be permissible to commit given one's property rights, so as to optimally resolve an external effect. For instance, a factory may be required to use a smoke arrestor to prevent pollution, a fisherman may be required to limit his catch to alleviate depletion of the fishery, or a person may be prevented by a zoning ordinance from opening a business establishment in a residential area in order to preserve its ambience.

Closely related to regulation is the assignment of property rights and their protection at the request of parties who hold the rights. If a person possesses the right to clean air, for example, he can prevent a firm from continuing its polluting operations by asking the state to intervene. ${ }^{135}$ Intervention is often accomplished through the complaining party's obtaining an injunction against the injurer; the police powers of the state then are brought to bear to enforce the injunction. Unlike the situation under regulation, where a polluter would be required not to pollute, under victims' property rights in clean air, it is up to the discretion of the potential victim of pollution whether to prevent the polluter from polluting (and the victim might allow the injurer to pollute if he were paid enough -- but we are ignoring bargaining in this section).

Society can also make use of financial incentives to reduce harmful externalities. Under a liability rule, parties who suffer harm can bring suit against injurers and obtain compensation for their losses, motivating injurers to avoid causing harm. As we discussed in the chapters of Part One of this book, there are two major forms of liability: strict liability, under which the injurer must pay the victim even if the injurer was not at fault; and the negligence rule, under which the injurer is required to pay only if he was at fault. In terms of our simple model, an injurer is said to be at fault, to have acted undesirably, if the magnitude of the harm exceeds the benefit from the act or the cost of eliminating the harm. ${ }^{136}$

Another financial incentive to reduce harm is the corrective tax. ${ }^{137}$ Under it, a party makes a payment to the state equal to the expected harm he causes, as when a firm pays for the expected harm due to its discharge of a pollutant into a lake. Because a corrective tax is envisioned to reflect anticipated harm (the harm the pollution is expected to do), it is different from strict liability, which is liability for harm actually done. Also, the corrective tax is paid to the state, whereas liability payments are made to victims.

An additional type of financial incentive is a subsidy, an amount paid by the state to a party equal to the reduction in expected harm from some benchmark level that the party accomplishes.

5.2 Comparison of rules. Let me now sketch the comparison of the foregoing legal rules for controlling externalities, focusing on a list of factors of possible relevance.

${ }^{135}$ Under a legal rule that we are not considering, the person can have the state prevent the pollution but would have to pay the firm for the decline in profits it thereby suffered.

${ }^{136}$ Corresponding to strict liability and the negligence rule are two types of fines paid to the state, a fine equal to harm paid whenever harm is done, or a fine equal to harm paid only when harm is done and the benefit was less than the harm. I omit consideration of such fines here.

\footnotetext{
${ }^{137}$ Pigou 1912 first emphasized the utility of taxes for controlling external effects, and such taxes are sometimes called Pigouvian taxes.
} 
(a) Information of the state. If the state has complete information about acts, that is, if it knows the injurer's benefit and the victim's harm, then each of the rules leads to optimality. To amplify in terms of the example of pollution, suppose that the state can ascertain whether the cost of the smoke arrestor is less than the harm from pollution and thus can determine whether it is best to prevent pollution. If the state decides that pollution should be prevented, the state can accomplish its purpose by regulation: It can forbid pollution. The state can also achieve optimality by giving the property right to clean air to the victim. The state can also employ strict liability. This will lead the injurer not to cause harm because he would have to pay for it, and by hypothesis the harm would exceed his benefit. Likewise, under the negligence rule, the injurer would have to pay for the harm and would thus not pollute. Similarly, under the corrective tax he would not pollute. Under a subsidy, the injurer would not pollute because he would receive a payment equal to the harm for refraining, and this exceeds the benefit he would otherwise obtain.

If the state does not have complete information about harm and benefit, however, it cannot determine with certainty whether or not an action such as polluting should take place. Hence, the state cannot necessarily achieve optimality through regulation, assignment of property rights, or the negligence rule -- for under these approaches the state needs to know which action is optimal. For instance, under regulation, if the harm from pollution would be 100 and the state does not know whether the cost of an arrestor is 75 or 150 , it does not know whether or not to require the arrestor.

Yet as long as the state has information about the magnitude of harm, it can still achieve optimality under strict liability, the corrective tax, and the subsidy. Because under strict liability or the tax, it is the injurer who compares the cost of installing the arrestor to liability or to the tax for harm, and the injurer naturally knows the cost of the arrestor, then the injurer will cause pollution if and only if the cost of the arrestor exceeds the harm, which is optimal. The injurer for whom the cost of the arrestor is 75 will install it in order to avoid paying 100, and the injurer for whom the cost of the arrestor is 150 will not install it; in both cases the optimal result will occur. Essentially the same is true under the under the subsidy because the injurer will obtain a reward of 100 if he does not cause harm. The virtue of the strict liability, the corrective tax, and the subsidy is that they harness the information that potential injurers have about the costs of reducing harm, or the benefits they would obtain from acting, by making them compare these costs or benefits to the magnitude of harm. ${ }^{138}$

Hence, we have explained why, when the state's information about the cost of reducing harm is imperfect, strict liability, corrective taxes, or subsidies have an advantage over regulation, property rights assignment, or the negligence rule. ${ }^{139}$

\footnotetext{
${ }^{138}$ The argument given here assumed that the state knows the magnitude of the harm. However, it can be shown that the argument also applies even if the state does not know the magnitude of harm: If the state bases liability, the corrective tax, or the subsidy on expected harm, then on average the outcome will be superior to that under the other rules, namely, regulation, assignment of property rights, or the negligence rule. See Kaplow and Shavell 1996b, 2002 b.

${ }^{139}$ Although essentially this point is frequently mentioned by economists, especially in relation to regulation versus corrective taxes, it was apparently controverted in Weitzman 1974. Weitzman suggested that regulation, such as a required limit on the amount of pollution, might be superior to a corrective tax. His argument is essentially that expected harm might increase greatly if the quantity of pollution surpassed
} 
To illustrate this conclusion, let us consider why a scheme of marketable pollution rights ${ }^{140}$ is inferior to corrective pollution taxes when the government's information about pollution control costs is imperfect. Under a marketable pollution rights regime, a firm must surrender a pollution right to the government for each unit of pollution it generates. The government initially issues rights to firms (perhaps on the basis of a firm's size). The total quantity of rights issued corresponds to the total amount of pollution the government decides is desirable, and a particular firm can either use the rights it is issued or sell rights to other firms in a market for the rights. There is an advantage of this scheme over conventional regulation of the amount of pollution each particular firm is permitted to generate: Firms that find it relatively cheap to prevent pollution tend to do so and thus have rights left over that they sell, whereas firms that find it quite expensive to prevent pollution need more rights than they are allocated and tend to purchase rights in order to pollute. As a result, the induced distribution of prevention effort and of pollution among firms tends to be socially desirable. But the total quantity of pollution is fixed by government, and in setting this quantity, the government must use its imperfect estimate of pollution control costs; in general, therefore, the total quantity of pollution will be socially inappropriate. By contrast, if the government employs pollution taxes, not only will the distribution of pollution among firms be socially desirable (firms that find it relatively easy to prevent pollution will be inclined to do so rather than pay the tax, and firms that find it relatively expensive will pay the tax and pollute), but also the total quantity of pollution will be socially desirable -- since firms themselves will decide how much to pollute by comparing their pollution control costs (which they know) to the pollution tax, which is set equal to the expected harm from pollution.

(b) Information of victims. Information of victims is relevant to the functioning of those legal rules that require victims to play a role in enforcement. Namely, for victims to bring injunctions to prevent harmful acts and protect their property rights, they need to be aware of who might harm them, such as who might pollute, and of the harm if it occurs. If the pollution is difficult to detect (perhaps colorless and odorless), and does harm only over time, they might not observe it and thus would not have the knowledge to bring an injunction. Similarly, for liability rules to function, the victims must know who caused harm and that it did occur. For regulation or taxation or subsidies to function, victims do not need such information; the state imposes taxes or regulates harmful behavior regardless of whether victims understand who is causing them harm or its nature.

(c) Information of injurers. Injurers need to know certain things for the various rules to function appropriately, but it is not obvious that this consideration favors any

some threshold level. If a tax per unit were employed and the state chose the wrong rate, firms might generate enough pollution to exceed the threshold, whereas this danger can be averted by means of direct quantity regulation. Weitzman's argument, however, depends on the assumption that the corrective tax is a simple constant per unit tax. If the tax is equal to the expected harm, then the tax rate could increase with quantity if harm were thought to have that character. Consequently, it can readily be shown that the corrective tax is, as claimed in the previous footnote, superior to quantity regulation.

${ }^{140}$ As will be explained, marketable pollution rights are a hybrid of regulation of the total quantity of pollution and of a pollution tax-like regime. See Dales 1968 for an early discussion of marketable pollution rights; for more recent discussions, see, for example, Cropper and Oates 1992, Hahn and Stavins 1991, and Tietenberg 1996. 
type of rule over any other. It is tempting at first to believe that for liability rules to function well, injurers need to know more than they do under regulation and the other approaches, for under liability rules injurers must be able to predict their liability, they must have foreknowledge of it, whereas under the other approaches, they apparently need to know little. Under regulation, for instance, they must merely adhere to regulatory requirements. Yet if a regulatory requirement is easily understood, such as a requirement to install fire extinguishers, so should it be easy to understand that the courts will find a party negligent if he had not installed fire extinguishers. ${ }^{141}$ Another appealing view is that the rules like strict liability that require injurers to calculate for themselves how to act impose a greater burden on injurers than regulation and the rules that stipulate their behavior. But this viewpoint is problematic, for if calculation were deemed to be difficult to carry out, the state could supply individuals with information about the correct choices to make (for example, a table showing whether or not to take a precaution, as a function of factors relating to harm, its likelihood, and the cost of taking precautions).

(d) Administrative costs. Administrative costs are the costs borne by the state and the parties in connection with the use of a legal rule (but of course excluding the costs of acting in conformity with the rule, such as the costs of installing a smoke arrestor).

Liability rules possess a general administrative cost advantage over the other rules in that under liability rules the legal system becomes involved only if harm is done, whereas under the other approaches the legal system is involved whether or not harm occurs. This advantage may be significant, especially when the likelihood of harm is small.

Nevertheless, administrative costs may sometimes be low under the nonliability approaches. For example, compliance with regulation may be easily determined in some circumstances (ascertaining whether factory smokestacks are sufficiently high would be easy) and may be accomplished through random monitoring, saving enforcement resources. Also, applying corrective taxes can be inexpensive if, for instance, it is done at the time of the purchase of a product (a firm could be made to pay the tax when it buys fuel that generates pollution).

Administrative costs also tend to be lower when the informational requirements of a rule are lower. This consideration favors strict liability and the corrective tax, rules that require the state to obtain information only about harm, compared to regulation and the other rules that require the state to obtain information about benefits as well (in order to determine proper behavior).

Against the background of these general factors bearing on administrative costs, one has to examine the particulars of the situation at hand to determine which type of rule is superior on grounds of administrative cost.

(e) Level of activity. A distinction that was drawn in our discussion of accidents in chapter 2 is between the precautions an injurer takes while engaging in a particular activity -- does a firm use a smoke arrestor while producing, does a person keep his dog from barking at night? -- and his level of activity -- how many units of his good he produces, how many dogs the person owns. This distinction has relevance for the rules

\footnotetext{
${ }^{141}$ Conversely, if there are so many situations that could occur that one doubts the ability of a person to know or predict which situation will be found negligent, then if regulation were as detailed, it should be equally difficult to determine the actions that regulation requires.
} 
that control external effects because, the way they are often applied, some of the rules do not lead injurers to curtail properly their level of activity.

Notably, regulation and the negligence rule are typically concerned with precautions taken but not with the level of activity. A factory may be required by regulation to install smoke arrestors or may be found negligent for failure to have installed them, but the factory's level of operations will not ordinarily be regulated or subject to the negligence rule. If so, the factory will have no motive to do anything more than comply with regulation or the negligence rule. Yet even if the factory does so, there may still be a residual harm caused by the factory's activity (for it will often not be optimal to take steps necessary to eliminate all chance of harm; this would be too expensive). In consequence, although increasing its level of activity increases harm, the factory will have no motive to take this into account.

By contrast, under legal rules that make parties pay for harm done, namely, under strict liability or the corrective tax, parties will moderate appropriately their level of activity. Thus, consideration of injurers' activity levels makes strict liability and the corrective tax appealing compared to regulation and the negligence rule. ${ }^{142}$

(f) Ameliorative behavior of victims. Victims can often take steps to reduce harm (purchasing dryers for their laundry rather than hanging it outdoors where it can be soiled by smoke), and it will thus be optimal for them to do take these steps when they are sufficiently cheap and effective, taking into account injurers' opportunities to reduce harm. Now under regulation, corrective taxation, and other approaches that do not compensate victims for their harm, victims have a natural incentive to take optimal precautions because they bear their losses; they will want to take any precaution whose cost is less than the reduction in harm it accomplishes. ${ }^{143}$ Under strict liability, however, a victim would not have such an incentive because he will be compensated for any loss he suffers. But as we discussed in chapter 2, strict liability with a defense of contributory negligence will provide victims with a motive to exercise proper precautions.

Another consequence of victims' opportunity to take ameliorative actions is that the information required of the state to fashion optimal rules becomes much greater. Even to calculate corrective taxes -- which we had said above in subsection (a) required only that the state assess expected harm -- becomes difficult. For the state to determine the corrective tax, it needs to know the harm that the injurer's behavior would be expected to cause assuming that the victim is acting optimally, that is, taking ameliorative actions such as installing air conditioning (or even moving away). Thus, the state in effect needs to determine the optimal solution to the externality problem in order to formulate the optimal tax. $^{144}$

\footnotetext{
${ }^{142}$ It should also be noted that under the subsidy approach, the problem of excessive levels of activity is exacerbated.

${ }^{143}$ More precisely, victims have incentives to act optimally given the behavior of injurers. If, as under regulation, the state prescribes the behavior of injurers, it is important that the state take into account what victims can do to reduce risk and not, for example, insist that injurers take a step that is more expensive than an equally effective step that victims could take.

${ }^{144}$ This point can be exaggerated, however. While the tax in a literal sense cannot be chosen optimally without the state knowing the optimal behavior of the victim if there are interactions between
} 
(g) Ability of injurers to pay. For liability rules to induce potential injurers to behave appropriately, injurers must have assets sufficient to make the required payments; otherwise they will have inadequate incentives to reduce harm. As we discussed in section 3 of chapter 4 , this is especially relevant when harm may be large and exceed the assets of a potential injurer (a fire could cause a large harm, exceeding the assets of the owner of property, an explosion at a factory or a leak of toxic material could cause much more harm than the company's assets). The problem of inability to pay is likely to be less of a problem for the corrective tax, for it equals the expected harm, an amount generally less than the actual harm. Also, the corrective tax is presumably paid as parties take harm-creating actions; thus, if the party could not pay the tax, he could be prevented from continuing (he would not be allowed to release a pollutant into the atmosphere if he could not pay the tax). Where the problem of inability to pay is a problem, regulation and the other approaches become more appealing (although they may need to be enforced through the threat of use of nonmonetary, criminal sanctions).

(h) Conclusion. This review of factors bearing on the effectiveness of the rules suggests that their relative strengths will depend very much on the context. Let us illustrate by considering the classic problem of pollution caused by burning a fuel at factories. Here, liability rules might not be expected to work well because of problems victims would have in detecting harm and ascertaining who caused it, and the use of the injunction might not work well for similar reasons. Regulation of the quantity of fuel burned would be unappealing, because it would require the state to determine the optimal quantity, meaning that it would have to determine the value of production, or the cost of alternative fuels, and these would depend on many particular factors that would be expensive if not impractical to learn. Thus, the corrective tax, relying mainly on the state's knowing the harm that the pollution tends to cause, becomes appealing. Moreover, such taxes would often be inexpensive to administer, because they could be imposed when the fuel is purchased.

5.3 Actual use of legal rules to control external effects. Regulation and the liability system are the preeminent tools that society employs to control externalities. The state uses a vast array of regulatory devices: safety regulations for food and drugs, consumer products, and the workplace; speed limits and other traffic safety rules; zoning ordinances governing the physical structure and use of buildings; and so forth. ${ }^{145}$ Liability for harm is also omnipresent; individuals and firms are potentially liable for virtually all kinds of harm. ${ }^{146}$ The injunction is somewhat limited in scope, applying only when a potential or actual victim establishes the existence of a fairly substantial and continuing danger. ${ }^{147}$ Subsidies are utilized relatively infrequently, and corrective taxes

victim behavior and injurer behavior, the tax may still be easy to approximate if the interactions are not very important.

${ }^{145}$ On regulation in general see, for example, Breyer 1982, Hahn 1990, Kahn 1988, and Viscusi, Vernon, and Harrington 2000.

\footnotetext{
${ }^{146}$ See for example Dobbs 2000.

${ }^{147}$ See, for example, Federal Procedure 2000 19:526-27, and Thomas 1994 8:122-24.
} 
are used rarely, although marketable pollution rights have been employed to control specific pollution problems. ${ }^{148}$

\section{Resolution of External Effects Through Legal Rules Given the Possibility of Bargaining}

Let us now briefly reconsider the resolution of external effects through the use of legal rules when, unlike in the last section, parties are assumed to be able to bargain with one another. This will be done supposing, first, that bargaining proceeds perfectly and without cost, second, that bargaining is a costly process, and third, that bargaining is subject to problems of imperfect information.

6.1 Frictionless bargaining and the irrelevance of legal rules: invariance version of the Coase Theorem. In this case the parties will always arrive costlessly at a mutually beneficial outcome and thus at the outcome that maximizes social welfare, assuming that social welfare equals the sum of utilities and that the simple model we have discussed above applies. In particular, the socially desirable outcome will be achieved whatever the starting point of the parties when they begin to bargain, whatever their property rights are or, more generally, whatever the governing legal rule. That is, the legal rule will not matter to the outcome.

For example, in discussing the smoke arrestor in section 3, we saw that if the injurer enjoys the property right to generate smoke, bargaining would result in the victim avoiding harm of 50 by making a payment to the injurer of at least 30 to install a smoke arrestor. It is clear that if, instead, the victim possessed the right to prevent generation of smoke, he would do so, and the injurer would install the arrestor: The injurer would prefer to spend 30 to do this than to pay the victim at least 50 to obtain agreement to suffer exposure to smoke. Hence, whether the injurer has the right to generate smoke or the victim has the right to enjoin this, the act chosen, after possible bargaining, will be the same.

Let us consider one more version of this example, and show that the outcome under the rule of strict liability where the harm is correctly estimated by courts will be the same as the outcome if the harm is incorrectly estimated (which may be considered to be another legal rule). If the harm is correctly evaluated by courts, then the injurer will of course be led to purchase the arrestor for 30 to avoid having to pay 50 in liability. What, however, if the harm is estimated to be only 25 ? In this event, in the absence of bargaining, the injurer will cause harm and pay damages of 25 rather than spend 30 on an arrestor. But the victim will be willing to pay the injurer sufficiently to induce him to purchase the arrestor: If the victim pays him 15 and the injurer purchases the arrestor for 30 , his net expense will be 15 rather than 25 , and the victim will lose 15 instead of 25 (if he were to suffer harm of 50 and collect a liability payment of 25).

Because, as in these examples, the outcome does not vary with the legal rule when bargaining occurs, the point under consideration is sometimes described as the invariance version of the Coase Theorem. It should be noted, however, that although the legal rule will be irrelevant to the outcome under present assumptions, the legal rule obviously does alter the utility positions of parties. The victim is worse off when the injurer is not liable,

\footnotetext{
${ }^{148}$ For descriptions of the use of subsidies, corrective taxes, and marketable pollution rights, see, for example, Hahn and Stavins 1991 and Menell and Stewart 1994, 69, 72, 377-84, 519-20.
} 
or when he, the victim, does not have the right to be free from smoke, because he then has to pay the injurer to install an arrestor.

6.2 Comments and limitations. Although this invariance conclusion is correct in the simple model, as just illustrated by the examples, it is not necessarily valid more generally even though bargaining is frictionless, or apparently so.

(a) Coase Theorem and wealth effects. For reasons similar to those discussed in section 3.3, the effect of wealth on parties' behavior may make the outcome depend on the legal rule. To illustrate, if the victim does not have wealth of 30 , the smoke arrestor will not be installed if the injurer has the legal right to generate smoke, whereas the injurer will install the arrestor if the victim has the right to be free from smoke. ${ }^{149}$ Also, if the victim does have wealth of 30 but the marginal value of wealth to him is high because his level of wealth is low, the legal rule may affect the outcome and social welfare. The victim may not be willing to pay 30 for the injurer to install a smoke arrestor, so that no arrestor will be installed if the injurer has the right to generate smoke; yet the victim may insist on receiving more than 30 to be willing to be exposed to smoke, so that an arrestor will be installed if the victim has the right to be free from it. ${ }^{150}$

As a general matter, then, because of the effects of the levels of wealth that parties happen to possess, the choice of legal rules may influence the ultimate outcome, even though there is no problem with bargaining between parties. Still, the invariance of outcome to the choice of legal rule is likely to hold, or at least approximately so, if the harm or cost of preventing it is not large in relation to the involved parties' assets.

(b) Coase Theorem in an industry in the long run. An issue that has received some attention is whether the invariance version of the Coase Theorem holds in the long run in an industry in which production causes externalities. It has been asserted that the theorem does not hold in this context because legal rules affect costs; thus, in the long run, when price and output adjust to costs, the legal rule that is adopted will influence the amount sold by an industry. Suppose, for example, that each firm in an industry is like the one we have discussed above and can suppress smoke with an arrestor that costs 30 and thereby

\footnotetext{
${ }^{149}$ For the injurer would prefer to pay 30 for the arrestor than to pay the victim 50 to induce him to agree to exposure to the smoke.

${ }^{150}$ Note that the amount that the victim would insist on being paid to accept exposure to smoke is the amount of wealth that would raise his utility by 50. This amount could easily exceed 30 units of wealth -- even though losing 30 units of wealth might entail a loss of utility exceeding 50 . The reason for these two possibilities -- a loss of 30 units of wealth corresponds to a utility loss exceeding 50, and a gain of 30 units of wealth corresponds to a utility gain of less than 50 -- is that the marginal utility of wealth declines with its level. Formally, let $h$ be the harm in utility the victim would sustain from a nonmonetary adverse event, let $v(\mathrm{~A})$ be his utility of wealth, where $v$ is increasing but concave, let $w$ be his initial wealth, and let $c$ be the cost of the precaution that would prevent $h$. Then it is possible that $v(w) ! v(w ! c)>h>v(w+c) ! v(w)$, in which case the victim would not pay $c$ to avoid $h$ and yet would insist on more than $c$ to accept $h$.

The literature concerning the point under discussion is often found under the heading of "offer versus asking price" (the offer price being what the victim would offer to pay for the smoke arrestor, the asking price being what he would want to be paid to accept exposure to smoke). Some writers explain a higher asking price than offer price not on the basis of wealth effects, but rather on the basis of an "endowment effect." The endowment effect refers to the tendency of an individual to attach an extra value to property if it comes into the individual's possession (if the person is "endowed" with the property). See, for example, Kahneman, Knetsch, and Thaler 1990, Korobkin 1994, Jolls, Sunstein, and Thaler 1998, 1497-501, and Arlen, Spitzer, and Talley 2002.
} 
prevent harm to victims of 50. It is true that, given frictionless bargaining between firms and potential victims, arrestors will be purchased whether or not the legal rule gives firms the right to pollute. But a firm's costs will depend on the rule; if firms have a right to pollute, their costs will be lower than if they do not have the right and must pay for the arrestors themselves. Hence, over time, when prices and output adjust, prices will be lower and the quantity produced and sold will be higher when firms have the right to pollute. $^{151}$

As stated, this argument that the legal rule affects outcomes is correct, and thus seems to invalidate the invariance version of the Coase Theorem. However, the argument allowed only for bargaining between firms and the potential victims of pollution. If we permit victims to bargain with consumers of the product, then we can show that output will not be higher when firms have the right to pollute. (The reason is that victims will pay consumers to purchase less; victims will do this to save themselves from having to pay for as many smoke arrestors. ${ }^{152}$ ) Because the premise of the Coase Theorem is that there are no obstacles to bargaining, we should permit victims to enter into bargaining with consumers, so that we should conclude in strict logic that the theorem does hold in the present context. Yet because it is in fact implausible that victims would bargain with consumers, ${ }^{153}$ one would predict that in reality the choice of legal rule would matter to output and sales.

(c) Coase Theorem and corrective taxes. The imposition of corrective taxes affects outcomes when parties bargain frictionlessly with each other, and so seemingly conflicts with the Coase Theorem. Specifically, in the presence of bargaining, corrective taxes generally result in suboptimal outcomes involving socially excessive effort to reduce harm. ${ }^{154}$ To illustrate, suppose that a polluter could eliminate 100 of harm by

${ }^{151}$ Articles that assert that legal rules affect output, along lines illustrated by the example just provided, include Carlton and Loury 1980.

${ }^{152}$ For instance, suppose that the cost and price of each unit is 10 when firms have the right to pollute, but that victims pay 5 per unit for smoke arrestors. Consider a consumer who places a value of 11 on having a unit of the good. He will buy it at a price of 10 in the absence of bargaining with victims. But a victim would be willing to pay a consumer up to 5 not to buy the unit -- for 5 is the victim's savings for not having to support the purchase of smoke arrestors. Hence, the only consumers who would, after possible bargaining with victims, purchase the good are consumers who are willing to pay more than 15 for the good. But these are exactly the consumers who would purchase the good if firms had to spend 5 on smoke arrestors themselves and thus charged a price of 15 for units of the good.

It should be noted that the bargaining here between victims and consumers must be bargaining between all victims and all consumers. It is not enough for a single victim to bargain with a single consumer to refrain from consumption, for then another consumer could make a purchase from the factory near the victim and cause him to pay for a smoke arrestor. An agreement must be reached among all potential consumers to refrain from consumption.

The general point that, given sufficiently general bargaining, the invariance result will hold even in a long-run setting where output adjusts is made by Calabresi 1968, Frech 1973, and Hamilton, Sheshinski, and Slutsky 1989.

${ }^{153}$ Especially because (see the previous footnote) victims would have to bargain with all consumers.

${ }^{154}$ This observation was initially made in Buchanan and Stubblebine 1962. 
spending 110 on a smoke arrestor, so that that expenditure would be undesirable. In the absence of a tax, say if the injurer had the right to generate smoke, the victim would not be willing to pay him enough to purchase the arrestor, so he would cause 100 of harm. In the presence of a tax for pollution harm, however, the injurer would purchase the arrestor, for by doing so he would avoid 100 in taxes and could collect more than 10 (in fact, up to $100)$ in addition from the victim for so doing.

Why do corrective taxes in the presence of bargaining lead to the wrong result, one different from the result that would obtain in the absence of taxes? The reason is that for the injurer and the victim considered jointly, harm has double the cost it should: not just the loss suffered by the victim but the tax as well. That the outcome under taxes is different from that in their absence does not contradict the invariance version of the Coase Theorem, however. The premise of the theorem is that all concerned parties bargain, meaning the government too. If the government were to bargain along with the injurer and victim, then it can readily be shown that the tax would not lead to an undesirable result. $^{155}$

The points made here and in paragraph (b), that legal rules may have clear effects on outcomes, shows that the invariance version of the Coase Theorem needs to be carefully interpreted, and is not necessarily a good guide for thinking, even when bargaining is apparently frictionless.

6.3 Bargaining is costly. Suppose now that bargaining is a costly process. Hence, when the situation is not optimal and a mutually beneficial agreement exists in principle, one of two disadvantageous outcomes will occur. First, the parties may elect to bargain and incur bargaining costs in the process; this will be the result as long as bargaining costs are small enough. Second, the parties may decide not to bargain in order to avoid bargaining costs, and the suboptimal outcome will occur; this will be the result if the costs of bargaining are sufficiently large. If the injurer has the right to generate smoke and the cost of bargaining is only 5 for each party, we would expect them to bargain and conclude an agreement. If the victim were to pay the injurer 38 , say, to install an arrestor, the victim's total cost would be 43, making him better off than if he suffered harm of 50, and the injurer's net return after installing the arrestor at a cost of 30 would be 3 , making him better off as well. But if the costs of bargaining for each party are larger than 10, the parties will not bargain and the injurer will not install the arrestor. ${ }^{156}$

It follows that the choice of legal rules will matter to social welfare; legal rules should be selected so that more costly bargaining is not needed to achieve the socially optimal outcome. Thus, if it is usually optimal for firms not to pollute, because the benefits they would obtain if they pollute are unlikely to exceed the harm caused, victims

${ }^{155}$ In the example with the smoke arrestor, suppose that, in the absence of government bargaining, the victim pays the injurer 20 for him to buy the arrestor. Hence, the government collects 0 , the victim loses 20, and the injurer loses 90 (as he spends 110 on the arrestor). Now let the government bargain and offer to reduce the tax to only, say, 5 if harm occurs and the injurer pays the victim 82 . Then all three parties will be better off: The government collects 5 rather than 0 , the injurer loses 87 rather than 90, and the victim loses 18 rather than 20 .

${ }^{156}$ When the cost of bargaining exceeds 10 for each party, the victim will not be willing to pay as much as 40 to avoid the harm of 50 (for $40+10$ is 50). But the injurer will want at least 40 to be willing to purchase the arrestor since it costs 30 (for $30+10$ is 40 ). 
should enjoy the right to clean air. Or firms should be regulated, taxed, or held strictly liable for harm due to pollution, for under these legal policies, bargaining is not necessary when it is optimal for injurers not to pollute. By contrast, if firms have the right to pollute, bargaining will be required to achieve the optimal outcome whenever it is best for them not to pollute.

6.4 Bargaining is subject to problems of imperfect information. Just as the cost of bargaining may prevent formation of a mutually beneficial agreement, so may asymmetric information between the parties stymie such agreements, for the reasons discussed in section 4.3. Therefore, we have another basis for favoring legal rules (such as liability) that lead to optimal outcomes without parties having to bargain. However, for the state to know what legal rule to employ requires that it has certain knowledge about parties (such as the harm from smoke). Yet our present assumption is that the parties themselves lack information about each other -- this is why bargaining may not succeed. And, as a general matter, it would be unlikely for the state to possess more information about the parties than they have about each other. (If the injurer does not know the level of harm the victim would suffer from smoke, will the state?) Accordingly, the state may be unable to select a legal rule that leads to optimality without parties having to bargain, complicating the problem of the socially best choice of legal rule.

\subsection{Conclusion about bargaining and legal rules for controlling externalities.}

We may summarize and conclude roughly as follows. When conditions are such that parties may bargain with one another, the choice of legal rules matters less to the optimal control of external effects than would otherwise be the case, because bargaining may lead to mutually and socially advantageous outcomes. Yet the choice of legal rules is important because it can produce such outcomes directly, reducing the need for parties to bargain and to incur associated transaction costs, and also avoiding suboptimality where bargaining would not succeed due to asymmetry of information between the parties.

Note on the literature. The subject of externalities was adumbrated in Sidgwick (1901, 399-418) and may properly be said to have originated with Pigou (1912, 148-71; 1932, 172-203). Pigou first emphasized the generality of the problem of externalities and spoke of the solution as lying mainly in government intervention in the form of taxes, subsidies, and regulation. An extensive literature now exists on externalities. ${ }^{157}$ Economists for the most part have emphasized corrective taxes and subsidies as the theoretically preferred solution to the externality problem (despite the infrequency of their use), though some have pointed to the difficulties in calculating appropriate taxes. ${ }^{158}$ Economists have also considered regulation as a solution to externality problems and compared it to corrective taxes, finding it generally inferior because it requires the state to have more information. ${ }^{159}$ However, economists largely ignored liability and property 2000 .

${ }^{157}$ See, for example, De Meza 1998, Goulder and Bovenberg 2002, Laffont 1987b, Ostrom 1990,

${ }^{158}$ Difficulties in estimating harm necessary to impose proper taxes were early stressed by Davis and Whinston 1962, for example.

${ }^{159}$ For a typical example, see the argument that taxes are superior to regulation in the introductory economics text of Mankiw 2001, 215-17. (Weitzman 1974 and others suggest that regulation may be superior to taxes, but this view is based on an assumption that seems unreasonable; see note 25 above.) 
law solutions to externality problems until the development of economic analysis of law, stimulated mainly by Coase (1960), Calabresi (1970), and Posner (1972). Coase, whose work was particularly influential, stressed three points: (1) the reciprocal nature of the externality problem -- the victim's ability to ameliorate harm or to alter his activity so as not to be exposed to it; (2) the possibility that externality problems would be cured by bargaining, and the consequent irrelevance of the law to substantive outcomes, when parties can bargain with little cost; ${ }^{160}$ and (3) the problems of information that government faces in trying to correct externality problems, making its intervention problematic. Calabresi and Melamed (1972) contains a suggestive analysis of liability versus property rules as general solutions to externality problems, ${ }^{161}$ and Landes and Posner (1987b) and Shavell (1987a) summarize economic analysis of the liability system. At present the comparative analysis of the various means of controlling externalities is relatively underdeveloped. ${ }^{162}$

${ }^{160}$ Although Pigou is criticized by Coase for viewing government intervention as necessary to solve externality problems, Pigou himself emphasizes the possibility that externalities will be resolved through bargaining when parties are in a contractual relationship.

${ }^{161}$ On property and liability rules generally, see also Ellickson 1973, Polinsky 1980b, and Kaplow and Shavell 1996b.

${ }^{162}$ See Shavell 1993a for an attempt to compare systematically the major methods for controlling externalities. For examination of liability and regulation alone, see Wittman 1977, Shavell 1984b,c, and Kolstad, Ulen, and Johnson 1990. 


\section{Chapter 11}

\section{PUBLIC PROPERTY}

Much property in modern states is public in nature, and I begin this chapter by inquiring about the justifications for the existence of public property. I then discuss acquisition of property by the state through purchase and through its unilateral power to take property.

\section{Justifications for Public Property}

1.1 Definitions and general justifications. By public property I mean land, buildings, or moveable goods owned by the state. Public property is available for free use if a person can enter upon it and utilize it without constraint. Clearly, much public property is available for free use: roads, sidewalks, parks, rivers and lakes, airspace, schools, and libraries are often open to all. Some public property, however, is only available for use for a fee: a person may be charged for driving on a turnpike, cutting timber from public lands, or entering a museum. Other public property is available for use only by authorized parties. Military bases and fire stations, for example, fall into this category.

I will attempt to explain in this section why it makes sense that property like the above-mentioned should be public, and why such property should or should not be available for free public use. The main justifications for public property are either that the private sector cannot profit sufficiently to be led to supply certain property when its supply would be socially desirable, or that a private supplier of property would charge too high a price for, and thus undesirably discourage, its use.

1.2 Provision and free use of certain property is socially desirable. Suppose that once the cost of developing or setting aside a piece of property for some purpose is incurred, there would be no added cost associated with an individual's use of the property. Suppose, for example, that once a road is constructed, its use by a person would not absorb additional resources. ${ }^{163}$ Then if the property is developed, it will be socially desirable for it to be freely available for use. And because the property should be freely available for everyone to use if developed, it should be developed whenever the sum of its values to all individuals who would use it exceeds its development cost. ${ }^{164}$

1.3 Private provision of such property is unlikely to be adequate. Would the private sector be likely to supply property - for which a price would of course be

\footnotetext{
${ }^{163}$ The assumption that there is no cost associated with an individual's use of property such as a road is closely related to the assumption of nonrivalry in the use of property -- where one person's use of property does not detract from the ability of another person to use the property. The assumption of nonrivaly, or essentially equivalently, of no marginal cost of use, is, of course, an abstraction; use of a road in fact causes some wear and tear to the road and possible congestion. But such costs are often small, especially in relation to the cost of purchasing land and constructing a road. I will maintain the assumption until section 1.10 , when I will consider explicitly the case where there is a positive marginal cost associated with a person's use of property.

${ }^{164}$ In saying this, I am assuming for simplicity that the measure of social welfare is the sum of values individuals obtain from using things minus costs of production, and I will maintain this assumption in this chapter unless otherwise noted.
} 
imposed -- that ought to be provided for free use? There are two reasons for thinking that private parties might not be able to profit sufficiently to provide such property.

First, to earn anything from the property, a private provider of it would plainly have to be able to prevent those who do not pay for use from using it. But this may be difficult or expensive; to exclude nonpayers from a road would require controlling access to it. The cost of excluding nonpayers from property that ideally ought to be developed may mean that private providers would find it unprofitable to supply (or that the scale of its development would be suboptimal).

Second, and less obviously, even if a private provider can relatively cheaply exclude nonpayers and charge for use of property, the revenues the provider would be able to obtain would generally fall short of the total value people attach to its use. Suppose that the values that ten people place on use of property are 1,2, and so on, up to 10 , so that their total valuation is 55 , and suppose that the price the provider would charge is 5 . Then, because those individuals who value use at less than 5 would not use the property, the revenue the provider would receive from userse would not reflect the sum of valuations of the individuals unwilling to pay 5 (namely, $1+2+3+4$, or 10 ). Moreover, the revenue received from those who do pay 5 would not fully reflect their valuations (these six people pay 30 , but their total valuation is $5+6+7+8+9+10$, or 45). Because a private provider's revenues will tend to fall short of the total public valuation of property, the private provider might not earn enough to cover the cost of supplying it, even though the total valuation does exceed its cost. ${ }^{165}$

\subsection{Even if property that is socially desirable to provide is provided by} private parties, two problems remain. Suppose that, despite the factors just discussed, the private sector finds it worthwhile to develop property that is socially desirable to provide. Then two factors imply that there will still be disadvantages associated with private provision of the property. First, the expenses borne by private providers to exclude nonpaying parties from use represent a social waste. If a private company spends $\$ 2$ million erecting gates and toll stations in order to collect revenue from use of a road, the $\$ 2$ million constitutes a social waste: The barriers to entry on the road do not enhance the utility of the road and fulfill no direct social need; their sole purpose is to allow the owner to obtain revenues from the road.

Second, too few individuals will use the property because use is not free. Individuals who place a value on use below the price charged will not use the property even though it would be desirable that they do. Individuals who place a positive value on use of a road that is below the price charged for access will not use it, even though all who place a value on it ought to be able to use it.

1.5 Public provision of property that ought to be provided for free use. The state does not face the above-mentioned problems associated with private provision of property that ought to be provided and be made available for free use. First, the state can, in principle, compare the cost of developing property, such as a road, to the total value placed on it, and supply it if the total value exceeds the cost. Unlike the private sector, the

\footnotetext{
${ }^{165} \mathrm{I}$ am assuming in this paragraph that the provider is not able to identify each individual's valuation and charge him a separate price. If a provider is able to do this -- to engage in perfect price discrimination - his revenue will equal total valuation, as he can charge each person a price fully equal to that person's valuation -- the 1-valuation person will be charged 1, the 2-valuation person will be charged 2 , and so on.
} 
state does not have to incur costs to exclude nonpayers from property like a road for the simple reason that it does not need to finance property from revenues from use -- the state can finance property from tax revenues (see the next section). Second, if the state does develop property that ought to be available for free use, it can simply allow the property to be freely used. Thus, the socially ideal outcome might be thought to occur if the state acts as the potential provider of this type of property.

1.6 Problems with public provision. There are, however, several possible problems with public provision of property for free use. One problem has to do with the state's need to raise revenues through taxation for development of property. The raising of revenues through taxation is not socially costless, but rather involves administrative expense and causes distortions of its own (notably, an income tax may depress work effort). ${ }^{166}$ Thus, there is an implicit cost associated with public expenditures on development of property. It should be remarked, though, that this problem does not always arise because in some cases the state owns property from the outset (as with airspace and rivers).

A second possible problem with state provision of property concerns the state's ability to obtain information about the public value of property and also about the cost of its development. It was assumed above that the state is able to determine the total value that individuals would place on use of property and the cost of developing it. In fact, the state may have difficulty obtaining such information (see the next section). Moreover, the state's decision may be influenced by a political process that leads to incorrect decisions.

1.7 Comment on elicitation of preferences. How can the state obtain information about the value people place on property that it contemplates developing? One possibility is for it to make use of data on purchases relating to similar property or goods. Thus, if the state wants to determine whether to develop a park and there is a similar park for which individuals paid a fee for use, or which they had to spend time and money to reach, statistics on usage will provide information about valuation. Another possibility is to survey individuals, asking them for their valuations. ${ }^{167}$ If, however, the question posed in a survey is simply what is a person's valuation, then he may have an incentive to distort his answer. Individuals who place a positive value on a park, say $\$ 100$, may have a motive to exaggerate their valuation, reporting $\$ 1,000$ or $\$ 10,000$, since this may increase the chances that the park will be constructed. ${ }^{168}$ Similarly, others may have an incentive to overstate their aversion to having the park developed. There are

\footnotetext{
${ }^{166}$ However, Kaplow 1996 emphasizes that it is in principle possible to raise tax revenues for public property without distorting work effort.

${ }^{167}$ Polling of individuals to determine their willingness to pay for things is called contingent valuation (the valuations that individuals report are contingent in the sense that they are hypothetical -- what individuals say they would spend on things -- not what they actually do spend). On contingent valuation, see, for example, Mitchell and Carson 1989 and, for a critical analysis, Hausman 1993.

${ }^{168}$ To amplify, suppose that if the park is built, people know that each will have to pay $\$ 50$ more in taxes, and that it will be built if the sum of reported values exceeds a threshold. Then anyone who values the park at more than $\$ 50$ will have an incentive to exaggerate his value in order to increase the chance that the park will be built.
} 
however, ways of designing questions that will tend to elicit the truth from individuals. ${ }^{169}$ But these techniques have problems of their own. ${ }^{170}$ A distinct difficulty is that individuals may be unfamiliar with the type of good in question and therefore not really be capable of easily evaluating it.

1.8 When public provision is best. Public provision of property that ought to be developed and freely used is best, loosely speaking, when the disadvantages of private provision -- the possible failure to supply the property, the cost of excluding nonpayers, and the underuse of privately-supplied property due to the charging of a price for use -outweigh the disadvantages of public provision -- the possible costs of raising funds through taxation, and the possibly problematic features of the process for deciding about development of property.

1.9 Examples. I consider here briefly several examples of property that is usually publicly provided and discuss why this might make sense in the light of the considerations from above.

(a) Roads. It is self-evident that it is socially desirable for land to be set aside for the building of a network of roads; the need for people and goods to be able to move about on a road system in a modern economy is obvious. It is clear as well that access to much of the road system should be essentially unrestricted (because wear and tear on the roads and congestion effects will often not be substantial).

It was suggested above that problems would arise if we were to rely on private provision of roads. To amplify, roads would then probably be far too few in number due to the cost and difficulty of restricting access in order for providers to charge for use; the expense of erecting fences and installing toll booths, together with the administrative

\footnotetext{
${ }^{169}$ For example, suppose that a person is told that his reported valuation will be added to other reported valuations and that he will pay a tax only if his reported valuation is pivotal -- only if his particular reported valuation turns out to make the sum of reported valuations exceed the cost of the park. Thus, if the sum of other reports is $\$ 2,000$, his report is $\$ 200$, and the cost of the park is $\$ 2,100$, his reported valuation would be pivotal because it would make the reported sum rise from $\$ 2,000$, which is below the cost of $\$ 2,100$, to $\$ 2,200$. If his reported valuation is pivotal, suppose that the tax he must pay equals the difference between the cost of the park and the sum of others' reported valuations. Thus, in the example just mentioned, he would pay a tax equal to $\$ 2,100 ! \$ 2,000=\$ 100$ if his report is pivotal. Then it can be shown that the person will be motivated to report the truth about his own valuation. To illustrate, suppose that his true valuation is $\$ 200$ and consider his situation if he reports a number, such as $\$ 300$, that exceeds his true valuation. This will increase the probability that he is pivotal (make it more likely that his reported valuation will make the sum exceed $\$ 2,100$-- for this will be the case whenever others' reports sum to between $\$ 1,800$ and $\$ 2,100$, rather than only when they sum to between $\$ 1,900$ and $\$ 2,100$ ). But his incorrect report will have no effect on the tax he pays if he is pivotal, for that tax amount does not depend on the magnitude of his report (his tax equals $\$ 2,100$, the cost of the park, less the sum of what others report). Further, the only new circumstances in which his higher than truthful reported value would result in his being pivotal are those in which he would be made worse off by having exaggerated his valuation: For instance, if other reports sum to $\$ 1,850$, his tax would be $\$ 250$, but since his valuation is $\$ 200$, he is worse off by $\$ 50$ relative to his situation if he reports $\$ 200$, since then he would not be pivotal). A similar argument shows that he will not want to report a number less than his true valuation of $\$ 200$. For further discussion of this and other mechanisms for eliciting the truth from individuals, see Atkinson and Stiglitz 1980, 513-16, and for a survey, see Laffont 1987a.

${ }^{170}$ One problem is that individuals need to be rather sophisticated to understand that it is rational for them to report the truth; another is that the techniques are vulnerable to collusion among surveyed individuals. For further discussion, see the references in the previous note.
} 
costs associated with collecting payments, would be significant. Not only would the roads be too few in number, they would depart in character from what is desirable. It is beneficial for roads to allow people many points of entry and exit along the way, since places of origin and destinations are dispersed. However, it would be too expensive for a private system to allow a real multiplicity of points of entry and exit, because the costs of control and collecting payments would become excessive. (Related to, and compounding, these difficulties is the factor of multiple private owners of roads; whenever a person passed from one owner's road to another's, a fee might have to be paid.) Of course, all the costs of controlling access and collecting fees would be a social waste as they do not produce anything of direct value to people. Further, many individuals would not use roads because they would be unwilling to pay the tolls, which would mean that a benefit that they could have enjoyed, at little or no social cost, would be forgone.

When roads are instead publicly provided, then, because access need not be limited, nothing is spent on controlling access and collection, roads may have many points of access and exit, and so forth. As a general matter, one suspects that these advantages of public provision of roads are so great as to outweigh the possible disadvantages of public provision associated with the need to raise money through taxation and with the political process. Were roads left for the private sector to supply, society would be much worse off.

This theoretical argument for the rationality of public provision of roads is borne out by fact: Road systems are predominantly public in all countries today, and the road system covers a substantial fraction of land in developed urban areas (about a quarter of land area in urban centers is taken up by roads ${ }^{171}$ ).

It should be stated, however, that with modern technology, it might be possible in the future for private entrepreneurs to charge for use of roads without building expensive physical barriers to control access. If use of roads can be cheaply monitored by electronic means (each automobile might send out a distinct signal that is registered by receivers), making users pay might become relatively cheap. (Such electronic road pricing has actually been implemented on an experimental basis in California, in Hong Kong, and in the Netherlands. ${ }^{172}$ ) If so, the disadvantages of private supply of roads would involve mainly the pricing of road use. ${ }^{173}$

(b) Rivers. As with roads, it is plain that it is socially desirable for many rivers to be freely available for transport. But a private owner of a river would not seem to face a significant expense for controlling access to it, or at least one comparable to that for roads. (People cannot move vessels on and off rivers in the same way that they can drive

\footnotetext{
${ }^{171}$ See, for example, Jacobs 1993, 6, who states that about 25 per cent to 35 per cent of developed land in cities in the United States is devoted to public rights of way, mostly streets. Niedercorn and Hearle 1964, 6, estimate that about 26 per cent of developed land in 48 large American cities is devoted to roads and highways.

${ }^{172}$ A private company has set up an electronic billing system for use of a toll road in California; see Ayres 1996. In Hong Kong and the Netherlands, the government has tested electronic billing systems; see McCarthy and Tay 1993, 297, and Hau 1990.

${ }^{173}$ These disadvantages would be serious if there were not much competition among owners of alternative roads.
} 
cars on and off roads; in part, this is because there isn't a network of crisscrossing rivers similar to that of roads.) However, a potentially significant problem with private ownership of rivers is that the prices charged might discourage their use. In fact, this problem emerged as a serious obstacle to trade in France and Germany in the Middle Ages, when territory was divided among multiple feudal lords who charged tolls individually for passage on sections of rivers that they controlled. ${ }^{174}$ Indeed, it has been argued too that one of the reasons for England's rise as an economic power at the time is that, owing to England's internal unification, transport on her rivers was not stifled by tolls. ${ }^{175}$ Such problems with private ownership of rivers may justify their largely public ownership.

(c) Airspace. The case of airspace is similar to that of rivers. Airspace is useful for transportation and should be freely available for use (except for controlling congestion). Restricting access to airspace might or might not be difficult for a private provider (perhaps use of airspace could be monitored electronically). In any event, the expense involved in limiting access to airspace would be a waste, and the price charged would unnecessarily discourage use. Thus, as with rivers, the argument in favor of public ownership of airspace, which is what is observed, seems fairly strong. ${ }^{176}$

(d) Recreational areas. The social desirability of preserving certain areas for recreation and enjoyment of nature is apparent. The cost a private supplier would incur in controlling access to such areas would sometimes be relatively low. For example, control of entry into even a large park might be accomplished merely by collecting tolls along a single road entering the park; fencing in the park would not be necessary if the typical visitor would be traveling by automobile. Similarly, it might not be very expensive to erect a fence around a relatively small park in a city, and to collect for entry. However, controlling access to miles of beachfront, or to a long trail (such as the Appalachian Trail) would be so costly as to be impractical, so one could not easily imagine the private sector supplying such recreational areas. In any case, were a park or other recreational area to be provided by the private sector, the cost of controlling entry would be a social waste, ${ }^{177}$ and the pricing policy that would be pursued would tend to discourage use relative to the optimal amount. Thus, there is a case for public ownership, although its strength depends on the cost of controlling entry and the degree to which use would be discouraged versus the disadvantages, discussed above, of public development.

Parks in reality are often publicly owned, notably our municipal, state, and national parks. Also, much of the seashore is publicly held. There are, however, many private parks and camping grounds owned by profit-making entities.

\footnotetext{
${ }^{174}$ For example, in the late fifteenth century, half of the final selling price of grain shipped 200 miles down the Seine River was accounted for by tolls. See Postan and Miller 1989, 134-35.

${ }^{175}$ See Heilbroner 1962, 51.

${ }^{176}$ Ownership of airspace above 500 feet is public in the United States; see, for example, Cahoon 1990.

${ }^{177}$ If, however, it is optimal to control access to prevent congestion, then under public ownership, access would also be controlled. Thus, the cost of controlling access would not be a social waste; see the discussion in section 1.10 below.
} 
(e) Land and moveable things with unique characteristics. Consider land of unique value -- such as a natural wonder, or a historic battlefield -- or moveable things of special significance to the public -- such as paintings, documents of historical importance, and the like -- and assume that it is socially desirable that the public be allowed free access to observe them (as long as congestion problems do not develop). Along with the two general problems with private provision of these goods, there is a special problem involving their enjoyment at a distance. It may be thought, for example, that an individual derives benefits from knowing that the Gettysburg battlefield, Yellowstone National Park, the Declaration of Independence, and the Mona Lisa are preserved, even if the individual never actually goes to see these things. That is, individuals may place a value on the mere existence of certain things. ${ }^{178}$ However, a private owner will not be able to capture much, or any, of this existence value, since the private owner will obtain its revenue primarily from those who actually visit the land or the thing. Were a private company to own the Gettysburg battlefield, it might decide to sell the land to a real estate developer because the profits it makes from visitors are small, since the profits reflect only the valuations of those who go to Pennsylvania to visit the site; the profits would not reflect the amount that others in the population would pay, perhaps small on an individual basis but large when added, for the knowledge that the Gettysburg site is preserved. Hence, if existence value is significant, there is a special reason to expect an undersupply of things by the private sector. This might help to justify what we often observe, the public ownership of land and objects with unique character.

1.10 Public property that should only be available for use for a fee. The argument that certain property should be freely available was based on the assumption that one person's use did not absorb resources or detract from another's use. Let us now relax this assumption and take into account, for example, that wear on the roadbed and congestion (which slows traffic and increases accident risks) makes use of a road by an individual costly. This implies that, were it easy to impose fees on users of a road (or other property), it would be best that a public provider of the property impose a charge equal to the marginal cost of use. Then, as is socially desirable, a person would not use the property unless his valuation exceeded the marginal cost of his use. But because excluding nonpayers and imposing fees may be expensive, a public provider should make the expenditure in order to impose fees if and only if the expenditure is outweighed by the benefits from limiting use to those whose values exceed marginal cost. This might be the case, for instance, for a bridge or tunnel, since the cost of excluding nonpayers equals only that of controlling access at either end.

Note that when it would be desirable for a public provider of property to impose fees for use, one of the two advantages of public provision over private disappears -- it is no longer true that only private providers bear costs of excluding nonpayers, now so does a public provider. However, private providers would still generally tend to charge a price that is too high, one exceeding the marginal cost of use -- consider the toll that might be

\footnotetext{
${ }^{178}$ The notion of existence value was introduced by Krutilla 1967 ; it should be carefully distinguished from the value people place on their being able to see a thing in the future (or on their descendants being able to do so) or on their being able to see photographs or other images of a thing. The concept of existence value is felt to be overstated by some because, among other things, after proper account is taken of the values just noted, there may be little if any residual value, that is, little if any existence value. See, for instance, Milgrom 1993 for a skeptical discussion of existence value.
} 
charged for passage over a privately owned bridge -- and thus undesirably discourage use.

1.11 Public property that is needed for the provision of public services. There are a variety of services that are, or may well be, socially desirable for the public to provide, notably, national defense, certain educational and health-related services, and fire and police protection. For these services to be provided, the state needs to acquire certain property. The military needs bases for its troops and equipment; and schools, libraries, hospitals, and fire and police departments all need property to carry on their activities. In some cases, it would not be desirable for individuals to have access to the state's property. For example, there are obvious security reasons for limiting people's access to military bases and to police stations.

Two primary justifications exist for public provision of services. First, a service might not be privately provided because of the practical impossibility of a private seller preventing nonpayers from benefiting from the service. If nonpayers would automatically receive a service, no one but a public-spirited person would buy it, so that a private seller could not profit from offering it. A classic example is national defense. If a private company attempted to sell the service of national defense, which would be provided to the whole country, a self-interested person would rationally refuse to make a purchase, realizing that he would benefit from national defense even if he did not pay for it. A lighthouse, or more precisely, the navigational aid its lights furnish, is also a stock example of a service that must be publicly supplied. The argument is that it would be impossible for a private owner of a lighthouse to provide a light only to those ships that paid for it -- all ships will see a light from a lighthouse, so none would voluntarily pay for what they will see in any event. Hence, the market would not be expected to supply lighthouses. ${ }^{179}$

The other justification for public provision of a service does not concern the difficulty of excluding nonpayers from the receiving a service, but rather positive external effects associated with its purchase. Restricting use of libraries or schools to payers, or restricting immunizations to payers, would not be difficult, but if these services were privately provided, people would not be willing to offer as much for them as they are worth to society when they create beneficial external effects. For example, when a person receives an immunization against a communicable disease, he not only does himself good but he also does others good, because he will not spread the disease to them. What the person would be willing to pay for an immunization, however, will reflect only his personal benefit, and he might not purchase an immunization when, socially, it would be desirable that he do so. Similar arguments apply for education generally, including libraries, since there are various spillover benefits from receipt of an education; society profits from having an educated populace. When individuals value services at less than their social value, the privately sold quantity of the services will be undesirably low, and thus there is an argument for their public provision, or for subsidy of their purchase.

\footnotetext{
${ }^{179}$ A change in technology can alter this conclusion. Suppose that the warnings provided by electronic "lighthouses" could be furnished by devices that send out scrambled electronic warning signals that can be received aboard ship by those who pay for unscramblers. Then a private supplier of warning signals might develop, because it could charge for its services.
} 
Both of these justifications are applicable with respect to some services. Consider, for example, fire protection. Although it would be possible for a fire protection company to limit its services to payers, a company might decide to put out a nonpayer's fire in order to prevent its spread to payers' property, and fear of public outrage for allowing a fire to burn might also lead a company to extinguish a nonpayer's fire. Thus, individuals might rationally believe that they would benefit from fire protection services even if they do not pay for it. This point aside, the motive of a person to purchase fire protection services will only be to put out his own fires; he will not take into account the benefit he will provide to others by reducing the likelihood that he will have a fire that spreads. For these reasons, many might decide not to purchase fire protection service despite its social value, and this weakness in market demand may warrant its public supply. (These justifications are roughly consistent with the history of fire fighting in England, where private fire protection service was replaced by public service. ${ }^{180}$ ) Similar arguments can be made for the services of police. In particular, private police would have a reason to catch criminals who are about to victimize nonpayers, in order to prevent the criminals from later harming payers; and the motive of a person to purchase crime protection will not reflect the associated crime reduction benefits to others. In consequence, the private demand for police service might be weaker than is socially appropriate, justifying its public provision. ${ }^{181}$

A qualifying remark should be made about the arguments in this section rationalizing public provision of certain services (and therefore the public need for associated property). While the private market would not be expected to supply various services, or to supply them in adequate quantity, this does not imply that the public needs to provide them directly. The public can pay a private company to do that; for example, it can pay a private company to supply fire protection services. Such private provision of public services might be more efficient than direct public provision for various reasons, including the superior ability of private companies to dismiss employees for incompetence. (Note that this publicly-financed private provision of services should not be confused with true private provision of services, that is, private provision financed by private sale in the market. ${ }^{182}$ )

\subsection{Public property acquired by conquest or by purchase from other}

countries. Another category of public property is undeveloped land obtained by conquest or by purchase from another state. There are arguments why such property

\footnotetext{
${ }^{180}$ See Eyre and Hadfield 1945 and Evans 1967. In the United States, fire fighting was originally accomplished by volunteer organizations, and the history whereby fire fighting became public is different; on this, see McChesney 1986.

${ }^{181}$ The arguments concerning public versus private provision of police services involve a number of factors beyond those sketched here; for further discussion, see sec. 2.4 of chap. 25.

${ }^{182}$ An example of such confusion concerns lighthouses. Coase 1974 emphasized that lighthouses in England were generally provided by private parties in much of the eighteenth and nineteenth centuries. This has been interpreted by many as an example of direct private provision of lighthouses, but that is mistaken. The only reason that the lighthouses were provided by private parties is that the Crown forced ships that came into port to pay a fees to lighthouse owners. In other words, private providers were unable to charge fees for lighthouse services themselves and needed the power of the state to accomplish that crucial function. On this point, see Van Zandt 1993.
} 
originally should be owned by the state. In brief, this is to prevent a wasteful rush by private parties to acquire the land. ${ }^{183}$ However, public property acquired by the state through conquest or purchase should, over time, be sold or given over to private use, unless it has a valid public purpose as described above.

In some countries today, there is much public land that the state owns that falls into this category. Vast land areas in the western United States and most of Alaska are residues of conquest and purchase, ${ }^{184}$ and the same is true in Brazil. Also, the point may be relevant for extraterrestrial bodies in the future.

Notes on the literature. The notion that the government ought to own certain property and supply certain services has been developed over the years, but was first given clear expression by Samuelson (1954) along the lines discussed here. For a history of the concept of public goods, see Musgrave (1985); for an accessible textbook exposition of the theory of public goods, see Stiglitz (1986), and for a survey of the theory, see Oakland (1987).

\section{Acquisition of Property by the State: By Purchase and by Power of Eminent Domain}

2.1 In general. Acquisition of property by the state occurs because the state will sometimes need new property for the purposes discussed in the preceding sections. The state can either simply purchase property from private holders, or else the state can possess a legal right to take it -- the power of eminent domain -- and I will discuss when it is socially beneficial for the state to have that power. If the state has the power to take property, a subsidiary question then arises as to whether the state should be required to pay compensation; I will also address this question in what follows.

2.2 The state will need to acquire property from time to time. As has been discussed above, certain property ought to be public. Some of the property that ought to be public is known ab initio: The state knows from the start that rivers, airspace, natural wonders (the geysers at Yellowstone National Park) ought to be public; thus there is no need, or no recurring need, for the state to acquire additional property on this account. But the requirements of the state for roads, schools, libraries, and the like, will vary and are in important respects unpredictable. For that reason, there will be a continuing need for the state to acquire property from private parties. Of necessity, therefore, the question arises as to how the state should acquire such property.

2.3 Acquisition of property by the state through purchase. When property is socially desirable for the state to acquire, one would usually expect the state to be able to purchase it. However, in some circumstances problems in bargaining may stymie or at least delay purchase of property by the state when its acquisition is socially desirable. In particular, because the state generally will not know precisely how much a private owner values his property, it may offer him too little for the property; or because a private holder of property generally will not know exactly how much the state is willing to pay,

\footnotetext{
${ }^{183}$ On this general subject, see for example Anderson and Hill 1990.

${ }^{184}$ In 1999, 27.7 per cent of land in the United States was owned by the Federal Government; 82.9 per cent of land in Nevada, and 62.4 per cent of land in Alaska was similarly held; see Statistical Abstract of the United States 2001, 209.
} 
he may hold out for more than the state is willing to pay. The possibility of such breakdowns in bargaining is not special to transactions involving the state, however -- it is an aspect of virtually all trade - so this alone does not furnish a justification for the state to enjoy the power to take.

However, the problem of an impasse in bargaining may become severe when there are many private owners who own parcels and when, if any one of them does not sell, the whole project would be seriously affected or halted. In the building of a road, for example, the ability of essentially any individual on its planned path to prevent the project from going forward could cause serious bargaining problems for a government agency that must acquire land through purchases. ${ }^{185}$

An additional problem that can prevent a bargain from being consummated when it is socially best for property to be acquired by the state is that no mutually agreeable price may exist. For example, a person might hold a sentimental attachment to his land, have sufficient wealth to meet his needs, and be unwilling to sell the land for any price that the state is willing to offer. ${ }^{186}$

Apart from these problems, two other factors must be assessed in considering the policy of state acquistion through purchases. One is transaction costs; these can be of substantial significance when there are many private owners with whom the state must deal. The other factor is that the state must raise funds for purchases through taxation, which involves administrative costs and distorts private behavior.

\subsection{Acquisition of property through exercise of eminent domain power} compared to acquisition by purchase. What differences exist between a regime in which the state has power to take property and one in which the state must purchase property that it desires? First, the problems in bargaining that can prevent or delay consummation of purchase of property are avoided when the state can appropriate property. If the state wants to assemble land to build a road, it can simply take the land; it need not bargain with the many owners to acquire the land and face delay or unwillingness to sell. This is a primary advantage of the use of eminent domain powers over acquisition by purchase.

\footnotetext{
${ }^{185}$ In some cases, such problems could be alleviated by secret purchases by the government agency, in much the way that private parties manage to assemble large parcels (such as for a shopping center) through purchases made by agents who do not reveal the identity or purpose of the buyer of the parcels. However, government is often unable to keep its plans quiet (indeed, the plans may have come about through a public decisionmaking process), and if so, the secret purchase option is not feasible.

${ }^{186}$ To be specific, suppose that the utility of land to a person is $v$,and the utility he derives from wealth $y$ is $u(y)$, where $u$ is increasing in $y$ but at a decreasing rate. Let $w$ be the (for simplicity) monetary value of the person's land to the state (that is, $w$ is the sum of values to individuals who will use the land, say for a library). If $w>v$, it is socially desirable (under a sum-of-utilities social welfare function) for the land to be used by the state. However, because the landowner's utility from money $u$ does not rise linearly with the amount of money, there may not exist a price the state is willing to pay sufficient to induce the owner to sell, that is, $u(y)$ may be bounded below $v$. (Indeed, because the expected utility theorem implies that utility must be bounded (see, for example, Arrow 1971), this is clearly possible.) The point, in essence, is that the increase in utility that receipt of money in payment for the property can bring is limited, and may be less than the utility of the property itself to the person. Hence, even though the value of the person's land to society may be large, exceeding its utility to the person, there is no price that can be offered that will induce him to sell his land.
} 
But second, whether consideration of transaction costs favors eminent domain or acquisition by purchase is not clear. The cost of eminent domain proceedings could be imagined to exceed that of purchases, especially if the state is required to determine private values and to compensate property owners for takings. Yet the cost of takings could readily be lower than that of purchases. Suppose, for example, that an eminent domain proceeding that allows the state to lay a water pipe under peoples' land is quickly done and determines their compensation according to a simple formula (or that they do not even receive compensation). If the state had to purchase these rights to lay pipe, the transaction costs would be much larger, perhaps prohibitive.

Third, the relevance of the state's costs of raising funds to acquire property depends on the circumstances. If the state must pay compensation when it takes property, then the implicit cost of raising funds through taxation will be borne under both regimes. If, though, the presumption is that the state will not compensate for takings, then eminent domain enjoys a cost advantage over acquisition by purchase.

Fourth, the possibility of undesirable state acquisition of property arises when it has eminent domain powers but not when it must acquire property through purchase. The state might underestimate the private value of property and take it when its true private value exceeds its value to the public. ${ }^{187}$ This type of socially undesirable outcome could not occur if the state must acquire property by purchasing it, as a private owner will not accept an offer that is less than his value. ${ }^{188}$

\subsection{Eminent domain power may be justified by the problems with state} purchase. The rationale for eminent domain follows from the comparison just made. Eminent domain may be warranted by the advantage of avoidance of the bargaining

\footnotetext{
${ }^{187}$ The state might also take property that it ought not because its incentives to take are socially undesirable; on this issue, see section 2.7.

${ }^{188}$ To amplify on the comparison between a regime of takings without compensation and a regime of purchase, taking into account the factors in the last two paragraphs, suppose that property owned by riskneutral private parties sometimes has positive value to the state and that the state contemplates acquiring it. Let $v$ be the value of a property to its owner, $f(v)$ be the density of $v$ across the population of owners, where $v$ is in $[0, \mathrm{~m}]$, and $w$ be the value of the property to the state. Assume that the state does not know $v$ in a particular case but does know the distribution $f$ of $v$. Social welfare is the value of the property to whomever uses it, the state or the private party, less any costs of raising funds needed by the state to make payments; the costs of funds are assumed to be " per dollar, where " $>0$.

Under a regime of takings without compensation, the state will take a property if and only if $w>$ $\mathrm{E}(v)$, for that is when a taking would raise expected social welfare. (E is the expectation operator.)

Under a system of purchase, suppose for simplicity that the state makes a single offer $x$ to a party, which he accepts or rejects. Social welfare as a function of $x$ is $F(x)(w ! " x)+\mathrm{I}_{\mathrm{x}}{ }^{\mathrm{m}} v f(v) d v$, for an offer is accepted when $v \leq x$. ( $F$ is the cumulative distribution of $f$.) The first order condition determining the optimal $x$ is $f(x)(w ! " x)$ ! " $F(x) ! x f(x)=0$, or $x=w /(1+")$ ! " $F /[f(1+")]<w$. Thus, were there no cost of funds $("=0)$, the optimal offer of the state would be $w$, since then all who valued the property less than the state would sell it; but since there is a cost of funds, the state shades down the offer.

Either takings without compensation or a regime of purchase could be superior to the other. For example, if the state is certain that $w$ exceeds $v$ for all possible $v$, it will take under a regime of takings and social welfare will be first best. But under a regime of purchase, its offer might be refused, and if accepted involves the social cost " $x$, so that social welfare will not be first best. If, though, $w$ is less than many $v$, even though it exceeds $\mathrm{E}(v)$, the government would take under a regime of takings and social welfare would be $w$ ! $\mathrm{E}(v)$. Yet social welfare might be higher under a regime of purchase: As " tends to 0 , the state's optimal bid tends to $w$, and social welfare tends to the first best level, $\mathrm{E}(\max (w, v))$.
} 
problems associated with purchase, and possibly by transaction cost savings. Such advantages must, however, outweigh the disadvantage that the state may mistakenly take property too often. Moreover, if the state is required to pay compensation when it exercises its power of eminent domain, then it will bear implicit costs of financing similar to those that it incurs when it must raise funds to purchase property. In any case, let us now assume that eminent domain power is warranted and consider whether the state should pay compensation for property that it takes.

2.6 Risk-averse individuals' desire for compensation for losses is not a reason for the state to pay compensation for the property that it takes. Does the risk aversion of individuals argue for government payment of compensation for takings? In a society like ours with highly developed insurance markets, the desire of risk-averse individuals to have an arrangement under which they would be compensated for losses can be satisfied by their purchase of insurance coverage against takings by the state. There is no need for the state to insure individuals against takings by paying them compensation.

Indeed, one can see that, other things being equal, there is an equivalence between the state paying compensation in the event of takings and individuals purchasing insurance against uncompensated takings. Suppose that individuals face a one-tenth of a percent risk of their property being taken by the state, and that the property that might be taken is worth $\$ 100,000$. The fair premium for private insurance against a taking would then be $\$ 100$. But if the state pays compensation for takings, it will have to impose higher taxes to finance its takings, and the increase in the tax burden necessary to do that will be the same as the insurance premium, $\$ 100$. Hence, through payment of higher taxes to finance compensation for takings, individuals must implicitly pay exactly the premium they would be charged for private insurance coverage against takings. Thus, given the existence of well-functioning insurance markets, the social need for risk averse individuals to be compensated against loss does not imply that the state should pay compensation if it takes property; a regime in which private parties purchase insurance coverage would be essentially the same as one of state payment of compensation.

Of course, insurance markets may be subject to various problems, notably moral hazard (individuals insured against takings might have little reason to challenge them, raising the risk of excessive takings). But these problems do not seem to be substantially more serious with respect to the risk of takings than with respect to many other risks for which insurance is sold (for instance, that of fire). Further, even if the problems would reduce the amount of coverage sold in a private market, that would not justify provision of coverage by the state unless the state enjoyed an advantage over insurance companies in combatting the problems. ${ }^{189}$

\footnotetext{
${ }^{189}$ For example, suppose the problem that insured individuals would not resist takings would so much raise their frequency that the insurance would not be sold, because premiums would be more expensive than is worthwhile. Then if the state were to pay compensation for takings, one would suppose that individuals would be equally lax about resisting takings, so that the implicit insurance premium (in the form of taxes to finance takings) would be as high as the insurance premium would be. Hence, the lack of a market for insurance would imply that the state should not pay compensation for takings, rather than justify that. Blume and Rubinfeld 1984 suggest that problems with insurance markets might warrant payment of compensation as implicit insurance; but their argument appears problematic, or at least incomplete, for essentially the reasons expressed in this note. Also, Michelman 1967, 1217, offers the argument that the risks associated with takings are systematic and would not be insured by private insurers, so that the government must compensate for them. This argument, however, appears unpersuasive, at least because the
} 


\subsection{Payment of compensation, administrative costs, and costs of raising}

funds. If the state pays compensation, two categories of cost are incurred: first, the administrative costs and distortions associated with taxation, and second, the administrative costs incurred in connection with the compensation process itself. In considering these latter costs, bear in mind that if the state does not compensate for takings and individuals purchase insurance, there will be administrative costs associated with the collection of insurance premiums, the settling of claims by insurers, and the state's determination of when a taking is appropriate. One suspects that these insurancerelated administrative costs would be lower than those of the state under a regime of compensation, for the process by which the state determines the amount of compensation is likely to be more cumbersome than insurers' procedures.

2.8 Payment of compensation and the state's incentives to take property. To this point it has been assumed that the state's motive to take property is socially correct, but in reality, of course, that may not be the case. In this regard, it is often asserted that if the state must pay for property that it takes, the frequency with which the state takes might be altered in a beneficial direction. Why might the state's motive to take property be socially inappropriate if it does not have to pay compensation for takings? Several answers are advanced: Those who are in control may wield their power to take to punish political opponents; individuals working for the state may benefit from taking property because their salary and status may increase as the scope of their activities broadens or because they may enjoy the sheer exercise of authority; individuals working for the state may be bribed in some fashion by firms seeking profit from contracts to carry out public projects (such as road construction). If for such reasons the state's motive to take property would be excessive without a requirement to pay compensation, then a payment requirement might be thought to serve as a beneficial check on takings.

This argument, however, may be challenged on various grounds. First, perhaps the state's motive to take would not be excessive in the absence of a requirement to pay compensation. For example, individuals who work for the state might be overly cautious bureaucrats. If there is too little incentive for the state to exercise its powers of eminent domain even when it does not pay compensation, requiring the state to pay compensation would only exacerbate a problem of too little government activity. Second, supposing again that there would be a problem of excessive incentives to take in the absence of payment of compensation, one might question the degree to which payment would reduce takings: After all, the state may be able to raise taxes to finance takings, and in any case, the individuals who make decisions whether or not to take property may themselves not be much affected by the state's compensatory disbursements. Third, if compensation is paid for takings, then victims of takings will have less reason to resist them, so that a problem of excessive takings could arise because of the practice of paying compensation.

In a different vein, it is worth observing that the argument that compensation for takings is necessary to induce government to behave better is in some tension with our attitude toward government behavior outside of the domain of takings: We see no general call for government to pay for the negative consequences of its actions, even though

reasons for takings seem many and varied, no more correlated with each other than many risks that are covered by the private market. For criticism of the notion that government is a superior insurer against the risk of takings, see generally Kaplow 1986a, 533-42. 
enactment of virtually any regulation or law will disadvantage some persons. One presumes that the reason that there is no overall policy for government to compensate for the losses its regulations cause is that we believe that, on one hand, government's motives are in a rough but acceptable sense to advance social welfare and, on the other hand, that making government pay for negative consequences would not clearly cure incentive problems that exist. Thus, it needs to be explained why making government pay is of particular advantage in securing better government behavior in the context of its exercise of eminent domain powers. ${ }^{190}$

\subsection{Payment of compensation and individuals' excessive incentives to invest} in improvements of property. If the state pays compensation when it takes property, individuals may have a socially undesirable and excessive incentive to invest in improving their property. Suppose that there is a probability of 40 per cent that a person's land will be taken for the purpose of building a road and that, if taken, anything built on the land would be destroyed. Then this probability ought to be accounted for in deciding whether to invest in improving the land: If the land is taken, the investment will turn out to be a social waste. For instance, suppose the person contemplates an investment, say adding a porch, that will increase the value of his home by $\$ 10,000$. Then the expected social value of the investment in the porch is only $\$ 6,000$ (as 60 per cent is the probability that his land will not be taken), rather than $\$ 10,000$, and it would be socially appropriate for him to build the porch only if the cost is less than $\$ 6,000$. But if the person would be compensated for the value of his property in the event of a taking, he would decide whether to proceed with the investment in the porch without taking into account the probability of its being wasted. To him, the payoff to the investment would be certain -- if his land is not taken, he benefits from the investment in the porch by $\$ 10,000$, and if the land is taken, he benefits equally because of the $\$ 10,000$ of additional compensation he will be paid by the state. Thus, he would be led to make the investment in the porch as long as his cost is less than $\$ 10,000$. If the cost exceeded $\$ 6,000$ but were less than $\$ 10,000$, say if it were $\$ 8,000$, he would make the investment even though, socially, that would be undesirable. ${ }^{191}$

\footnotetext{
${ }^{190}$ On the issue of how the compensation requirement may affect the incentives of the state to take, see, for example, Farber 1992, and see the general discussion and references cited in Kaplow 1986a, 566-75.

${ }^{191}$ Let $z$ be the investment a risk-neutral party makes in property and $v(z)$ its value given $z$, where $v^{\prime}(z)>$ 0 and $v^{\prime \prime}(z)<0$. Assume that with probability $p$, the property will have value $w$ to the state, where $w>v(z)$ (for simplicity, whatever is $z$ ), so that it will be desirable for the state to take the property. The socially optimal investment $z^{*}$ is the $z$ that maximizes $(1 ! p) v(z)+p w ! z$ (note that the value of $z$ is wasted with probability $p)$; thus $z^{*}$ is determined by $\quad(1 ! p) v^{\prime}(z)=1$. Now observe several points. (a) If there are takings without compensation, the party will maximize $(1 ! p) v(z) ! z$, so he will choose $z^{*}$. (Also, if parties are risk averse and insure, a person will choose $z^{*}$ : The premium will be $p v(z)$, so he will maximize $v(z) ! p v(z) ! z$.) (b) If there are takings with compensation of $v(z)$, a party will maximize $v(z)-z$, as he will either obtain $v(z)$ if there is not a taking or will receive $v(z)$ as compensation if there is a taking. Hence, he will choose $z$ determined by $v^{\prime}(z)=1$, so will choose $z^{* *}>z^{*}$ (because $\left.v^{\prime \prime}(z)<0\right)$. The reason that $z^{* *}>z^{*}$ is, as emphasized in the text, that the party treats the investment in his property as one with a sure payoff even though, socially, its payoff is uncertain. (c) If there is acquisition by purchase, the outcome is similar to that when there is compensation of $v(z)$, for the state will have to pay at least $v(z)$ to induce the owner to sell. These points were first developed in Blume, Rubinfeld, and Shapiro 1984.
} 
This problem could be combatted by the state if it recognized that the person's investment was excessive under the circumstances. If the state knew that the value of the investment in the porch, discounted by the likelihood it would be a waste, did not justify its $\$ 8,000$ cost, then the state could refuse to pay additional compensation for the porch. The state could adopt the policy of paying only for the unimproved value of property, and thus remove the incentive to improve property inappropriately. However, the state would not always have the information needed to do this successfully. ${ }^{192}$

In the absence of payment of compensation by the state, there would be no problem with individuals' incentives to improve property. If individuals do not purchase insurance, this is obvious. A person would balance the cost of an improvement against the benefit, discounted by the probability that his property would be taken. Since he would suffer any loss due to a taking, he would properly take the likelihood of loss into account and not overinvest. On reflection, it can be seen that the same would be true if the person insured against a taking, for his insurance premium would rise if he improved his property and increased his coverage. In the example, if he improves his property by $\$ 10,000$ and the likelihood of a taking is 40 per cent, then his premium would rise by $\$ 4,000$. Thus, he would obtain a net gain of $\$ 6,000$ by making the investment, and he would thus make the investment only if the cost was less than $\$ 6,000$, as is socially appropriate.

\subsection{Comments on incentives to invest. (a) Limited practical importance of the} excessive incentive to invest when government compensates for takings. The importance of individuals' excessive incentives to invest in property due to payment of compensation for takings is often probably quite small, because the likelihood of takings is, for most property, insignificant and thus unlikely to figure in most investment decisions. One would imagine that, usually, property that is likely to be taken would be so identified only for a short period, during which few investments would be made.

(b) The mistaken notion that compensation is needed to support investor expectations. Some commentators and jurists find that fulfilling investors' expectations about their property interests is a justification for the state to pay compensation. ${ }^{193}$ But, as just explained in the previous section, giving owners the expectation that their investments will pay off when there is a taking is socially disadvantageous because it creates socially perverse incentives (even if they are small in magnitude) to invest in property when such investments will be wasted. It is, in other words, socially undesirable to prop up these expectations. ${ }^{194}$

\footnotetext{
${ }^{192}$ To be precise (and continuing from the previous note), assume that compensation equals a constant $k$, regardless of the actual $v(z)$. Then $z$ will be chosen optimally: Parties will maximize $(1 ! p) v(z)+p k ! z$, so that the first-order condition determining $z$ will be the optimal one. The constant $k$ could in fact be set equal to $v\left(z^{*}\right)$-- or an estimate of that. Thus, it is not payment of compensation for takings, but rather the linkage of compensation to the improved value of property, that creates excessive incentives to invest.

${ }^{193}$ See, for example, Jones 1995, 7-8, and Michelman 1967, 1208-13, discussing this view. A number of commentators have criticized the argument about investor expectations on the ground of its circularity: There will be no expectation of investment returns if it is announced by the state that it will not compensate for takings; see, for example, Graetz 1985, 1823, Kaplow 1986a, 522-23, and Levmore 1993, 288.

${ }^{194}$ The point reviewed here, note, is that it is undesirable to compensate because this will lead to excessive investment given the probability of takings. A different point that could justify the compensation
} 
(c) Qualification -- when private investment is not rendered a waste by a taking. The argument that payment of compensation leads to socially excessive investment depends on the assumption that, after a taking, investments made by private parties turn out to be a social waste, such as the addition of a porch on a home that will be leveled to make way for a road. But if the house would be used by the state for some purpose, then the porch would have social value after the taking. In that situation, payment of compensation would lead to proper investment, and failure to pay compensation would lead to underinvestment.

\subsection{Compensation for takings; factors favoring and disfavoring}

summarized. Our discussion concerning whether the state should be required to pay compensation for takings may be summarized as follows. First, favoring payment of compensation, is that payment may serve as a check on excessive takings. This point was significantly qualified, though, by questions concerning whether the actual incentives of the state to take are excessive and by related issues. Second, and working against payment of compensation, were higher administrative costs, the implicit costs of raising funds through taxation, and the potential for individuals to overinvest in their property.

2.12 Comment on actions by the state that affect property values even though they are not complete takings. The state may sometimes act in ways that affect the value of property to an individual. For example, the state may build a school near a person's property and thereby lower its value to him, perhaps because of noise, or because there is interference with the view from the property. Or the state may pass regulations affecting the value of property, for example a regulation requiring expensive measures to prevent soil erosion, lowering the value of land. (Such an outcome is sometimes referred to as a regulatory taking.)

In these cases, the state is not engaging in a complete taking, that is, it is not appropriating the entire bundle of property rights that a person has in a thing. The state is, however, taking particular property rights, and the analysis that has been presented above may be applied to these particular property rights. Consider first the issue concerning whether the state needs to take property, rather than to acquire it through purchase. It was noted above that a primary advantage of allowing the state to take property was that this would prevent breakdowns in bargaining over purchase. Such breakdowns would seem likely to arise in certain contexts but not obviously in others. In the case of building a school, the number of individuals who would be affected in relevant ways (such as by noise) would typically be large. Accordingly, were the state to have to purchase the necessary property rights from all these individuals, the likelihood is substantial that some of them would refuse to sell and prevent the school from being built. However, in the case of a regulation requiring measures to prevent soil erosion, the situation seems different, because failure to conclude a bargain with an individual farmer does not imply that the whole prevention project would be compromised. The state could therefore be imagined to bargain with each individual farmer and purchase the rights to make him engage in practices to prevent soil erosion, rather than to mandate it by regulation.

Now consider the question of whether the state should pay compensation if it has the power to take certain property rights. It appears that the administrative costs of paying

requirement is, of course, that the requirement would discourage a state with imperfect incentives from taking property when it ought not, as discussed in section 2.8 . 
compensation would sometimes be relatively high in relation to the losses involved, due to the numbers of individuals who could claim some type of loss (some type of disturbance from the presence of the school) and the often modest nature of the loss. This problem might also sometimes be important in the regulatory context as well, if the cost of determining compensation would be high relative to the probable importance of the regulation.

In sum, it seems that in certain examples of government actions that may be regarded as implicit takings of property rights without compensation, the analysis of takings indicates that it is rational for the government to act in this manner (as with the building of the school). In other examples, it is not clear that present policy is desirable. In any case, the main point is that one can analyze the government's actions using the framework described above.

2.13 The law. The government enjoys a general right to take property in the United States when the taking is for a public use as long as it pays "just compensation," and the law is similar in other countries. ${ }^{195}$ There is some uncertainty and debate, however, concerning the borderlines of this right and the obligation to pay compensation, notably, over what constitutes a public use. (If the government plans to sell the land it takes to a private corporation that will hire the unemployed, would that be a public use?) When government regulation and other government actions that are not complete takings (see the previous section) lower property value, they are deemed takings for which compensation is due only in limited circumstances. ${ }^{196}$ Note on the literature. The major economic analyses of takings are Blume, Rubinfeld, and Shapiro (1984), focusing on the effects of compensation on incentives to improve property and first emphasizing that compensation may lead to overinvestment in property, and Kaplow (1986a), a synthetic, general article stressing that government compensation not only may lead to overinvestment but also that the private market can supply insurance against government takings. ${ }^{197}$

\footnotetext{
${ }^{195}$ On the law of takings in the United States, see generally Sackman 2000, and see also Nowak and Rotunda 2000, sect. 11.12; on the law in other countries, see, for example, Garner 1975 and Van der Walt 1999. On the history of takings, see for example Bosselman, Callies, and Banta 1973, chap. 6.

${ }^{196}$ See, for example, Stoebuck and Whitman 2000, 524-45.

${ }^{197}$ The economic literature is surveyed in Miceli and Segerson 2000. It includes Blume and Rubinfeld 1984, Epstein 1985, Farber 1992, Hermalin 1995, Knetsch and Borcherding 1979, Merrill 1986, Munch 1976, and Quinn and Trebilcock 1982; see also Fischel 1995, Miceli and Segerson 1996, 1998 on regulatory takings. A number of earlier articles on takings that have significant economic and policyanalytic dimensions include Baxter and Altree 1972, Berger 1974, Michelman 1967 (which was particularly influential), and Sax 1971.
} 


\section{Chapter 12}

\section{PROPERTY RIGHTS IN INFORMATION}

In this chapter I will discuss the generation and the subsequent use of information, as well as the extent to which each is promoted in a socially desirable way by property rights in information. By property rights in information, I refer, of course, to patent, copyright, and trademark law, and I include also trade secret law and closely related aspects of contract law and tort law. For convenience, I will sometimes speak of information in the abstract, but other times I will refer to embodiments of information in goods and services, and to particular forms of expression of information, notably, the spoken word, printed matter, and broadcasts and recordings in electronic media.

The chapter is divided into three major parts. The first part will examine information of repeat value: information that is useful for producing multiple units of things. The words of a book, for example, are of repeat value, as the book can be printed over and over, and the design of a new device is of repeat value, as multiple units of the device can be made with the design. The second part of the chapter will briefly consider various other types of information. For example, I will discuss information that can be used only once (such as information about the location of an oil deposit). The last part of the chapter will deal with information that possesses value as a label signifying characteristics of a good or service; logos, product packaging, and brand names illustrate this species of information.

\section{Information of Repeat Value}

1.1 In general. The social value of information often exceeds its cost of development, making it socially desirable to generate. If, however, information can be copied at low cost by anyone who comes to possess it, the person who first develops information will not be able to sell it to very many buyers: Any buyer will be able to disseminate or resell the information himself. As a consequence, the reward to a person who creates information will tend to be less, perhaps substantially less, than its social value. The development of information will therefore be undesirably retarded, other things being equal.

To spur the generation of information, the state can grant property rights in it. If the creator of information is granted an exclusive right to sell the goods embodying it, he will enjoy super-competitive profits, and the prospect of such profits may encourage effort to produce information in the first place. Thus, property rights in information may be a socially valuable institution.

Yet the granting of property rights has a socially disadvantageous consequence: Too little of the goods embodying information will be produced, because those who hold property rights will be able to charge a price exceeding production cost of the goods. To ameliorate this problem (and others to be noted), property rights in information may be limited in various ways.

An alternative to property rights in information is a system of state rewards paid to the creators of information. The rewards provide a stimulus to creation of information. And because the creator of information does not gain property rights in information under 
the reward system, the goods embodying information will tend to sell at competitive prices and the level of production will thus be superior to that when creators possess property rights in information. Nevertheless, there are problematic features of reward systems.

Let me now amplify these points, beginning with a consideration of the socially desirable generation and use of information.

1.2 Socially ideal use of information that exists. How should information be used once it has been developed? Clearly, in the ideal, a good embodying information should be produced and obtained by a person whenever that would enhance social welfare, that is, whenever the value of the good to him exceeds its production cost. ${ }^{198}$ Thus, a new device should be produced for any person who values it more highly than its cost of manufacture: A book should be printed for anyone who values it more highly than its printing cost; computer software should be made available to any individual who values it more highly than the cost of the disk on which the software is recorded (or the even lower cost -- essentially zero -- of downloading the software from the Internet).

1.3 Social value of information. The social value of information is the amount by which it will raise social welfare for the entire group of individuals who obtain the good embodying the information. The optimal social value of information is its social value when the good is optimally produced, that is, produced for each and every individual who values it more highly than its production cost. For example, suppose that each of 1,000 people value a book at 10 , and its printing cost is 4 . Then the book should be produced for each of these people, and the optimal social value of the book is therefore $6,000 .^{199}$

1.4 Socially ideal creation of information. Given the optimal social value of information, it is evident how we should determine the socially ideal generation of information. Information should be created if and only if its development cost ${ }^{200}$ is lower than its optimal social value. If the book just mentioned can be written by the author at a cost of less than 6,000 , then it is optimal for it to be written, but not otherwise. ${ }^{201}$

\footnotetext{
${ }^{198}$ In this chapter I generally employ the usual criterion of social welfare: the sum of utilities obtained from goods minus costs associated with production, minus costs of developing information, minus certain other costs, notably those of law enforcement.

${ }^{199}$ In this example, the information allows production of a new good, namely, a new book. Another possibility is that the information constitutes a so-called process innovation, that is, it allows an existing good to be more cheaply produced. Suppose in the numerical example that the process innovation lowers printing costs from 4 to 3 per book, saving 1 per book. Then the optimal social value of the information would be 1,000 . More generally, the increase in social welfare associated with a process innovation equals the reduction in production cost per unit multiplied by the number of units presently produced, plus an amount reflecting the welfare gained by individuals for whom it is now optimal to produce because of the reduction in the production costs (there were no such individuals in the numerical example). For expositional simplicity, I will refer in the text mainly to information allowing production of new goods, not to process innovations.

${ }^{200}$ For simplicity, assume the development cost is known in advance.

${ }^{201}$ If, however, the social value of the book would be less than optimal -- because the production level of the book would be less than optimal -- then it would be desirable for the book to be written only when the cost of so doing is less than this suboptimal value the book would have.
} 


\subsection{Use of created information in the absence of property rights: tends}

toward the optimal. In the absence of property rights in information, once information is released by a party who possesses it, goods embodying the information will tend to become available at their production cost, and thus the level of production of the goods will tend toward the socially optimal. If there were no property rights in books, then any printer could obtain a copy of a book and reproduce it. Assuming that there would be competition among book producers, the price of books would reflect production costs alone and thus the book would become available for purchase at this cost. Hence, anyone who valued the book above production cost would purchase it, so that the number of books printed would be optimal.

\subsection{Creation of information in the absence of property rights: tends to be} inadequate. In the absence of property rights in information, the reward to a creator of information will be lower than the social value of the information because goods embodying information will, as just discussed, tend to sell at prices reflecting their production cost alone. Indeed, if this is literally the case, a potential creator of information would not anticipate any profits and thus would have no incentive to develop information.

\subsection{Qualification: It may be time-consuming or impossible to copy} information. As a general matter, it will take time for competitors to copy the information and produce goods like that of the creator, and in the interim the creator can make profits. For a book, which is easily copied, the time during which the creator can obtain profits may be short, but for products that require engineering and a substantial manufacturing process to produce, the creator may enjoy a relative monopoly position for a significant period. In some cases the information necessary to reproduce a good may be so hard to deduce from the good itself that the creator will enjoy a monopoly position for an extended time. For instance, it may be very difficult to duplicate a food product (as is apparently the case with Coca Cola, which for more than 100 years has not been copied even though there is no patent held in $\mathrm{it}^{202}$ ). Moreover, the creator of information will have an incentive to manufacture the good embodying it in such a way that it is difficult to copy.

1.8 Are property rights in information necessary to induce its creation? For the reasons just given, creators of information can frequently look forward to positive profits even in the absence of a system of property rights, raising questions about the need for property rights in order to induce a tolerably good degree of development of information. Some commentators have argued that, even in the case of books, the returns to being first to publish might be sufficient to result in a satisfactory amount of writing and publication. ${ }^{203}$ Although this belief about books is probably unduly sanguine, the

\footnotetext{
${ }^{202}$ Pendergrast 1993, 11, 421.

${ }^{203}$ See, for example, Hurt and Schuchman 1966 and Breyer 1970.These writers also emphasized that authors are induced to write to win recognition and esteem. However, such nonmonetary rewards would not motivate editors and publishers. For other skeptical reactions to the view that copyright is not needed, see, for instance, the discussion following Hurt and Schuchman's article, 435-38, and also Tyerman 1971. It may also be mentioned that after the French Revolution, copyright was eliminated, the publishing industry was thrown into economic turmoil due to pirating of works, and as a consequence copyright was reinstated; see Hesse 1989.
} 
point that in reality we could expect some substantial degree of creation of information in the absence of property rights protection is worthy of note. In this connection, it is relevant that, in historical terms, broad property rights protection in information is relatively recent (see section 1.15), and that some highly industrialized countries did not adopt patent law until the end of the nineteenth century. ${ }^{204}$

1.9 Property rights in information. Property rights in information are, of course, rights of parties to use certain information to produce goods or services and to prevent others from using the information in this way. There are three principal ways that the legal system accords parties property rights in information of repeat value: through patent law, dealing with novel products and processes; through copyright law, concerning original written and certain other types of works that can be copied; and through trade secret and associated law, barring such behavior as an employee divulging a manufacturing process to his employer's competitor. Although it will be seen from their description below (sections 1.15-1.17) that these forms of property rights are incomplete in a variety of respects, in the next several sections I will assume for simplicity that property rights are complete.

\subsection{Use of created information in the presence of property rights: tends to} be inadequate. When parties possess property rights in information, they will sell goods embodying the information at prices exceeding the cost of production, so that the level of purchases of the goods will be less than is socially desirable. If the holder of a copyright in a book that costs 4 to print charges 15 for it, then the number of copies printed will be socially inadequate, for individuals who would be willing to pay more than 4 for it, and thus should obtain it, will not purchase it if their valuation is below the sales price of 15 . The importance of this point depends on the magnitude of the difference between price and the cost of production. The social loss will be great when the difference is substantial, as for instance, is the case for patented pharmaceuticals selling at multiples of their cost of production, ${ }^{205}$ and for computer software for which prices are often $\$ 100$ or more but for which the cost of copying the software on a storage medium is nominal. ${ }^{206}$

\footnotetext{
${ }^{204}$ This was true of the Netherlands and Switzerland; see section 1.21. However, trade secret protection may have provided some intellectual property right protection in these countries; it should also be noted that they benefited from innovations developed abroad.

${ }^{205}$ For example, Scherer 1980, 450, notes that during a period in which Pfizer Corporation held a patent in tetracycline, a powerful antibiotic, it sold 100-capsule bottles to druggists for about $\$ 30$, whereas production cost ranged from $\$ 1.60$ to $\$ 3.80$. More generally, comparison of the prices of patented drugs to their prices when their patents expired and they became generic (and thus when their prices presumably approximated production cost) suggests that patent prices are often from 3 to 5 or more times production cost; see, for example, Berndt, Cockburn, and Griliches 1996 and Grabowski and Vernon 1992.

${ }^{206} \mathrm{~A}$ qualification to the point of this paragraph arises in the case of process innovations. The holder of a patent in a process innovation may well not be charging a monopoly price, for his product might be sold on a competitive market. However, there would still tend to be a disadvantage due to the patent in the innovation because other producers would not be able to use the innovation to lower their production costs. (It is true that the patent holder might license his process innovation to them. But then the price charged in the industry would be likely to exceed the social cost of production because it would reflect the licensing fee.) It should be added that if the process innovation lowered production cost sufficiently, the patent holder would become a monopolist; this would be so when his monopoly price, given his low cost of production, would be lower than the price competitors could charge given their higher costs. Thus, the conclusion that there will be disadvantages associated with property rights in information holds in the case
} 


\subsection{Creation of information given property rights: tends to exceed that in} the absence of property rights. Because parties who possess property rights can sell the goods embodying the information at prices above marginal cost, they will obtain positive profits from generating information, in contrast to the situation in the absence of property rights where goods sell at cost due to competition. Further, where positive profits can be made in the absence of property rights, for the reasons discussed above (see section 1.7), one would still expect creators of information to obtain greater profits if they possess property rights (the time period during which the creator would enjoy monopoly power would be longer, and the creator would not have to take costly steps to keep his innovation secret).

It may be noted, however, that property rights do not engender socially perfect incentives to create information, for monopoly profits will generally fall short of the full social value of products; sellers will typically be unable to identify and to extract from each buyer an amount equal to his particular valuation. Thus, the incentive to generate information is not socially ideal under property rights, even though it exceeds that in the absence of property rights.

1.12 Sale of property rights. Allowing parties to sell property rights in information enables them to enhance their profits, especially because the creator of information may be poorly situated to produce the good embodying the information. The author of a book will generally not be in the printing and publishing business, the inventor will sometimes not be able to produce the machine he has designed. Thus, the ability of authors and inventors to sell and license their intellectual works may significantly raise the profitability of creation of information. For this reason, and because it tends to lower production costs, allowing the sale of property rights is socially desirable, on the assumption that property rights are socially desirable in the first place.

1.13 Are property rights in information socially desirable? Whether property rights in information lead to a socially superior outcome depends on whether their advantage -- inducing greater development of information -- is more important than their disadvantage -- curtailment of the production of goods embodying information due to the high prices charged by holders of property rights. In the simple situation in which a financially-motivated creator of information would make virtually no profits because of the ease of reproducing the good embodying the information, the existence of property rights is unambiguously socially desirable: Property rights are necessary for there to be any incentive for information creation -- and it is simply a moot point that, were information generated in the absence of property rights, the level of production of the associated goods would be higher.

Realistically, though, creators of information can often obtain positive profits in the absence of property rights, so that there will be a positive incentive to produce information in the absence of property rights, meaning that the answer to the question of the social desirability of property rights in information becomes ambiguous. ${ }^{207}$

of process innovations, but differs in its details and reasoning from that in the cases of product innovations and copyrightable works.

\footnotetext{
${ }^{207}$ This ambiguity stands in contrast to the desirability of property rights in physical things (if we abstract from the cost of enforcing property rights). The reason for the difference is that allowing property rights in physical things does not lead in any automatic way to monopoly pricing of goods.
} 
Nevertheless, and perhaps with justification, economists tend to assert that the added incentive to generate information under property rights outweighs their drawbacks, at least in a broad sense. ${ }^{208}$

1.14 Additional issues concerning property rights in information. To round out our discussion, it is useful to consider a number of additional issues.

(a) Wasteful effort to create information due to the race to be first. Multiple parties who have the ability to generate information may each be induced to spend on development of the information in the hope of being the first to succeed and thus of obtaining property rights. But this race to be first may well be socially wasteful, for it may involve duplication of efforts as well as expenditures to speed development when the social value of earlier generation of information is small. ${ }^{209}$ Such problems can be mitigated if property rights are awarded early, notably, as soon as it is known that a party has worked out the essentials of an invention, without waiting for it to be refined; in this way, the period of the race and of duplicative effort can be truncated. ${ }^{210}$ Further, the race can sometimes be avoided: If the parties contemplating developing information know each others' identities and successfully contract to conduct a joint venture, they would not be competing but rather cooperating and thus would not duplicate efforts or spend excessively to complete their research earlier.

It should be observed, however, that the problem of the race to be first is of no relevance for copyrightable works. Under copyright law, unlike under patent, intellectual property rights are given to innovators who are not first: As long as a person independently creates a work, he will obtain a copyright in it even if others already have done so. ${ }^{211}$

(b) The duration of property rights. The duration of property rights is of interest because the longer the life of a patent or of a copyright, the greater the profits and thus the incentive to create information, but the greater also is the disadvantage due to excessive prices. As a general matter, the optimal length of property rights for a class of possible inventions is the minimum period necessary to induce invention, that is, the minimum period necessary to generate monopoly profits usually sufficient to cover development costs. This suggests that the desirable length of property rights should be higher the greater the development costs, other things being equal. There is, however, no

\footnotetext{
${ }^{208}$ However, there are many features of property rights that seem undesirable; for a broad discussion and cataloguing of these, see Scotchmer 1998.

${ }^{209}$ Suppose that by spending an additional $\$ 10,000$, a firm can develop an innovation a day earlier and therefore increase its likelihood of beating its competition and obtaining a patent worth $\$ 1,000,000$ by 10 percent. The firm would definitely spend the $\$ 10,000$, as the expected payoff from that would be $\$ 100,000$, yet the social value of having the innovation made a day earlier might be negligible.

${ }^{210}$ This point is a theme of Kitch 1977.

${ }^{211}$ See section 1.16 below. This aspect of copyright law, and the whole issue of the race to be first, would seem to be irrelevant in wide ranges of innovative activity, such as the writing of a book, for it is quite unlikely, if not impossible, that more than one individual would be attempting to author the very same book. However, as noted below in section 1.16, it is possible that more than one individual would take the same photograph, or arrive at the same basic musical composition, so a race to be first would exist in these areas but for the doctrine of copyright law preventing that.
} 
clear relationship between the social value of an innovation and the optimal length of property rights: More valuable innovations lead to higher monopoly profits per year, tending to reduce the period necessary to cover development costs, but more valuable innovations are also more desirable to stimulate (and may cost more to develop), tending to raise the desirable period of property rights protection. ${ }^{212}$

(c) The scope of property rights. Although I have spoken above of property rights simply as obtaining or as not obtaining, they may often better be viewed as applying to this or that degree, depending upon what may be called their scope. Issues of the scope of protection are exemplified by whether a closely-related improvement on a patented invention will be considered infringing, by whether a patent-holder will be forced to license his invention to others (and, if so, at what price), or by whether a copyright-holder in a television broadcast will be allowed to prevent recording and later use of its broadcast. The larger the scope of property rights protection, the greater the profits to the property-right holder and the greater the incentive to create information, but the larger the scope, the greater also is the problem of excessive prices and inadequate use of information. Thus, the social tradeoff involved in increasing the scope of protection is of the same character as the one pertaining to duration of protection.

Two additional comments may be made about the scope of protection. First, the optimal scope of protection and its optimal duration are interrelated, because increasing the scope of protection and increasing the duration of protection are each means of enhancing profits and incentives to create information. ${ }^{213}$

Second, a given scope of protection can be achieved in many different ways, by the state's deeming some behaviors as infringing and not others. It is generally socially desirable for the state to treat as infringing those behaviors that produce profits for the property right holder at relatively low social cost, and to treat as not infringing those

\footnotetext{
${ }^{212}$ It may be helpful to set out a simple model in terms of which the points of this paragraph can be expressed. Suppose that possible inventions are described as follows: $c$ is the cost of development; $q$ is the likelihood of successful development if $c$ is invested; $b$ is the per year social benefit from an invention if there are no property rights given in it; $\mathbf{B}<b$ is the per period profits given property rights in the invention; and $b ! m$ is the per period social benefit if there are property rights, where $m$ is the social loss due to monopoly pricing. Also, let $r$ be the discount rate. Assume that the state can observe all the variables, $c, q$, $\mathrm{B}, b$, and $m$ and that an invention is socially worthwhile inducing. Then the optimal length of property rights is the minimum time $T$ necessary to generate expected discounted profits of $c$ for the innovator, that is, the optimal $T$ is such that $\mathrm{I}_{0}^{T} q \mathrm{~B} e^{-r t} d t=c$. Note that, given this $T$, social welfare will be $\mathrm{I}_{0}^{T} q(b-m) e^{-r t} d t+$ $\mathrm{I}_{T}^{4} q b e^{-r t} d t ! c$. More generally, the state will not be able to observe the different variables but will have probability distributions over them. In that case, for any $T$, social welfare will equal the expected value (with respect to the probability distribution over the variables) of

$\mathrm{I}_{0}^{T} q(b ! m) e^{-r t} d t+\mathrm{I}_{T}^{4} q b e^{-r t} d t ! c$ for all $c$ for which invention is induced, that is, for which $c \mathbb{1}_{0}{ }^{T} q \mathrm{~B} e^{-r t} d t$. The optimal $T$ will maximize this expected value over $T$.

The classic study of the optimal duration of patent protection is Nordhaus 1969; see also Scherer 1972. Scotchmer 1999 examines the policy whereby patent holders can lengthen their patents by renewing them if they pay a fee for renewal. Note as well the related discussion and references in the next subsection.

${ }^{213}$ When account is taken of the substitute nature of the scope and the duration of property rights as means of providing incentives to create information, the conclusions about their optimal nature can change. For example, under certain assumptions it is best for property rights to endure forever but for the monopoly pricing problem to be ameliorated by limiting the scope of property rights. On these issues, see Gilbert and Shapiro 1990 and Klemperer 1990.
} 
behaviors which, were they infringing, would result in relatively high social costs per dollar of profits for the property right holder. For example, it might be desirable to treat as infringing the recording and use by a sports bar of a televised sports event, but to treat as not infringing the recording and use of the same event by a person in his home. To treat home use of such television broadcasts as infringing might involve substantial social costs, especially due to high administrative and enforcement expenses per dollar of profits that would be collected by the owner of the broadcast. ${ }^{214}$

(d) Dependence of present innovations on past innovations. ${ }^{215}$ Today's innovations stand on the shoulders of past innovations; the creation of knowledge and the development of products is a cumulative process. For example, James Watt's eighteenth century invention of the separate condensor steam engine was improved upon by Hornblower and Trevithick's high pressure engines; the latter could not have developed their engines had not Watt laid the groundwork with his. Similarly, the development of an efficient computer operating system like DOS enabled subsequent creation of computer software relying upon it. How does the dependence of second innovations on first innovations affect the optimal breadth of protection accorded first innovations? The general answer is, not in any clear direction, because of two competing factors. On one hand, the broader the protection granted first innovations, the greater the incentive to make such innovations. Indeed, for incentives to be ideal for first innovations, their creators should obtain the entire social benefits due to first innovations, meaning the direct benefits from the innovations plus those benefits due to dependent, second innovations, and patent holders in first innovations will be able to engross benefits from second innovations if their patent protection is broad enough to give them rights to these innovations. On the other hand, the broader the protection granted to first innovations, the lower the incentives of others to generate second innovations (in fact, Watt's refusal to license his steam engine retarded Hornblower and Trevithick's development of their engine; they had to wait until Watt's patent expired in 1800 to produce and sell theirs $\left.^{216}\right)$. $^{217}$

${ }^{214}$ The point of this paragraph may be expressed more formally as follows. Suppose that there are many different behaviors $b_{i}$ that can be treated as infringing, and that if so treated, $b_{i}$ would yield profit $\mathrm{B}_{i}$ to the property right holder and involve social $\operatorname{cost} c_{i}$ due to reduced use of the goods embodying information and administrative and enforcement costs. A given scope of protection is a particular selection of the behaviors (such as $b_{2}, b_{5}, b_{8}$, and $b_{10}$ ). A selection is socially efficient if the total profit associated with it (such as $B_{2}+$ $\mathrm{B}_{5}+\mathrm{B}_{8}+\mathrm{B}_{10}$ ) cannot be achieved at lower total social cost (lower than $c_{2}+c_{5}+c_{8}+c_{10}$ ); that is, a selection is not socially efficient if there is another possible selection that would yield at least as much profit at lower social cost. If the $B_{i}$ are individually small, then behaviors should be selected only if the ratio of profit $\mathrm{B}_{i}$ to social cost $c_{i}$ is sufficiently high. This general theme is informally advanced in the area of patent in Kaplow 1984.

\footnotetext{
${ }^{215}$ See generally Scotchmer 1991, and see also Chang 1995, Green and Scotchmer 1995, and Merges and Nelson 1990.

${ }^{216}$ See Singer et al. 1958, 188-97.

${ }^{217}$ More precisely, consider the situation of a second innovator whose innovation infringes on the first innovation. The second innovator, having already expended resources on his innovation, may not succeed through bargaining with the first in obtaining enough profit to offset his expenses. (Furthermore, because inventive activity is inherently risky, he will need to obtain more than enough to cover his expenses on just those occasions when he is successful.) Anticipating the possibly indequate profits they will be able to
} 
It should be observed, however, that if those who create initial innovations are likely themselves to be able to make subsequent innovations (which they would often be in a good position to do, given the knowledge they acquire from making first innovations), then broader protection should be given to first innovations: This will result in good incentives for initial innovations and not compromise incentives for second innovations. A similar conclusion holds when initial innovators, though not themselves well suited to make subsequent innovations, can form joint ventures with other parties. ${ }^{218}$ Furthermore, giving broad protection to initial innovators can ameliorate the problem of a race among second innovators.

(e) Effort to copy and to prevent copying of information. An advantage of the system of property rights in information is that it reduces costly efforts of developers of information to protect their knowledge, and it likewise reduces the efforts of others to appropriate information through copying where possible, reverse engineering, and other "piracy" measures. For example, because of the existence of property rights in computer software, a writer of software need not invest in a storage format that is hard to duplicate, and individuals are not led to try to deduce the source code of a program or to circumvent copy protection.

(f) Disclosure of information and property rights. Because society desires to eliminate the monopoly pricing problem when property rights in innovations expire, it will want patent holders to disclose information lying behind their innovations (obviously, there is no issue of disclosure for holders of copyrights in written material). Note, however, that this requirement can sometimes be avoided by not obtaining a patent, which is the course an innovator would take were he sufficiently confident that competitors could not duplicate his product through reverse engineering (see the discussion of trade secret law below in section 1.17).

(g) Enforcement costs of protecting property rights. Of course, the advantages of property rights in information have to be compared to the costs of their enforcement. These costs include the expenses of detecting infractions of property rights in information and of imposing sanctions for violations. Detection of violations should often be easy, for when goods are offered for sale to the public by a party without property rights, this will usually quickly become known. If goods can be sold or exchanged secretly, detection may be problematic, but the necessity for secrecy will typically mean that the magnitude of the problem of violations will be small. ${ }^{219}$ When information can be used in many indirect ways, or when it can be built upon in combination with other information, the detection and policing of its use may be very difficult, however (as is true of basic research; see section 1.22 below). In any case, another enforcement cost of a system of

secure through bargaining with first innovators, potential second innovators may decide against investing effort to make their innovations.

\footnotetext{
${ }^{218}$ If they can form joint ventures before undertaking effort to develop second innovations, then as long as the payoff to investment in a second innovation is outweighed by the benefits, there will be some agreement between the parties that they will each find acceptable. On problems surrounding cooperation and patent, see Heller and Eisenberg 1998.

${ }^{219}$ A possible exception concerns the private copying of computer software. One supposes that the magnitude of this violation of property rights is substantial and, perhaps, hard to defeat.
} 
property rights is the cost of maintaining the administrative and legal apparatus for deciding who will obtain property rights and for settling disputes about property rights.

1.15 Patent law. ${ }^{220}$ Patents are exclusive rights to use, make, and sell inventions for a specified period. The first patent law generally granting rights to inventors was apparently that enacted by the city-state of Venice in the late fifteenth century (although patents had been given to innovators on an individual basis before). English patent law may be traced to a 1624 statute, and some of the American colonies adopted patent statutes not long afterward. The United States passed its first patent law in 1790, and most of the countries of Europe enacted patent legislation in the early 1800s (although -see section 1.21 below -- some countries temporarily abolished patent law later in the century). $^{221}$

The subject matter of patentable innovations encompasses products -- machines, manufactures, and compositions of things (such as new chemicals) -- processes -methods of making things -- and several other categories, including plant forms, genetic information, ornamental designs for manufactured products, and certain computer programs. $^{222}$

An innovation whose subject matter falls outside that stipulated in patent law cannot be patented (but might be protected by copyright or trade secret law). An important class of innovations that cannot be patented are abstract ideas. For example, Einstein's discovery of the law of nature $E=m c^{2}$ was not patentable, nor, probably, would be the idea of pressing pants. The sense behind barring patents in such discoveries is various: difficulty in enforcing property rights in abstract ideas (it is more difficult to police use of an idea than use and sale of products -- how would one practically detect use of the idea of pressing pants?); the fact that some ideas are either obvious (pressing pants), or, in any case, likely to be discovered in due course without substantial investment; the fact that individuals who discover significant new ideas often are rewarded, and thus motivated, in alternative ways (notably, by fame and professional advancement, or by receipt of grants and awards); the great loss that society would suffer were very general and useful ideas restricted by giving a party a monopoly in them. ${ }^{223}$ It should be emphasized, however, that ideas are patentable if they are not abstract and are put in useful form. Notably, process innovations (see note 2) typically fall in this category, for example, a specific, complicated method of making creases in pants. The resolution of the fact that process innovations are patentable but that abstract ideas

\footnotetext{
${ }^{220}$ On patent law in the United States, on which I focus, see, for example, Chisum 1996, Chisum et al. 2001, Miller and Davis 2000, and Schlicher 2001. On patent law in other countries, see, for example, Dinwoodie, Hennessey, and Perlmutter 2001, and Metaxas-Meranghidis 1995.

${ }^{221}$ See Machlup 1958, 2-4, and references cited therein.

${ }^{222}$ See, for example, Chisum 1996, 1: chapter 1, Miller and Davis 2000, chapter 2, and Schlicher 2001, chapter 3.

${ }^{223}$ On the inability to patent abstract ideas, see, for example, Chisum 1996, 1: 1-84, 1-85, and Schlicher 2001, section 3.032A.
} 
generally are not may be found in part in the particularity of patentable process innovations and the ability to enforce property rights in them. ${ }^{224}$

To obtain a patent in a product or process, it must be shown to be novel, nonobvious, and useful. ${ }^{225}$ To satisfy the novelty requirement, the invention must be shown to be new, meaning that it was not previously patented, sold, used, described in print, or anticipated (in the sense that enough was known to allow a person with expertise in the relevant field to make the product or determine the process). ${ }^{226}$ An economic rationale for the novelty requirement is that products or processes that do not satisfy it are either ones that society already enjoys or will soon possess (that is, when already described in print or anticipated), so that society has no reason to suffer the losses associated with patent monopoly.

The second requirement goes beyond the novelty requirement in insisting that an invention not only be new, but also that it be nonobvious. ${ }^{227}$ The meaning given to "nonobvious" is determined in a complicated manner, the thrust of which involves identifying those inventions that could not fairly readily have been generated by persons familiar with the relevant art. For example, an improvement to a machine that involves straightforward application of engineering principles might well fail the nonobviousness test. A justification for the general nonobviousness requirement is similar to that for the novelty requirement: to ensure that society not bear the monopoly costs of patent if a product or process would probably have been created soon enough without the stimulus of patent, on account of its obviousness. ${ }^{228}$

\footnotetext{
${ }^{224}$ Many if not most process innovations concern production of commercial products or services offered for sale, where the ability to determine whether there is infringement may well be tolerably good. For example, if a new method of cracking hydrocarbons for production of refined oil products is employed, this could perhaps be determined from observation of the design of the plant or from the character of the refined products.

${ }^{225}$ The requirements for patents in plants and design are somewhat different; see Alces and See 1994, $55-56$.

${ }^{226}$ See, for example, Chisum 1996, 1: chapter 3, Miller and Davis 2000, chapter 3, and Schlicher 2001, chapter 4 .

${ }^{227}$ See, for example, Chisum 1996, 2: chapter 5, Miller and Davis 2000, chapter 5, and Schlicher 2001, chapter 5 .

${ }^{228}$ This is not to say, however, that the principles governing the nonobviousness requirement are always consistent with economic analysis. For instance, an invention that probably would not have occurred to a person familiar with the art because it had a surprising, nonobvious aspect would tend to pass the requirement. But such an invention might have been cheaply developed and have allowed its creator much greater profits than the development cost in the absence of a patent. Hence, economic analysis would suggest that no patent should be granted because the invention would have been made anyway. Conversely, imagine an invention that is obvious in the sense that those familiar with the art agree it can be developed. Such an invention would tend to fail to pass the nonobviousness requirement and thus not be patentable. But if the development cost is high and would clearly not be covered by profits in the absence of patent protection, it would be a mistake, under economic analysis, not to award a patent.
} 
The last requirement of utility is met by showing that the invention passes some threshold of usefulness. ${ }^{229}$ Thus, for example, a new drug that has no apparent function, or one whose value is too speculative, would not satisfy the requirement. The requirement of utility, unlike the previous two requirements, lacks a clear economic basis. It is true that society does not want to spur useless inventive activity. But granting patents in useless inventions will not have this effect: A patent monopoly in a useless drug, for example, will be valueless, so no firm would invest resources to develop and patent a drug that it anticipated would be useless. ${ }^{230}$ Yet some innovations that appear to be useless or of speculative value to the patent office may in fact be valuable and be so judged by their creators, who we would generally presume to have superior information to the state about such matters. Thus, the hurdle of showing adequate utility to the patent office can discourage innovations recognized by their creators to be socially desirable. ${ }^{231}$

To obtain a patent, it is not necessary that the innovation have been refined or made commercially viable. Indeed, studies show that for many important products (for instance, the automatic transmission, the ball point pen, and the safety razor), the period between the award of a patent and the sale of the product was more than five years. ${ }^{232}$ The award of patents early in the stage of development meliorates the problems of patent races and duplicative effort, as noted above (see section 1.14).

The duration of patents is generally 20 years, although this may be extended for an additional period for drugs. ${ }^{233}$ The patent length is apparently of historical origin (derived mainly from the period necessary to train two sets of apprentices). ${ }^{234}$ Were the duration of patents decided with regard to the incentive benefits of patents and their social costs, patent length would depend on the class of innovations (for example, length might be shorter when profits that exceed development cost would be generated in just a few years). The uniform nature of the duration of patents stands in significant contrast to the highly elaborated legal consideration given to whether to award patents and to their

\footnotetext{
${ }^{229} \mathrm{Also}$, inventions that are harmful, illegal, or immoral are said not to satisfy the utility requirement and thus are not patentable. On the utility requirement, see, for example, Chisum 1996, 1: chapter 4, Miller and Davis 2000, chapter 4, and Schlicher 2001, section 3.02.

${ }^{230}$ It might be that a person seeks a patent on a useless drug because he can sell it to gullible consumers. But if there is a problem with consumer knowledge, this problem should be addressed directly, one presumes, perhaps by providing information to consumers or by prohibiting misleading advertising, not by the indirect and blunt method of barring patents on the whole class of innovations seemingly lacking in utility.

${ }^{231} \mathrm{An}$ argument for the utility requirement that is sometimes encountered is that it might reduce administrative costs by winnowing out patents on which the patent office should not be spending time, but this function could be achieved by imposing an appropriately high filing fee for patent applications.

${ }^{232}$ See Kitch 1977, 272.

${ }^{233} 35$ USC sect. 154. On the possible extension of patent duration for drugs, see, for example, Chisum 1996, 5:16-210-16-214.

${ }^{234}$ See White 1956.
} 
proper scope. ${ }^{235}$ One suspects, therefore, that the fixed 20-year patent length could be improved upon.

During the life of a patent, a patent holder is for most purposes free to use or not to use it and free also to set prices. ${ }^{236}$ However, in Europe, there are often requirements to use or "work" patents or else licensing of patents at court-determined prices is compelled. ${ }^{237}$ Policies aimed at inducing working of patents prevent strategic patent shelving (obtaining a patent only to prevent a competitor from doing so and then competing with a company's existing product), but they may result in the use of patents before they have been adequately refined and developed by their holders.

Patent holders are also allowed to sell and license their patents, which, as remarked above, raises their value to society and to patent holders, thus increasing the incentive to innovate.

The scope of patent protection enjoyed by patent holders is determined by a complex of doctrines and principles. ${ }^{238}$ In part, the tests of novelty, nonobviousness, and utility determine the scope of protection, because they affect whether other products can be patented. The scope of protection is also affected by determination of patent infringement, that is, by the products and practices of other parties that are deemed to interfere with the rights of a patent holder.

1.16 Copyright law. ${ }^{239}$ Copyrights are similar to patents; they are essentially exclusive rights to reproduce writings and certain other intellectual products for a specified period. In the Middle Ages, monasteries and other owners of manuscripts possessed the right to charge a fee for copying. With the invention of the printing press, exclusive privileges to print were granted. As with the award of privileges to manufacture new goods, the award of printing rights apparently occurred first in Venice, in 1469, and the practice quickly spread throughout Europe. In England, printing privileges were early awarded both individually and to the Stationers' Company, representing a guild of printers, which developed its own system of copyright. Copyright law in the United States began with a 1790 statute. ${ }^{240}$ In most countries today, copyright is governed

\footnotetext{
${ }^{235}$ Were the courts to employ the information that they use in these domains in relation to patent duration, they would presumably be able to improve on the present 20 year duration.

${ }^{236}$ However, failure to use a patent may cause a patent holder to run afoul of antitrust law; see, for example, Miller and Davis 2000, section 8.4.
}

${ }^{237}$ On working of patents and compulsory licensing in other countries, see, for example, Henry 1976 and Ruster 1991.

${ }^{238}$ On the scope of protection and infringement, see, for example, Chisum 1996, 5: chapter 16, Miller and Davis 2000, chapter 8, and Schlicher 2001, chapter 8.

\footnotetext{
${ }^{239}$ On copyright law in the United States, see generally Goldstein 2001a, Nimmer and Nimmer 1995 , Patry 1994, and Miller and Davis 2000. On copyright law in other countries, see, for example, Goldstein 2001b, Metaxas-Maranghidis 1995, Tritton et al. 2002, and Wineburg 1999.

${ }^{240}$ For a summary of the general history of copyright, see Rose 1993 , chapter 2 ; for the history in England, see Davenport 1993, 22-31 and Patterson 1968, chapters 1-8, and for the history in the United States, see Goldstein 2001a, 1: 1-32 - 1-40 and Patterson 1968, chapters 9-11.
} 
principally by general statutes that give exclusive rights to originators of works or to those to whom they assign their works.

Copyrightable material now includes much more than compositions of words, but also maps, paintings and other works of art, photographs, motion pictures, musical compositions and musical recordings, computer programs, architectural plans, and semiconductor chip designs. ${ }^{241}$ That there are so many types of copyrightable works raises the question of whether there is a general principle determining whether a work will be copyrightable as opposed to patentable. It seems from the list just given that copyrightable works have a self-revealing quality, making them easy to reproduce, whereas patentable works usually cannot be duplicated without considerable reverse engineering. However, this principle does not fully account for the distinctions the law draws between copyrightable and patentable works and, in any event, it is not legally relevant. $^{242}$

Several requirements must be met to obtain a copyright in a work (assuming that it falls into a copyrightable category). A basic requirement is fixation, that a work must have been expressed in a tangible medium. For instance, to be copyrighted a speech must have been written, and for a ballet to be copyrighted its choreography must have been recorded. Without this requirement of fixation, it would be difficult for courts to verify claims of copying, for there would be no tangible evidence of initial authorship. Another requirement is that the work constitute a particular expression of an idea rather than a basic idea itself. The play Romeo and Juliet would meet this test, but not the general plot of a love relationship between individuals from antagonistic families. The rationale for disallowing copyright in basic ideas is essentially that given with regard to patent.

An additional requirement for copyright is that of originality, meaning that a work have originated with the claimant, that he did not literally copy it. Originality in this limited sense is, as previously remarked, usually also sufficient for copyright; it is not generally required that the work in question add substantially to the stock of similar works or be novel or nonobvious, unlike in the case of patent. For example, a photographer who takes a picture of the same sight as a previous photographer, say of Niagara Falls, can obtain a copyright in it, however close his image is to the earlier one. $^{243}$

Why should originality generally be sufficient for the award of copyright but not for that of patent? Is this distinction socially rational? A speculative answer is that for books and much copyrightable material, it is the very particulars of the expressive work

${ }^{241}$ See Goldstein 2001a, vol. 1, chapter 2, Miller and Davis 2000, chapter 20, and Patry 1994, chapter 2.

\footnotetext{
${ }^{242}$ The main problem with the distinction is that some patentable works are very easily copied, for example, the hula hoop. To an important degree, the courts do not use this distinction or other general principles to decide what is copyrightable -- they instead refer to legislation that sets out in fairly specific terms what is copyrightable. But there are certain doctrines that are resorted to in problematic cases. Notably, "utilitarian" works, such as lamps, are not copyrightable; see Goldstein 2001a, 1: 2-55! 2-60, and Miller and Davis 2000, 300-01. (One may ask, however, why, exactly, any book, or certainly a textbook, is not utilitarian, or why a computer program is not utilitarian; they clearly provide utility. Yet they are copyrightable.) Finally, it should also be observed that the law sometimes allows a party to obtain both forms of protection for a work; see Goldstein 2001a, 1: 2-57 and Miller and Davis 2000, 305.
}

${ }^{243}$ See Goldstein 2001a, 1: 2-6! 2-21. 
that explain its value more than the underlying plots and ideas. The actual language employed by Shakespeare in Romeo and Juliet is what makes it such a worthwhile contribution to literature (one can imagine that most any other play built on essentially the same plot would be viewed quite differently). Thus, society should encourage creation of new written works, even if similar to old works in underlying ideas, by giving copyright to most any expression of the ideas; in that way, a person whose expression of the ideas is highly valuable will be rewarded. By contrast, society does not want to encourage development of machines that are similar to existing ones because the particulars of a machine are not what gives a machine its value; a new type of engine, like the steam engine, will be valued for its function, whether or not the size of its various components and other features are this or that. ${ }^{244}$ A second justification for the sufficiency of originality for copyright concerns the difficulty a claimant would face in determining whether his work is close to another's. Because written works are not catalogued or registered in a way that lends itself to easy checking for similarity, it would be hard for a person to ascertain whether his work is close to any other existing work. Hence, were there a requirement of novelty, people would either bear the risk of infringement or be led to spend on verification for novelty. These social costs are avoided when originality guarantees copyright. ${ }^{245}$

The duration of copyright has changed over time and is presently equal to the author's lifetime plus 70 years (and longer if the author is a company). ${ }^{246}$ Why this should be so, and why, for example, the duration of protection should be so much more generous than for patents, is not evident, and one surmises that it has no clear rationale.

Holders of copyrights are free to use or not to use their works, to set prices for use, and to sell their copyrights.

The scope of copyright protection is determined in various ways. The similarity of a work to a copyrighted one will determine whether it is found to be infringing if, as is often the situation, the second work cannot be demonstrated to have been independently created (in which case it too would enjoy copyright protection). Thus, literary works that follow the plots of an existing one too closely, a musical composition that borrows too much from an existing one, a cartoon character that too much resembles in appearance and "personality" an established one (like Snoopy) will be judged infringing. As a general matter, it appears that a work must be subjectively very close to an existing one to be found infringing, which makes sense assuming that, as noted above, the particularity of the expression of underlying ideas is what largely determines the value of a work.

Also of importance to the scope of protection is the doctrine of fair use, which sets out circumstances in which parties are allowed to use copyrighted works without

\footnotetext{
${ }^{244}$ Furthermore, and closely related, the granting of patents in a very similar steam engine would tend to reduce revenues for the holder of the first patent substantially. But the granting of a copyright in a book based on a very similar theme to that of another author might be thought not to reduce the first author's revenues substantially -- as the differences in the books' expressions of the common theme will tend to make them more like independent products.

${ }^{245}$ It is also true that checking whether one's innovation is similar to a patent is costly, but the organization of patents may make checking easier. This point is stressed by Landes and Posner 1989, 345.

${ }^{246} 17$ USC section 302.
} 
paying copyright holders. ${ }^{247}$ Examples of uses that have been treated as fair include: reproduction of short sections of copyrighted materials in class materials, the recording of a television program by an individual on a VCR for later viewing, quotation from a copyrighted book in a book review or parody. The economic justification for permitting a use is that, on one hand, it may detract very little from the profit of the copyright holder (and thus not reduce by very much incentives to create), and on the other hand, it may add substantially to the utility of users. ${ }^{248}$ To illustrate, permitting reproduction of several pages from a book for use in class materials might not much reduce sales of the book (students would have been unlikely to purchase the book to read just a few pages) and thus an author's incentive to write it, but their ability to read such selections may substantially enhance the educational value of their class materials. ${ }^{249}$ Although uses that are deemed fair seem in a rough and implicit way to reflect such economic reasoning, some of the legal tests used to decide fair use are inconsistent with the reasoning. ${ }^{250}$

Another significant aspect of the scope of copyright protection is that copyright holders enjoy also rights to derivative works, such as translations, films based on books, clothing and other articles featuring copyrighted cartoon characters, and generally any form in which a work may be recast or transformed. This legal policy can be justified on the basis of the discussion of dependent innovations in section 1.14 (d). Namely, suppose that copyright holders often are well suited to develop derivative works themselves or can contract to have that done. Then the creation of derivative works will be encouraged (translations will be undertaken) and the possibility of duplicative effort to create derivative works (races to complete translations) will be avoided. Furthermore, the generation of original works will be enhanced since they might not be created if the only reward is from the original works themselves (a movie might not be produced if profits cannot be obtained from dubbed versions for foreign audiences). Where, however, the copyright holder would not be likely to develop or contract with a party to develop a derivative work, perhaps because it is not obvious, it is not clear that giving the holder the right to the derivative work is desirable.

\footnotetext{
${ }^{247}$ On the law of fair use, see generally Patry 1995; this book also describes related doctrines in other countries, 589-99.

${ }^{248}$ On the economics of fair use, see Fisher 1988, Gordon 1982, and Landes and Posner 1989, 357-61.

${ }^{249}$ A potentially important qualification to the conjecture that the author of the book would not lose much profits should be mentioned: He might obtain profit not by selling extra copies of the book but by charging for reproduction of the pages. However, the transaction costs associated with securing permission and paying the author might deter classroom use, meaning that the author would not be losing profits due to the fair use doctrine. On fair use and photocopying, see Goldstein 2001a, 2: 10-7,10-8, and 10-36 ! 10-39.

${ }^{250}$ For an economically-oriented, critical discussion of the rationality of the legal criteria used to determine whether a use is fair, see Fisher 1988, 1667-95.
} 
1.17 Trade secret law. ${ }^{251}$ Trade secret law is the name given to various doctrines of contract and tort law that serve to protect commercially valuable information such as designs, manufacturing processes, and customer lists. In order to be protected, the information must not be known to the public and the holder of the information must take steps to prevent the information from becoming public. Trade secret law is governed by state law, as opposed to federal legislation that regulates patents and copyrights. Principal examples of trade secret law are the enforcement of employment contracts stipulating that employees not use employer trade secrets to compete with their employer (typically after having left the employer); enforcement of similar contracts restricting the right of firms working for a given firm from using certain information to compete with it or from revealing it to a competitor; and allowing suit for tort damages to be brought for acquisition of valuable information by improper means, including not only illegal behavior, notably theft, but also such practices as flying a plane over a factory to take pictures to deduce its production process. The protection of property rights under trade secret law does not extend, however, to reverse engineering. A competitor is free to deduce trade secrets by, for example, examining a product and analyzing it or by identifying the the customers of a competitor.

How does trade secret law relate to patent and copyright? It is of course similar in that it is a form of property right protection of information. But it is different in a number of respects. First, a party can obtain trade secret protection without incurring any real expense and without having to meet the tests (novelty, nonobviousness, and so forth) necessary for patent or copyright protection. Second, trade secret protection is not limited in duration. Relatedly, trade secrets need not ever be disclosed. As mentioned earlier, Coca Cola's formula has been protected for over a century under trade secret law. Third, trade secret protection is in some respects weaker than patent protection; notably, it does not protect against reverse engineering.

Trade secret protection is a supplement to patent and copyright because it can be obtained when parties are unable to obtain patents or copyrights, or in addition to them. And trade secret protection is also an alternative to patent or copyright because a party is free to elect such protection instead of either of them.

An evaluation of trade secret law should include consideration of the following two points. First, because trade secret law furnishes the only form of property rights protection for some information, it would seem to be socially desirable on the general grounds that protection of property rights in information is thought to be socially desirable. This is especially likely to be true for information of relatively low value, and thus for which the expenditures that private parties and society make on the patent and copyright process would not be warranted. Second, giving individuals the option to choose between trade secret and patent or copyright (when they would qualify for the latter) has a desirable feature: If individuals have better information than the state about the relative benefits and costs of trade secret versus patent or copyright protection, they will make a better decision than the state about which form of protection provides them greater net benefits. However, because net private benefits may be different from net

\footnotetext{
${ }^{251}$ On trade secret law in the United States, see generally Milgrim 1995, Cohen and Gutterman 1998, and Pooley 2001, and on trade secret law in other countries, see, for example, Ladas 1964 and Dinwoodie, Hennessey, and Perlmutter 2001.
} 
social benefits, allowing parties to elect trade secret protection over patent or copyright might be disadvantageous. For example, if Coca Cola had obtained a patent for its formula, it would have enjoyed property right protection only for 20 years rather than for the much greater period that it has in fact kept its formula secret, and perhaps one substantially exceeding that usually necessary to induce development of such a formula as Coca Cola's .

\subsection{Rewards for creating information: an alternative regime to property} rights in information. A system that provides a fundamental alternative to property rights in information is one in which the state pays rewards to creators of information and then places the information in the public domain, making it freely available to all -- so that no property rights in the information exist. Thus, under the reward system, an author of a book would receive a reward from the state for writing the book (the reward might well be paid only over time -- see below), but any firm that wanted to print the book and sell it could do so.

The reward system appears to have the virtue of the property rights system but not the drawback. Like the property rights system, the reward system encourages production of information because the creator of information obtains a financial benefit from so doing, namely the reward. But unlike the property rights system, the reward system appears to result in optimal dissemination of information because the information is in the public domain: Anyone can use it. Under the property rights system, a book would sell at a price exceeding cost because the copyright holder would be able to charge such a price, but under the reward system, the book would sell at a price reflecting only cost, because any firm could sell the book. In general, due to competition, goods embodying new information would tend to sell at prices resembling production cost, meaning that the quantity sold would tend toward the optimal. Hence, it seems that the reward system is superior to the property rights system because it provides incentives to innovate without causing prices to be high relative to cost, that is, without causing the use of information to be lower than socially desirable. However, we have not yet discussed how the reward would be calculated.

1.19 Determination of the reward. The reward system will generate incentives to create information in accordance with the magnitude of the reward the potential creators can expect. If the reward were to equal what the creators would obtain if they had property rights, then the reward system would lead to identical incentives to create information, and would therefore be superior to property rights, because the information created would be optimally disseminated. In the ideal, the reward system would result in a reward sufficiently high to induce creation of all socially worthwhile information; this could be accomplished by offering a reward reflecting the full social value of information. ${ }^{252}$ To give rewards that reflect the social value of information, the state might base the reward on the volume of use of the information, such as the sales volume of a book, and on some measure of its utility as well. Presumably, the rewards would be

\footnotetext{
${ }^{252}$ The virtue of setting the reward equal to the social value of information is that then, other things being equal, a potential creator will make the socially correct decision whether to develop the information. Of course, if the state knows not only the social value of the information but also how much it would cost to develop it, the state can determine whether it is desirable to develop and can offer a reward just high enough to induce the information to be developed; such an award would generally be less than the social value of the information.
} 
paid over time, such as annually, as sales of the good embodying the information occur, and as information about its social value is developed. However, the difficulties that the state would face in deciding upon rewards might lead to outcomes inferior to those under property rights. For example, suppose that there is a book that an author knows he could sell at a high price because it will be very valuable to a small sector of the market, such as a specialty or technical book of great interest to several thousand individuals but not to others. Under the property rights system, the author might well write it because he knows that he would be able to sell it for a price sufficient to justify his efforts. By contrast, if under the reward system his payment would be based mainly on the volume of sales (because it might be hard for the state to measure the high value placed on the book), he might not receive enough to make it worth his while writing the book. Thus, it cannot be said that the reward system is unambiguously better than the property rights system. Still, one supposes that in many plausible situations, the reward system would be superior to the property rights system. In any case, it does not seem that there is a clear and appealing case for the property rights system over the reward system. ${ }^{253}$

1.20 Additional issues concerning the reward system. (a) Duplicative effort and the race to be first. It was observed that under the property rights system, there would often be duplicative effort to create information and a wasteful race to be first. The reward system would also suffer from these disadvantages, since only the first party to create information would receive the reward.

(b) Dependence of present innovations on past innovations. The reward system would enjoy an advantage over property rights systems with respect to the dependence of present innovations on past ones. Under the reward system, present innovators would, by definition of the system, be able to use freely all past innovations, whereas, as discussed before, under the patent system, new innovation is sometimes retarded because it would be found to infringe on earlier innovation.

(c) Social cost of protecting property rights; efforts to copy and to prevent copying. Under the reward system, unlike under the property rights system, there would be no social effort expended protecting property rights, so there would be a savings on enforcement costs in that sense. Moreover, innovators would have no reason to prevent others from copying their work, and those who wanted to copy would not have to overcome obstacles to do so. But there would remain a cost of administering the reward system.

(d) Financing the reward system. The reward system would have to be financed by the state, which is to say, by taxes. Thus, an apparent disadvantage of the reward system is the social cost associated with income taxation. ${ }^{254}$

\footnotetext{
${ }^{253}$ As will be noted below, the reward system was a subject of intense study by economists and of public debate in the nineteenth century. Today, however, it receives relatively little attention from economists. For discussion of the reward system versus patent, see Mill [1848] 1872, 563, Polanvyi 1943, and Scherer 1980, 458; and for theoretical analysis, see Wright 1983, Kremer 1998, and Shavell and van Ypersele 2001. In the latter article, it is demonstrated that despite the imperfect information faced by government, an optional reward scheme -- under which innovators choose between intellectual property rights and a properly chosen reward -- is unambiguously superior to the intellectual property rights system. An economically-oriented legal treatment of the reward system is found in Calandrillo (1998).

${ }^{254}$ However, as explained in section 4.6 of chapter 28 , to the extent that the social costs have to do with the distortion of work effort, these costs do not constitute an argument against a legal policy, such as a
} 
1.21 Actual use of the reward system and debate about it. A reward-like system is employed today in the United States for innovations of possible military use where granting patents might compromise our national security. ${ }^{255}$ For example, the government might not want certain inventions in the area of atomic energy or germ warfare to be sold on the open market. A general system of rewards was used in the former Soviet Union and other socialist countries; for example, if a person devised a costsaving innovation, he might obtain payment equal to a percentage of its value. ${ }^{256}$ Of course, intellectual property rights could not have been employed in these countries, since parties were not free to produce, set prices, and sell goods in markets.

From the 1850 s to the 1870 s, the issue of how to promote inventive activity and creation of intellectual works was debated vigorously in Europe. The principal contest was between the patent system and the reward system. For a time, the reward system was believed to be the one that would be adopted, and it was championed by many economists. For example, in England a succession of Parliamentary committees and royal commissions were appointed to examine the patent system, and they proposed reforms or alternatives to it. In 1869, the Economist opined that "It is probable enough that the patent laws will be abolished ere long. ..." Chancellor Bismarck announced his opposition to the principle of a patent system for Prussia in 1868, the Netherlands abolished its patent law in 1869, and Switzerland, which had never had a patent law, rejected several proposals for one. But for a variety of reasons, apparently more political than based on consensus about the intellectual appeal of the patent system, the latter system won out. Still, it was not until late in the nineteenth century and the next that some European countries decided to adopt a patent law (Switzerland did so in 1887, the Netherlands in 1910). ${ }^{257}$

\subsection{Practices similar to the reward system: state support of basic research;}

bestowal of prizes and honors. The state carries out basic research through its own scientific agencies (such as the National Institutes of Health) and through the award of grants to private individuals and organizations. Those who carry out basic research usually do not obtain property rights in it so do not profit thereby. Indeed, the notion of a system of property rights in basic research results seems largely unworkable. This is because, as a general matter, a basic research result is not useful in a particular embodied form, not for producing any single named thing; rather, such a result is often used in combination with other knowledge to produce further knowledge or physical things. This makes the definition and enforcement of property rights in basic research results impractical. To summarize, then, state support of basic research resembles a reward

reward system, that is otherwise desirable. In any case, Lichtman 1997 suggests that a government subsidy of patented products may offer an advantage over rewards because the government will need less tax revenue to finance the subsidy.

${ }^{255}$ See, for example, Payne 1996, section 78; Lee 1997; and Riesenfeld 1958.

${ }^{256}$ See Sinnot 1988, 44 and Stepanov 1958.

${ }^{257}$ See Machlup and Penrose 1950, 1-6; the quotation from the Economist is included in note 3 of their article. 
system in that payments to creators of information are made by the state and the creators do not usually obtain property rights in what they create.

It should also be observed that the bestowal of prizes and honors on creators of information and the social esteem that they may enjoy function as species of reward system.

Note on the literature. The extensive economic literature on property rights in information uniformly stresses the compromise that property rights strike between generating incentives to innovate and hindering the sale of goods and services embodying the information. A review of the evolution of economic thinking about patent is contained in Machlup (1958). Summaries of the economics of property rights in information are found in chapter 17 of Scherer and Ross (1990) and in Menell (2000), and a concise, synthetic theoretical treatment of economic literature is contained in chapter 10 of Tirole (1988) ${ }^{258}$ There is by comparison relatively little economically-oriented writing analyzing intellectual property law; such literature includes Kitch $(1977,1998)$ on patent, Landes and Posner (1989) on copyright, and Friedman, Landes, and Posner (1991) on trade secret protection. ${ }^{259}$ Empirical study of intellectual property rights is surveyed in Gallini (2002), Jaffe (2000), and Lanjouw and Lerner (1998).

\section{Other Types of Information}

2.1 Variety of other types of information. There are many, diverse types of information different from that which is useful for producing multiple units of a good, and I mention several illustrative types here. One is information that is useful only a single time, such as information about the location of oil under a particular parcel of land. Another type of information is that pertaining to future market prices, for example, information about the production of commodities or about the earnings prospects of publicly traded companies. An additional type of information is personal information, from the mundane to the serious (such as about the commission of crimes).

\subsection{Socially desirable generation and use of the foregoing types of}

information; property rights in such information. With respect to information that can be used only a single time, there is sometimes no need for property rights protection. If the party who possesses the information can use it himself (perhaps the oil deposit about which he knows is located under land that he owns), then once he does so, the issue of others learning it becomes moot -- there will be no further value to the information. To the degree, though, that a person is unable to use the information himself (perhaps the oil is located on someone else's land and he cannot conveniently purchase drilling rights), his having property rights in the information might be valuable to him and might beneficially foster acquisition of information. Moreover, it should be emphasized that giving property rights in the information will not undesirably reduce the use of information when the optimal use of it is only once. In any case, the legal system usually does furnish property rights protection in such information as where oil is located, through trade secret law and allied doctrines of tort and contract law.

\footnotetext{
${ }^{258}$ See also Besen 1998, Besen and Raskind 1991, and Reinganum 1989.

${ }^{259}$ See also Dam 1994 on patent law, Lemley 1997 and Gordon and Bone 2000 on copyright, and Cheung 1982 on trade secret protection.
} 
Consider next information relevant to future market prices and observe that the private and the social value of gaining such information can diverge. For example, a person who first learns that a fungus has destroyed much of the cocoa crop and that cocoa prices are therefore going to rise can profit by buying cocoa futures; his profit measures the private value of his advance information. The social value of his information, however, inheres in any beneficial changes in nonfinancial behavior that it brings about. For example, an increase in cocoa futures prices might lead candy producers to reduce wastage of cocoa or to switch from chocolate candy production to production of another kind of candy. Now the profit that a person with advance information about future cocoa prices can make in the absence of property rights can easily be imagined to be either above or below the social value of this information. ${ }^{260}$ Hence, it is not evident whether it is socially desirable to further encourage acquisition of such information about price movements by giving individuals property rights in the information, but the law does do so, again mainly through trade secret law.

Last, consider personal information. The costs of acquiring this information are the effort to snoop, although the information is sometimes adventitiously acquired and thus costless. The social value of the information involves various complexities, and I mention a few of the elements at issue. The release of information of a personal nature to the outside world generally causes disutility to those persons exposed and utility for others, the net effect of which is ambiguous. Further, the prospect of someone's obtaining personal information and then releasing it, or of his demanding payments not to reveal his information, can alter behavior of potential victims: They may be led not to engage in socially undesirable behavior (such as commission of crimes) or not to engage in socially desirable behavior that might be embarrassing if publicly revealed, and they may make costly efforts to conceal their behavior. Thus, there are reasons why acquisition and revelation of personal information may be socially desirable, and reasons as well why they might be socially undesirable. Now although the law penalizes blackmail and in this way attempts to discourage profit from acquisition of personal information, it does extend limited property rights in personal information. For example, an individual who wants to sell personal information he has obtained to a publication can often make a contract to do that, which is something that he may want to do when the information describes a public figure. This makes some sense in that a rough judgment might be that the social value of revelation of information about public figures outweighs the harm to them.

As this brief discussion illustrates, the factors bearing on the desirability of protecting property rights in information vary significantly according to the type of

\footnotetext{
${ }^{260}$ For example, a single person with the information might not be able to capture much profit, because others might soon get wind of what he knows and quickly raise the price of cocoa futures. If so, his profit might be significantly less than the social value associated with a timely increase in cocoa futures prices. But another possibility is that the person will be able to purchase a substantial volume of cocoa futures before the price rises to reflect his information. Moreover, the social value of the information could be small -- perhaps there is little that candy manufacturers could do to reduce cocoa wastage over the period in question. In this case, the private value of the information would exceed the social value. The general contrast between the private value of information about market prices and the social value of this information was first emphasized by Hirshleifer 1971.
} 
information, and the issue of the desirability of protection calls for analysis quite different from that concerning information of repeat value that I considered above.

\section{Information of Value as a Label}

\subsection{Goods and services whose quality is hard for consumers to ascertain}

directly. As will be explained, the social value of labels has to do with the many goods and services whose quality is hard for consumers to determine directly. For a consumer to be able to ascertain directly the quality of a hotel or of a breakfast cereal, for example, he would have to inspect the hotel room or sample the cereal. This would take time and would be impractical in many contexts (such as when making reservations at a hotel in another city). Furthermore, even if a person does examine a good, this would often reveal little, for in a modern economy products are often complicated in nature and their character is not clear from their outward appearance.

\subsection{Social value of labels for goods and services whose quality is difficult to} ascertain directly. By a label for a good or service is meant a word, phrase, or symbol that is uniquely associated with its particular seller. Labels have social value when consumers associate them with the true quality of labeled goods (or services) and when the quality of such goods would otherwise be hard to determine. The social value of labels inheres in two factors.

First, labels enable consumers to make purchase decisions on the basis of product quality or to do so without going to the expense of independently determining their quality (if this is even possible). A person who wants to stay at a high quality hotel in another city can choose such a hotel merely by its label, such as "Hilton Hotel"; the consumer need not visit the hotel. A person who wants assurance of the freshness and taste of a breakfast cereal, or who seeks a long-lasting consumer durable like a washing machine, will be able to find what he wants by reference to the brand name -- he need not open the box of cereal or somehow test the washing machine. At the same time, someone who wants a medium quality good or service, for instance, a Holiday Inn rather than a Hilton Hotel, will be able to identify and purchase that grade of good. That is, the existence of labels enables consumers to choose along a continuum of qualities when direct identification of qualities would otherwise involve cost or be practically impossible.

Second, and related, if labels can be established, sellers will have an incentive to produce goods and services of high quality, for a seller will know that the quality of his good or service will be recognized by consumers through its label and that the seller will therefore be able to charge a price reflecting true quality. If sellers did not have this incentive, high quality goods would tend not to be sold when consumers could not readily independently ascertain quality.

3.3 Social value of property rights in labels. The existence of property rights in labels -- that is, the power of holders of the rights to bar other sellers from using holders' labels -- is necessary for the benefits of labels to be enjoyed. In the absence of property rights in labels, the label of a high quality good or service would be adopted by a lower quality competitor, who would be able to charge the same price but operate at lower cost. If any hotel could call itself a Hilton Hotel, it would be motivated to do so. In consequence, the term "Hilton Hotel" would lose meaning as hotel-goers discovered that 
Hilton Hotels are not necessarily of high quality. The informational content of labels would quickly erode, if it was ever established.

When property rights in labels exist, however, sellers will plainly have incentives to create effective labels in order that the labels come to be associated with the qualities of their products and services. ${ }^{261}$ Specifically, these incentives will exist whenever sellers wish to make and sell products and services above the lowest quality.

3.4 Social costs of property rights in labels. Maintaining a system of property rights in labels involves certain administrative and enforcement costs, which most obviously concern preventing infringing uses of labels. But there is also a latent cost of allowing property rights in labels: encumbering our use of language and symbols. Suppose that it were possible for a seller to obtain a property right in an ordinary descriptive phrase, such as "delicious soup" or "well-engineered automobile." Then sellers would generally face difficulty in describing their products; normal use of language would be problematic because it would expose sellers to the risk of liability for infringement of property rights in words, and they would thus be led to spend time and energy checking that their apparently innocuous descriptive language did not infringe on another's property rights. Such costs can be largely eliminated, however, by restricting property rights in labels to uncommon and distinctive usages. As will be discussed below, this is essentially what the law does, so that the potential cost in question should be considered to be negligible in reality.

Additionally, it is sometimes suggested that a possible social disadvantage of property rights in labels is that they enable sellers to create or to preserve market power or to mislead customers about product quality. These problems, though, may be addressed directly through the antitrust statutes and truth-in-advertising laws, so that the degree to which they should be regarded as implicit costs of property rights in labels is attenuated.

3.5 Optimal duration and extent of property rights in labels. It seems that the optimal duration of property rights in a label is potentially unlimited. A label might well best be continued as long as a seller is using it and society is therefore obtaining the benefits from consumer recognition of the associated product quality. Were property rights in a label discontinued after some stipulated number of years, the seller would have to invest, pointlessly, in a new label, and consumers would have to learn it, during which time they would not easily be able to recognize the quality of the seller's good.

There are, however, reasons apart from the mere passage of time for property rights in a label to be terminated. If a seller were to fail to employ his label, it might be desirable to withdraw the property right in the label, for the label might have some scarcity value. Also, were a seller to degrade the quality of his good in order to fool customers and enhance profits in the short run (perhaps because he is intending to go out of business), it might be desirable to cancel his property right in the label.

\footnotetext{
${ }^{261}$ The creation of labels per se can to some degree be counted as an independent benefit of property rights in them, for the labels add words (and symbols) to our vocabulary. For example, the words "aspirin" and "thermos" were originally trademarks and have now entered into our language. But because it seems that society can fairly easily invent new words as needed, I will not analyze the creation of new words as a benefit of property rights in labels in the text.
} 
What can be said about the desirable extent of property right protection in a label at any given time, that is, about such issues as the socially optimal geographic scope of protection or about protection against use of similar but not identical labels? Evidently, the guiding principle should be that use of a label should not lead consumers to confuse different products, for the social desirability of labels rests on their furnishing consumers the ability to identify product quality. Suppose, for example, that a firm doing business in state A alone adopts the very same label for its product ("Party-time Pizza") as does another firm doing business in state B alone, and that consumers would thus not be likely to be confused about the meaning of the label in either state (if they even knew about the use of the label in the other state). Then it might well be desirable to allow the use of both labels even though they are identical. But suppose that a firm uses a label (such as the brand name "Liz Claborne") that is different from an established label (the brand name "Liz Claiborne"), but not so different as to be noticed by most consumers. Here it would seem that the new label should be barred even though the label is not identical to the first.

\subsection{Property rights in labels contrasted with property rights in information}

of repeat value. The chief difference between property rights in labels and property rights in information of repeat value discussed earlier is that the granting of property rights in labels involves no significant social cost beyond that of enforcement. Society does not incur a cost when it gives the exclusive right to a label to a seller, whereas society does incur a cost -- due to a suboptimal volume of sales -- when it gives to a party the exclusive right to sell a book or a machine, for a monopoly price will be charged. Thus, unlike patents and copyrights, property rights in labels should be regarded as essentially socially unproblematic.

3.7 Trademark law. ${ }^{262}$ The area of law regarding what has been described here as labels is that of trademarks. A trademark can be any word, name, symbol, device, or signifier used by a manufacturer to identify its goods. To obtain a property right in a trademark, it must be deemed distinctive. This requirement is automatically met by fanciful words, such as "Exxon" and "Sanka"; by words used in arbitrary combination, for example, "Apple Computer"; by words employed in suggestive ways, such as "Ivory Soap"; and even by words used in a straightforward descriptive sense if they have acquired special meaning (known as secondary meaning), for example, "Holiday Inn" or "Pizza Hut". The description of the distinctiveness requirement seems broadly consistent with the uses of trademarks discussed above, especially in respect to the goal of minimizing interference with normal use of language. ${ }^{263}$

\footnotetext{
${ }^{262}$ I focus here on American and English trademark law, which is described in, for example, Kane 2001, McCarthy 1996, and Miller and Davis 2000. On trademark law in other countries (which resembles AngloAmerican trademark law), see Jacobs 1987, Pinner 1978, and Ruster 1991. On the history of trademark law, see Schechter 1925 and McClure 1979.

${ }^{263}$ Clearly, the use of fanciful words and arbitrary combinations does not interfere with normal usage, nor, probably, do suggestive combinations of words. Additionally, the very definition of secondary meaning ensures that when words used in a normal descriptive sense are allowed to constitute a trademark they are so well associated with a particular seller that in fact other sellers would not be at risk of unknowingly using the words (no motel chain would unknowingly use the words "Holiday Inn" in describing its motels).
} 
The legal treatment of symbols is similar to that of words. Symbols may be trademarks if they are specially conceived, like the three-spoked Mercedes symbol; common symbols (such as a circle) cannot receive trademark protection, nor can design characteristics that have functional significance (the feature of treads on a tire cannot be trademarked, but a logo on the tire wall can be). ${ }^{264}$

Trademarks can be acquired through use and through registration processes, ${ }^{265}$ and they can be sold.

The duration of trademarks is indefinite; they can be held as long as they are employed. If abandoned, however, or if rapidly degraded, they can be lost. These aspects of trademark duration make economic sense, as explained in section 3.5 above.

If a trademarked word enters the language because it acquires generic meaning -as has happened, for example, with "aspirin," "thermos," and "yo-yo" -- the trademark is lost. The social advantage of this doctrine is that it enables other sellers to describe their product without undue difficulty (how would a maker of yo-yos describe its product without using the word "yo-yo"?). A possible disadvantage of the doctrine is that holders of trademarks may be induced to spend to prevent the trademarks from becoming generic; such expenditures are a social waste and, if successful, imply that other sellers will have to establish a synonymous word for the product. ${ }^{266}$

The touchstone of trademark infringement doctrine is the likelihood of consumer misapprehension about the true seller of goods and services. Thus, as was suggested above (in section 3.5) to be socially desirable, infringement is more likely to be found the more the marks resemble each other, the more similar the marked goods, and the greater the geographic overlap in their markets.

The literature. Several articles adopt an economic orientation toward the analysis of trademark law, the most general of these being Landes and Posner (1987a). ${ }^{267}$

\footnotetext{
${ }^{264}$ Note that, were a feature with functional significance like treads to constitute a trademark, the maker of treaded tires would effectively be given a monopoly in a product characteristic that directly benefits consumers. Thus, consumer welfare would fall; the manufacturer would charge a monopoly price for treads, resulting in a suboptimal volume of tires with treads.

${ }^{265}$ In the United States, trademarks are governed by state common law and by federal trademark statutes, effectively establishing a federal registration system; see, for example, Hawes 1997 and McCarthy 1996.

${ }^{266}$ For literature on the genericness doctrine, see, for example, Palladino 2000 and Swann 1999.

${ }^{267}$ See also Burgunder 1985, Economides 1988, 1998, Lemley 1999, and Note 1984.
} 


\section{References}

Abel, Andrew B. 1985. Precautionary Saving and Accidental Bequests. American Economic Review 75:777-91.

Alces, Peter A., and Harold F. See. 1994. The Commercial Law of Intellectual Property. Boston: Little, Brown and Company.

Alston, Lee J., Gary D. Libecap, and Robert Schneider. 1996. The Determinants and Impact of Property Rights: Land Titles on the Brazilian Frontier. Journal of Law, Economics \& Organization 12:25-61.

Altonji, Joseph G., Fumio Hayashi, and Laurence J. Kotlikoff. 1997. Parental Altruism and Inter Vivos Transfers: Theory and Evidence. Journal of Political Economy 105:1121-66.

Anderson, Terry L., and Peter J. Hill. 1990. The Race for Property Rights. Journal of Law and Economics 33:177-97.

Andreoni, James. 1990. Impure Altruism and Donations to Public Goods: A Theory of Warm-Glow Giving. Economic Journal 100:464-77.

Andrews, Edmund L. 1995. Winners of Wireless Auction to Pay \$7 Billion. New York Times, March 14, 1995, p. D1.

Arlen, Jennifer, Matthew Spitzer, and Eric Talley. 2002. Endowment Effects Within Corporate Agency Relationships. Journal of Legal Studies 31:1-37.

Arrow, Kenneth J. 1969. The Organization of Economic Activity: Issues Pertinent to the Choice of Market Versus Nonmarket Allocation. In The Analysis and Evaluation of Public Expenditures: The PPB System. Joint Economic Committee, 91st Congress, 1st Session, 1:47-64. Washington, D.C.: Government Printing Office.

----- 1971. Essays in the Theory of Risk-Bearing. Chicago: Markham Pub. Co.

Atkinson, Anthony B., and Joseph E. Stiglitz. 1980. Lectures on Public Economics. New York: McGraw-Hill Book Co.

August, Ray. 1993. Cowboys v. Rancheros: The Origins of Western American Livestock Law. Southwestern Historical Quarterly 96:457-88.

Ayres, B. Drummond, Jr. 1996. A Toll Road in California Offers a High-Tech Answer to Traffic. New York Times, Jan. 2, 1996, p. A1.

Ayres, Ian, and Robert Gertner. 1989. Filling Gaps in Incomplete Contracts: An Economic Theory of Default Rules. Yale Law Journal 99: 87-130.

Bailey, Martin J. 1998. Property Rights in Aboriginal Societies. In The New Palgrave Dictionary of Economics and the Law, edited by Peter Newman, 3:155-57. London: Macmillan. 
Baird, Douglas, and Thomas Jackson.1984. Information, Uncertainty, and the Transfer of Property. Journal of Legal Studies 13:299-320.

Ballantine, Henry W. 1918. Title by Adverse Possession. Harvard Law Review 32:13559.

Bassano, Joseph, Laura Dietz, Edward Esping, Tammy Hinshaw, Theresa Leming, Anne Payne, Jeanne Philbin, Kimberly Simmons, Susan Thomas, Lisa Zakolski, and Anne Melley. 1997. Automobiles and Highway Traffic. In American Jurisprudence, second edition, 7A:477-914, 8:1-870. West Group.

Baxter, William F., and Lillian R. Altree. 1972. Legal Aspects of Airport Noise. Journal of Law and Economics 15:1-113.

Bean, Michael J. 1983. The Evolution of National Wildlife Law. Revised edition. New York: Praeger: Environmental Defense Fund.

Bentham, Jeremy. [1789] 1973. An Introduction to the Principles of Morals and Legislation. In The Utilitarians. Reprint of 1823 edition. Garden City, N.Y.: Anchor Books.

----- [1802] 1987. The Theory of Legislation. Translated by Richard Hildreth, edited by C. K. Ogden. Littleton, Colorado: Fred B. Rothman \& Co.

----- 1827. Rationale of Judicial Evidence. Vol. 5. London: Hunt and Clarke.

Berger, Lawrence. 1974. A Policy Analysis of the Taking Problem. New York University Law Review 49:165-226.

Berndt, Ernst R., Iain M. Cockburn, and Zvi Griliches. 1996. Pharmaceutical Innovations and Market Dynamics: Tracking Effects on Price Indexes for Antidepressant Drugs. Brookings Papers on Economic Activity: Microeconomics 1996:133-88.

Bernheim, B. Douglas. 1991. How Strong Are Bequest Motives? Evidence Based on Estimates of the Demand for Life Insurance and Annuities. Journal of Political Economy 99:899-927.

Bernheim, B. Douglas, Andrei Shleifer, and Laurence Summers. 1985. The Strategic Bequest Motive. Journal of Political Economy 93:1045-76.

Besen, Stanley M. 1998. Intellectual Property. In The New Palgrave Dictionary of Economics and the Law, edited by Peter Newman, 2:348-52. London: Macmillan.

Besen, Stanley M., and Leo J. Raskind. 1991. An Introduction to the Law and Economics of Intellectual Property. Journal of Economic Perspectives 5 (no. 1):3-27.

Besley, Timothy. 1995. Property Rights and Investment Incentives: Theory and Evidence from Ghana. Journal of Political Economy 103:903-37. 
----- 1998. Investment Incentives and Property Rights. In The New Palgrave Dictionary of Economics and the Law, edited by Peter Newman, 2:359-65. London: Macmillan.

Biblowit, Charles. 1991. International Law and the Allocation of Property Rights in Common Resources. New York International Law Review 4:77-85.

Blackstone, William. [1765-1769] 1992. Commentaries on the Laws of England. Reprint of the first edition. Buffalo: William S. Hein \& Co.

Blume, Lawrence, and Daniel L. Rubinfeld. 1984. Compensation for Takings: An Economic Analysis. California Law Review 72:569-628.

Blume, Lawrence, Daniel L. Rubinfeld, and Perry Shapiro. 1984. The Taking of Land: When Should Compensation Be Paid? Quarterly Journal of Economics 99:71-92.

Bosselman, Fred P., David L. Callies, and John Banta. 1973. The Taking Issue: A Study of the Constitutional Limits of Governmental Authority. Washington D.C.: U.S. Council on Environmental Quality.

Bouckaert, Boudewijn, and Ben W. F. Depoorter. 2000. Adverse Possession - Title Systems. In Encyclopedia of Law and Economics, edited by Boudewijn Bouckaert and Gerrit De Geest, 2:18-31. Cheltenham: Edward Elgar.

Bovenberg, A. Lans, and Lawrence H. Goulder. 2002. Environmental Taxation and Regulation. In Handbook of Public Economics, edited by Alan J. Auerbach and Martin Feldstein, 3:1471-1545. Amsterdam: Elsevier.

Breyer, Stephen. 1970. The Uneasy Case for Copyright: A Study of Copyright in Books, Photocopies, and Computer Programs. Harvard Law Review 84:281-351.

----- 1982. Regulation and Its Reform. Cambridge, Mass.: Harvard University Press.

Brown, Ray Andrews. 1975. The Law of Personal Property Third edition. Edited by Walter B. Raushenbush. Chicago: Callaghan.

Buchanan, James M., and Wm. Craig Stubblebine. 1962. Externality. Economica 29:37184.

Burgunder, Lee B. 1985. An Economic Approach to Trademark Genericism. American Business Law Journal 23:391-416.

Cahoon, Colin. 1990. Low Altitude Airspace: A Property Rights No-Man's Land. Journal of Air Law and Commerce 56:157-98.

Calabresi, Guido.1968. Transaction Costs, Resource Allocation and Liability Rules--A Comment. Journal of Law and Economics 11:67-73.

----- 1970. The Costs of Accidents: A Legal and Economic Analysis. New Haven: Yale University Press. 
Calabresi, Guido, and A. Douglas Melamed. 1972. Property Rules, Liability Rules, and Inalienability: One View of the Cathedral. Harvard Law Review 85:1089-1128.

Calandrillo, Steve P. 1998. An Economic Analysis of Intellectual Property Rights: Justifications and Problems of Exclusive Rights, Incentives to Generate Information, and the Alternative of a Government-Run Reward System. Fordham Intellectual Property, Media, and Entertainment Law Journal 9:303-60.

Carlton, Dennis W., and Glenn C. Loury. 1980. The Limitations of Pigouvian Taxes as a Long-Run Remedy for Externalities. Quarterly Journal of Economics 95:559-66.

Chang, Howard F. 1995. Patent Scope, Antitrust Policy, and Cumulative Innovation. Rand Journal of Economics 26:34-57.

Cheung, Steven N. S. 1973. The Fable of the Bees: An Economic Investigation. Journal of Law and Economics 16:11-33.

----- 1982. Property Rights in Trade Secrets. Economic Inquiry 20:40-53.

Chisum, Donald S. 1996. Chisum on Patents: A Treatise on the Law of Patentability, Validity, and Infringement. New York: LEXIS Publishing.

Chisum, Donald S., Craig Allen Nard, Herbert F. Schwartz, Pauline Newman, and F. Scott Kieff. 2001. Principles of Patent Law. Second edition. New York: Foundation Press.

Clark, Barkley, and Barbara Clark. 2001. The Law of Secured Transactions Under the Uniform Commercial Code. Revised edition. Vol. 1. Arlington: A.S. Pratt \& Sons. Thomson Financial.

Coase, Ronald H. 1959. The Federal Communications Commission. Journal of Law and Economics 2:1-40.

----- 1960. The Problem of Social Cost. Journal of Law and Economics 3:1-44.

----- 1974. The Lighthouse in Economics. Journal of Law and Economics 17:357-76.

----- 1988. The Firm, the Market, and the Law. Chicago: University of Chicago Press.

Cohen, Jerry, and Alan S. Gutterman.1998. Trade Secrets Protection and Exploitation. Washington D.C.: Bureau of National Affairs.

Cooter, Robert, and Thomas Ulen. 1999. Law and Economics. Third edition. Reading, Mass.: Addison-Wesley.

Corpus Juris Secundum. 1961. St. Paul, Minn.: West Publishing.

Cox, Donald. 1987. Motives for Private Income Transfers. Journal of Political Economy 95:508-46. 
Cropper, Maureen L., and Wallace E. Oates. 1992. Environmental Economics: A Survey. Journal of Economic Literature 30:675-740.

Croson, Rachel, and Jason S. Johnston. 2000. Experimental Results on Bargaining Under Alternative Property Rights Regimes. Journal of Law, Economics, \& Organization 16:50-73.

Dales, J. H. 1968. Pollution, Property, and Prices. Toronto: University of Toronto.

Dam, Kenneth W. 1994. The Economic Underpinnings of Patent Law. Journal of Legal Studies 23:247-71.

Davenport, Neil. 1993. United Kingdom Copyright \& Design Protection: A Brief History.

Davies, James B. 1981. Uncertain Lifetime, Consumption, and Dissaving in Retirement. Journal of Political Economy 89:561-77.

Davis, Otto A., and Andrew Whinston. 1962. Externalities, Welfare, and the Theory of Games. Journal of Political Economy 70:241-62.

De Meza, David. 1998. Coase Theorem. In The New Palgrave Dictionary of Economics and the Law, edited by Peter Newman, 1:270-82. London: Macmillan.

Demsetz, Harold. 1967. Toward a Theory of Property Rights. American Economic Review: Papers and Proceedings 57 (no. 2):347-59.

De Vany, Arthur S., Ross D. Eckert, Charles J. Meyers, Donald J. O'Hara, and Richard C. Scott. 1969. A Property System for Market Allocation of the Electromagnetic Spectrum: A Legal-Economic-Engineering Study. Stanford Law Review 21:14991561.

Dietz, Laura H. 2000. Salvage. In American Jurisprudence, second edition, 68:211-89. West Group.

Dinwoodie, Graeme B., William O. Hennessey, and Shira Perlmutter. 2001. International Intellectual Property Law and Policy. Newark: LexisNexis.

Dobbs, Dan B. 2000. The Law of Torts. St. Paul, Minn: West Group.

Dukeminier, Jesse, and James E. Krier. 1998. Property. Fourth edition. New York: Aspen Law and Business.

Eckert, Ross D. 1979. The Enclosure of Ocean Resources: Economics and the Law of the Sea. Stanford: Hoover Institution Press.

Economides, Nicholas S. 1988. The Economics of Trademarks. Trademark Reporter 78:523-39.

----- 1998. Trademarks. In The New Palgrave Dictionary of Economics and the Law, edited by Peter Newman, 3:601-03. London: Macmillan. 
Ellickson, Robert C. 1973. Alternatives to Zoning: Covenants, Nuisance Rules, and Fines as Land Use Controls. University of Chicago Law Review 40:681-781.

----- 1986. Adverse Possession and Perpetuities Law: Two Dents in the Libertarian Model of Property Rights. Washington University Law Quarterly 64:723-37.

----- 1991. Order without Law: How Neighbors Settle Disputes. Cambridge, Mass.: Harvard University Press.

----- 1993. Property in Land. Yale Law Journal 102:1315-1400.

Ely, Northcutt. 1938. The Conservation of Oil. Harvard Law Review 51:1209-44.

Epstein, Richard A.1985. Takings: Private Property and the Power of Eminent Domain. Cambridge, Mass.: Harvard University Press.

Evans, Robert. 1987. The Early History of Fire Insurance. Journal of Legal History 8:8891.

Eyre, Frank, and E. C. R. Hadfield. 1945. The Fire Service Today. London: Oxford University Press.

Farber, Daniel A. 1992. Economic Analysis and Just Compensation. International Review of Law and Economics 12:125-38.

Farnsworth, Ward. 1999. Do Parties to Nuisance Cases Bargain After Judgment? A Glimpse Inside the Cathedral. University of Chicago Law Review 66:373-436.

Feder, Gershon, and David Feeny.1991. Land Tenure and Property Rights: Theory and Implications for Development Policy. World Bank Economic Review 5:135-53.

Federal Procedure. 2000. Lawyers Edition. St. Paul, Minn.: West Group.

Feldman, Allan M. 1987. Welfare Economics. In The New Palgrave: A Dictionary of Economics, edited by John Eatwell, Murray Milgate, and Peter Newman, 4:88996. London: Macmillan.

Fischel, William A. 1995. Regulatory Takings: Law, Economics, and Politics. Cambridge, Mass.: Harvard University Press.

Fisher, William W., III. 1988. Reconstructing the Fair Use Doctrine. Harvard Law Review 101:1659-1795.

Flinn, Patrick J. 2001. Handbook of Intellectual Property Claims and Remedies. New York: Aspen Law \& Business.

Foster, Seena. 2000. Validity, Construction, and Application of Abandoned Shipwreck Act of 1987. American Law Reports, Federal Cases and Annotations 163:421-44.

Frech, H. E., III. 1973. Pricing of Pollution: The Coase Theorem in the Long Run. Bell Journal of Economics and Management Science 4:316-19. 
Friedman, David D., William M. Landes, and Richard A. Posner. 1991. Some Economics of Trade Secret Law. Journal of Economic Perspectives 5 (no. 1):61-72.

Gabel, George F., Jr. 1994. Abandoned, Lost, and Unclaimed Property. In American Jurisprudence, second edition, 1:1-54. Rochester: Lawyers Cooperative Publishing.

Gale, William G., and John Karl Scholz. 1994. Intergenerational Transfers and the Accumulation of Wealth. Journal of Economic Perspectives 8 (no. 4):145-60.

Gallini, Nancy. 2002. The Economics of Patents: Lessons from Recent U.S. Patent Reform. Journal of Economic Perspectives (forthcoming).

Garner, J. F., editor. 1975. Compensation for Compulsory Purchase: A Comparative Study. London: United Kingdom National Committee of Comparative Law.

Gilbert, Richard, and Carl Shapiro. 1990. Optimal Patent Length and Breadth. Rand Journal of Economics 21:106-12.

Glendon, Mary Ann.1989. The Transformation of Family Law: State, Law, and Family in the United States and Western Europe. Chicago: University of Chicago Press.

Goldstein, Paul. 2001a. Copyright. Second edition. New York: Aspen Law and Business.

---- 2001b. International Copyright: Principles, Law, and Practice. New York: Oxford University Press.

Gordon, Wendy J. 1982. Fair Use as Market Failure: A Structural and Economic Analysis of the Betamax Case and Its Predecessors. Columbia Law Review 82:1600-57.

Gordon, Wendy J., and Robert G. Bone. 2000. Copyright. In Encyclopedia of Law and Economics, edited by Boudewijn Bouckaert and Gerrit De Geest, 2:189-215. Cheltenham: Edward Elgar.

Grabowski, Henry G., and John M. Vernon. 1992. Brand Loyalty, Entry, and Price Competition in Pharmaceuticals after the 1984 Drug Act. Journal of Law and Economics 35:331-50.

Graetz, Michael J. 1985. Retroactivity Revisited. Harvard Law Review 98:1820-41.

Green, Jerry R., and Suzanne Scotchmer. 1995. On the Division of Profit in Sequential Innovation. Rand Journal of Economics 26:20-33.

Hahn, Robert W. 1990. Regulation: Past, Present, and Future. Harvard Journal of Law and Public Policy 13:167-228.

Hahn, Robert W., and Robert N. Stavins. 1991. Incentive-Based Environmental Regulation: A New Era from an Old Idea? Ecology Law Quarterly 18:1-42. 
Hamilton, Jonathan H., Eytan Sheshinski, and Steven M. Slutsky. 1989. Production Externalities and Long-Run Equilibria: Bargaining and Pigovian Taxation. Economic Inquiry 27:453-71.

Hannesson, Rögnvaldur. 1991. From Common Fish to Rights Based Fishing. European Economic Review 35:397-407.

Hansmann, Henry, and Reinier Kraakman. 2002. Property, Contract, and Verifications: The Numerus Clausus Problem and the Divisibility of Rights. Harvard John M. Olin Discussion Paper Series, no. 388. Cambridge, Mass: Harvard Law School.

Hau, Timothy D. 1990. Electronic Road Pricing: Developments in Hong Kong 19831989. Journal of Transport Economics and Policy 24:203-14.

Hausman, Jerry A., editor. 1993. Contingent Valuation: A Critical Assessment. Amsterdam: North Holland.

Hawes, James E. 1997. Trademark Registration Practice. Second edition. St. Paul, Minn.: West Group.

Heilbroner, Robert L. 1962. The Making of Economic Society. Englewood Cliffs, New Jersey: Prentice-Hall.

----- 1987. Capitalism. In The New Palgrave Dictionary of Economics, edited by John Eatwell, Murray Milgate, and Peter Newman, 1:347-53. London: Macmillan.

Heller, Michael A. 1999. The Boundaries of Private Property. Yale Law Journal 108:1163-1223.

Heller, Michael A., and Rebecca S. Eisenberg. 1998. Can Patents Deter Innovation? The Anticommons in Biomedical Research. Science 280:698-701.

Henry, David J. 1977. Multi-National Practice in Determining Provisions in Compulsory Patent Licenses. Journal of International Law and Economics 11:325-51.

Hermalin, Benjamin E. 1995. An Economic Analysis of Takings. Journal of Law, Economics, \& Organization 11:64-86.

Hesse, Carla. 1989. Economic Upheavals in Publishing. In Revolution in Print, edited by Robert Darnton and Daniel Roche, 69-97. Berkeley: University of California Press.

Hirshleifer, Jack. 1971. The Private and Social Value of Information and the Reward to Inventive Activity. American Economic Review 61:561-74.

Hobbes, Thomas. [1651] 1958. Leviathan, Parts I and II. Introduction by Herbert W. Schneider. Indianapolis: Library of Liberal Arts, Bobbs-Merrill.

Hoffman, Elizabeth, and Matthew L. Spitzer. 1982. The Coase Theorem: Some Experimental Tests. Journal of Law and Economics 25:73-98. 
Hume, David. [1739] 1992. Treatise of Human Nature. Buffalo, N.Y.: Prometheus Books.

----- [1751] 1998. An Enquiry Concerning the Principles of Morals. Edited by Tom L. Beauchamp. Oxford: Oxford University Press.

Hurd, Michael D. 1989. Mortality Risk and Bequests. Econometrica 57:779-813.

Hurt, Robert M., and Robert M. Schuchman. 1966. The Economic Rationale of Copyright. American Economic Review: Papers and Proceedings 56:421-32.

Izuel, Leeanna. 1991. Property Owners' Constructive Possession of Treasure Trove: Rethinking the Finders Keepers Rule. UCLA Law Review 38:1659-1702.

Jacobs, Alan J. 1987. Trademarks Throughout the World. Fourth edition. New York: Trade Activities.

Jacobs, Allan B. 1993. Great Streets. Cambridge, Mass.: MIT Press.

Jaffe, Adam B. 2000. The U.S. Patent System in Transition: Policy Innovation and the Innovation Process. Research Policy 29:531-57.

Johnson, Ronald N., and Gary D. Libecap. 1982. Contracting Problems and Regulation: The Case of the Fishery. American Economic Review 72:1005-22.

Johnston, Jason S. 1990. Strategic Bargaining and the Economic Theory of Contract Default Rules. Yale Law Journal 100:615-64.

Jolls, Christine, Cass R. Sunstein, and Richard Thaler. 1998. A Behavioral Approach to Law and Economics. Stanford Law Review 50:1471-1550.

Jones, G. Kevin. 1984. The Development of Outer Continental Shelf Energy Resources. Public Land and Resources Law Digest 21:36-111.

Jones, William K. 1995. Confiscation: A Rationale of the Law of Takings. Hofstra Law Review 24:1-88.

Kahn, Alfred E. 1988. The Economics of Regulation: Principles and Institutions. Second edition. Cambridge, Mass.: MIT Press.

Kahneman, Daniel, Jack L. Knetsch, and Richard L. Thaler. 1990. Experimental Tests of the Endowment Effect and the Coase Theorem. Journal of Political Economy 98:1325-48.

Kane, Siegrun D. 2001. Trademark Law: A Practitioner's Guide. Third edition (1997, updated 2001). New York: Practising Law Institute.

Kaplow, Louis. 1984. The Patent-Antitrust Intersection: A Reappraisal. Harvard Law Review 97:1813-92. 
----- 1986a. An Economic Analysis of Legal Transitions. Harvard Law Review 99:509617.

----- 1995. A Note on Subsidizing Gifts. Journal of Public Economics 58:469-77.

----- 1996. The Optimal Supply of Public Goods and the Distortionary Cost of Taxation. National Tax Journal 49:513-33.

Kaplow, Louis, and Steven Shavell.1996b. Property Rules versus Liability Rules: An Economic Analysis. Harvard Law Review 109:713-90.

-----2002b. Fairness versus Welfare. Cambridge, Mass.: Harvard University Press. (Also published in Harvard Law Review 114:961-1388.)

Kennan, John, and Robert Wilson. 1993. Bargaining with Private Information. Journal of Economic Literature 31:45-104.

Kitch, Edmund W. 1977. The Nature and Function of the Patent System. Journal of Law and Economics 20:265-90.

Klemperer, Paul. 1990. How Broad Should the Scope of Patent Protection Be? Rand Journal of Economics 21:113-30.

Knetsch, Jack L., and Thomas E. Borcherding. 1979. Expropriation of Private Property and the Basis for Compensation. University of Toronto Law Journal 39:237-52.

Kolstad, Charles D., Thomas S. Ulen, and Gary V. Johnson. 1990. Ex Post Liability for Harm vs. Ex Ante Safety Regulation: Substitutes or Complements? American Economic Review 80:888-901.

Korobkin, Russell. 1994. Policymaking and the Offer/Asking Price Gap: Toward a Theory of Efficient Entitlement Allocation. Stanford Law Review 46:663-708.

Kosmo, Fred. 1988. The Commercialization of Space: A Regulatory Scheme that Promotes Commercial Ventures and International Responsibility. Southern California Law Review 61:1055-89.

Kotlikoff, Laurence J. 1988. Intergenerational Transfers and Savings. Journal of Economic Perspectives 2 (no. 2):41-58.

----- 2001. Essays on Saving, Bequests, Altruism, and Life-Cycle Planning. Cambridge, Mass.: MIT Press.

Kotlikoff, Laurence J., and Avia Spivak. 1981. The Family as an Incomplete Annuities Market. Journal of Political Economy 89:372-91.

Kowalik, Tadeusz. 1987. Central Planning. In The New Palgrave Dictionary of Economics, edited by John Eatwell, Murray Milgate, and Peter Newman, 1:38992. London: Macmillan. 
Kremer, Michael. 1998. Patent Buyouts: A Mechanism for Encouraging Innovation. Quarterly Journal of Economics 113:1137-67.

Krutilla, John V. 1967. Conservation Reconsidered. American Economic Review 57:77786.

Ladas, Stephen P. 1964. Legal Protection of Know-How. Trademark Reporter 54:160-83.

Laffont, Jean-Jacques. 1987a. Externalities. In The New Palgrave Dictionary of Economics, edited by John Eatwell, Murray Milgate, and Peter Newman, 2:26365. London: Macmillan.

----- 1987b. Incentives and the Allocation of Public Goods. Chapter 10 in Handbook of Public Economics, edited by Alan J. Auerbach and Martin Feldstein, 2:537-69. Amsterdam: North-Holland.

Landes, William M., and Richard A. Posner.1987a. The Economic Structure of Tort Law. Cambridge, Mass.: Harvard University Press.

---- 1987b. Trademark Law: An Economic Perspective. Journal of Law and Economics 30:265-309.

----- 1989. An Economic Analysis of Copyright Law. Journal of Legal Studies 18:32563.

Langbein, John H., and Lawrence W. Waggoner. 1987. Redesigning the Spouse's Forced Share. Real Property, Probate and Trust Journal 22:303-28.

Lanjouw, Jean O., and Josh Lerner. 1998. The Enforcement of Intellectual Property Rights: A Survey of the Empirical Literature. Annales d'Economie et de Statistique 49/50:223-46.

Lee, Sabing H. 1997. Protecting the Private Inventor Under the Peacetime Provisions of the Invention Secrecy Act. Berkeley Technology Law Journal 12:345-411.

Lemley, Mark A. 1997. The Economics of Improvement in Intellectual Property Law. Texas Law Review 75:989-1084.

---- 1999. The Modern Lanham Act and the Death of Common Sense. Yale Law Journal 108:1687-1715.

Levmore, Saul. 1987. Variety and Uniformity in the Treatment of the Good-Faith Purchaser. Journal of Legal Studies 16:43-65.

----- 1993. The Case for Retroactive Taxation. Journal of Legal Studies 22:265-307.

Libecap, Gary D. 1986. Property Rights in Economic History: Implications for Research. Explorations in Economic History 23:227-52.

1989. Contracting for Property Rights. Cambridge: Cambridge University Press. 
Lichtman, Douglas Gary. 1997. Pricing Prozac: Why the Government Should Subsidize the Purchase of Patented Pharmaceuticals. Harvard Journal of Law and Technology 11:123-39.

Locke, John. [1689] 1988. Two Treatises of Government, edited by Peter Laslett. Cambridge: Cambridge University Press.

Lueck, Dean. 1998. First Possession. In The New Palgrave Dictionary of Economics and the Law, edited by Peter Newman, 2:132-44. London: Macmillan.

Lund, Thomas A. 1980. American Wildlife Law. Berkeley: University of California Press.

Machlup, Fritz. 1958. An Economic Review of the Patent System. Study of The Subcommittee on Patents, Trademarks, and Copyrights, Committee on the Judiciary, United States Senate, Study No. 15. Washington D.C.: United States Government Printing Office.

Machlup, Fritz, and Edith Penrose. 1950. The Patent Controversy in the Nineteenth Century. Journal of Economic History 10:1-29.

Mankiw, N. Gregory. 2001. Principles of Economics. Second edition. Fort Worth: Harcourt College Publishers.

McAfee, R. Preston, and John McMillan. 1996. Analyzing the Airwaves Auction. Journal of Economic Perspectives 10 (no. 1):159-75.

McCarthy, J. Thomas. 1996 (updated through 2002). McCarthy on Trademarks and Unfair Competition. Fourth edition. Deerfield, Ill.: Clark Boardman Callaghan.

McCarthy, Patrick S., and Richard Tay. 1993. Pricing Road Congestion: Recent Evidence from Singapore. Policy Studies Journal 21:296-308.

McChesney, Fred S. 1986. Government Prohibitions on Volunteer Firefighting in Nineteenth-Century America: A Property Rights Perspective. Journal of Legal Studies 15:69-92.

McClure, Daniel M. 1979. Trademarks and Unfair Competition: A Critical History of Legal Thought. Trademark Reporter 69:305-56.

McCormack, John L. 1992. Torrens and Recording: Land Title Assurance in the Computer Age. William Mitchell Law Review 18:61-129.

McMillan, John. 1994. Selling Spectrum Rights. Journal of Economic Perspectives 8 (no. 3):145-62.

Menell, Peter S. 2000. Intellectual Property: General Theories. In Encyclopedia of Law and Economics, edited by Boudewijn Bouckaert and Gerrit De Geest, 2:129-88. Cheltenham: Edward Elgar.

Menell, Peter S., and Richard B. Stewart. 1994. Environmental Law and Policy. Boston: Little, Brown. 
Merges, Robert P., and Richard R. Nelson. 1990. On the Complex Economics of Patent Scope. Columbia Law Review 90:839-916.

Merrill, Thomas W. 1986. The Economics of Public Use. Cornell Law Review 72:61-116.

Merrill, Thomas W., and Henry E. Smith. 2000. Optimal Standardization in the Law of Property: The Numerus Clausus Principle. Yale Law Journal 110:1-70.

Metaxas-Maranghidis, George, editor. 1995. Intellectual Property Laws of Europe. Chichester: John Wiley \& Sons.

Meyer, Keith G. 1990. UCC Issues. Journal of Agricultural Taxation \& Law 12:179-87.

Miceli, Thomas J. 1998. Land Title Systems. In The New Palgrave Dictionary of Economics and the Law, edited by Peter Newman, 2:433-37. London: Macmillan.

Miceli, Thomas J., and Kathleen Segerson. 1996. Compensation for Regulatory Takings: An Economic Analysis with Applications. Greenwich, Conn.: JAI Press.

----- 1998. Compensation for Regulatory Takings. In The New Palgrave Dictionary of Economics and the Law, edited by Peter Newman, 1:360-64. London: Macmillan.

----- 2000. Takings. In Encyclopedia of Law and Economics, edited by Boudewijn Bouckaert and Gerrit De Geest, 4:328-57. Cheltenham: Edward Elgar.

Miceli, Thomas J., and C. F. Sirmans. 1995. An Economic Theory of Adverse Possession. International Review of Law and Economics 15:161-73.

Michelman, Frank. 1967. Property, Utility, and Fairness: Comments on the Ethical Foundations of "Just Compensation" Law. Harvard Law Review 80:1165-1258.

Milgrim, Roger M. 1995. Milgrim on Trade Secrets. New York: Matthew Bender.

Milgrom, Paul R.1993. Is Sympathy an Economic Value? Philosophy, Economics, and the Contingent Valuation Method. Chapter XI in Contingent Valuation: A Critical Assessment, edited by Jerry A. Hausman. Amsterdam: North Holland.

Mill, John Stuart. [1848] 1872. Principles of Political Economy. Boston: Lee and Shephard.

Miller, Arthur R., and Michael H. Davis. 2000. Intellectual Property: Patents, Trademarks, and Copyright in a Nutshell. Third edition. St Paul, Minn.: West Group.

Mims, Peter E. 1984. Promotional Goods and the Functionality Doctrine: An Economic Model of Trademarks. Texas Law Review 63:639-69.

Mitchell, Robert C., and Richard T. Carson. 1989. Using Surveys to Value Public Goods. Washington, D.C.: Resources for the Future. 
Munch, Patricia. 1976. An Economic Analysis of Eminent Domain. Journal of Political Economy 84:473-97.

Musgrave, Richard A. 1985. A Brief History of Fiscal Doctrine. Chapter 1 in Handbook of Public Economics, edited by Alan J. Auerbach and Martin Feldstein, 1:1-59. Amsterdam: North-Holland.

Netter, Jeffry M. 1998. Adverse Possession. In The New Palgrave Dictionary of Economics and the Law, edited by Peter Newman, 1:18-21. London: Macmillan.

Nicholas, Barry. 1962. An Introduction to Roman Law. Oxford: Clarendon Press.

Niedercorn, John H., and Edward F. R. Hearle. 1964. Recent Land-Use Trends in FortyEight Large American Cities. Land Economics 40:105-10.

Nimmer, Melville B., and David Nimmer. 1995. Nimmer on Copyright. Second revised edition. New York: Matthew Bender.

Nordhaus, William D. 1969. Invention, Growth, and Welfare: A Theoretical Treatment of Technological Change. Cambridge, Mass.: MIT Press.

Nowak, John E., and Ronald D. Rotunda. 2000. Constitutional Law. Sixth edition. St. Paul, Minn.: West Group.

Oakland, William H. 1987. Theory of Public Goods. Chapter 9 in Handbook of Public Economics, edited by Alan J. Auerbach and Martin Feldstein, 2:485-535. Amsterdam: North-Holland.

Ostrom, Elinor. 1990. Governing the Commons: The Evolution of Institutions for Collective Action. New York: Cambridge University Press.

----- 2000. Private and Common Property Rights. In Encyclopedia of Law and Economics, edited by Boudewijn Bouckaert and Gerrit De Geest, 2:332-79. Cheltenham: Edward Elgar.

Palladino, Vincent N. 2000. Genericism Rationalized: Another View. The Trademark Reporter 90:469-88.

Patterson, Lyman Ray. 1968. Copyright in Historical Perspective. Nashville: Vanderbilt University Press.

Patry, William F. 1994. Copyright Law and Practice. Washington, D.C.: Bureau of National Affairs.

---- 1995. The Fair Use Privilege in Copyright Law. Second edition. Washington, D.C.: Bureau of National Affairs.

Payne, Anne M. 1996. Energy and Power Sources. In American Jurisprudence, second edition, 27A:1-355. Rochester: Lawyers Cooperative Publishing. 
Pendergrast, Mark. 1993. For God, Country, and Coca-Cola: The Unauthorized History of the Great American Soft Drink and the Company that Makes It. New York: Macmillan.

Philbin, Jeanne. 1997. Aviation. In American Jurisprudence, second edition, 8A:1-247. West Group.

Pigou, A. C. 1912. Wealth and Welfare. London: Macmillan.

----- 1932. The Economics of Welfare. Fourth edition. London: Macmillan.

Pinner, H. L. 1978. Pinner's World Unfair Competition Law: An Encyclopedia. Second edition, edited by Heinz David. Alphen aan de Rijn, Netherlands: Sijthoff \& Noordhoff.

Polanvyi, Michael. 1944. Patent Reform. Review of Economic Studies 11:61-76.

Polinsky, A. Mitchell.1980b. Resolving Nuisance Disputes: The Simple Economics of Injunctive and Damage Remedies. Stanford Law Review 32:1075-1112.

Pooley, James. 2001. Trade Secrets. (Update of 1997 edition.) New York: Law Journal Seminars Press.

Posner, Richard A. 1972a. Economic Analysis of Law. Boston: Little, Brown.

Postan, M. M., and Edward Miller, editors. 1987. Cambridge Economic History of Europe. Volume 2: Trade and Industry in the Middle Ages. Second edition. Cambridge: Cambridge University Press.

Prott, Lyndel V., and P. J. O’Keefe. 1995. Law and the Cultural Heritage. Vol. 4: Movement. New York: Lexis Publishing.

Quinn, John, and Michael J. Trebilcock. 1982. Compensation, Transition Costs, and Regulatory Change. University of Toronto Law Journal 32:117-75.

Reinganum, Jennifer F. 1989. The Timing of Innovation: Research, Development, and Diffusion. In Handbook of Industrial Organization, edited by Richard Schmalensee and Robert D. Willig, 1:849-918. Amsterdam: North-Holland.

Riesenfeld, Stefan A. 1958. Patent Protection and Atomic Energy Legislation. California Law Review 46:40-68.

Roberts, Lawrence D. 2000. A Lost Connection: Geostationary Satellite Networks and the International Telecommunication Union. Berkeley Technology Law Journal 15:1095-1144.

Rose, Carol M. 1998. Evolution of Property Rights. In The New Palgrave Dictionary of Economics and the Law, edited by Peter Newman, 1:93-98. London: Macmillan.

Rose, Mark. 1993. Authors and Owners: The Invention of Copyright. Cambridge, Mass.: Harvard University Press. 
Rudden, Bernard. 1987. Economic Theory v. Property Law: The Numerus Clausus Problem. In Oxford Essays in Jurisprudence, edited by John Eekelaar and John Bell. Oxford: Clarendon Press.

Rüster, Bernd, editor. 1991. World Intellectual Property Guidebook: Federal Republic of Germany, Austria, Switzerland. New York: Matthew Bender.

Sackman, Julius L. 2000. Nichols on Eminent Domain. Revised third edition (updated). New York: Matthew Bender.

Samuelson, Paul A. 1954. The Pure Theory of Public Expenditure. Review of Economics and Statistics 36:387-89.

----- 1958. Aspects of Public Expenditure Theories. Review of Economics and Statistics 40:332-38.

Sax, Joseph L. 1971. Takings, Private Property and Public Rights. Yale Law Journal $81: 149-86$.

Schechter, Frank I. 1925. The Historical Foundations of the Law Relating to Trademarks. New York: Columbia University Press.

Scherer, F. M. 1972. Nordhaus' Theory of Optimal Patent Life: A Geometric Representation. American Economic Review 62:422-27.

----- 1980. Industrial Market Structure and Economic Performance. Second edition. Boston: Houghton Mifflin.

Scherer, F. M., and David Ross. 1990. Industrial Market Structure and Economic Performance. Third edition. Boston: Houghton Mifflin.

Schlatter, Richard. 1951. Private Property: The History of an Idea. London: Allen \& Unwin.

Schlicher, John W. 2001. Patent Law: Legal and Economic Principles. Deerfield, Ill.: Clark Boardman Callaghan.

Scotchmer, Suzanne. 1991. Standing on the Shoulders of Giants: Cumulative Research and the Patent Law. Journal of Economic Perspectives 5 (no. 1):29-41.

-----1998. Incentives to Innovate. In The New Palgrave Dictionary of Economics and the Law, edited by Peter Newman, 2:273-77. London: Macmillan.

----- 1999. On the Optimality of the Patent Renewal System. RAND Journal of Economics 30:181-96.

Scott, Anthony. 1988. Development of Property in the Fishery. Marine Resource Economics 5:289-311. 
Settanni, Andrea M. 1994. Competitive Bidding for the Airwaves: Meeting the Budget and Maintaining Policy Goals in a Wireless World. CommLaw Conspectus 2:11732.

Shavell, Steven. 1984b. Liability for Harm versus Regulation of Safety. Journal of Legal Studies 13:357-74.

----- 1984c. A Model of the Optimal Use of Liability and Safety Regulation. Rand Journal of Economics 15:271-80.

----- 1987a. Economic Analysis of Accident Law. Cambridge, Mass.: Harvard University Press.

----- 1993. The Optimal Structure of Law Enforcement. Journal of Law and Economics 36:255-87.

Shavell, Steven, and Tanguy van Ypersele. 2001. Rewards versus Intellectual Property Rights. Journal of Law and Economics 44:525-47.

Shleifer, Andrei. 1998. State versus Private Ownership. Journal of Economic Perspectives 12(no. 4):133-50.

Sidgwick, Henry. 1901. The Principles of Political Economy. Third edition. London: Macmillan.

Simes, Lewis M. 1955. Public Policy and the Dead Hand. Ann Arbor: University of Michigan Law School.

Simes, Lewis M., and Allan F. Smith. 1956. The Law of Future Interests. Second edition, volume 3. St. Paul, Minn.: West Pub. Co.

Singer, Charles, E. J. Holmyard, A. R. Hall, and Trevor I. Williams. 1958. A History of Technology, vol. 4: The Industrial Revolution. Oxford: Clarendon Press.

Sinnot, John P. 1988. World Patent Law and Practice. Vol. 2M. New York: Matthew Bender.

St. Julian, Andrea R. 1995. Animals. In American Jurisprudence, second edition, 4:337512. Rochester: Lawyers Cooperative Publishing.

Stake, Jeffrey Evans. 2000. Decomposition of Property Rights. In Encyclopedia of Law and Economics, edited by Boudewijn Bouckaert and Gerrit De Geest, 2:32-61. Cheltenham: Edward Elgar.

Staple, Gregory C. 1986. The New World Satellite Order: A Report from Geneva. American Journal of International Law 80:699-720.

Starrett, David A. 1972. Fundamental Nonconvexities in the Theory of Externalities. Journal of Economic Theory 4:180-99. 
Statistical Abstract of the United States 2001. 2001. Economics and Statistics Administration, U.S. Census Bureau. Washington, D.C.: U.S. Department of Commerce.

Stepanov, S. 1958. Increasing the Role of Innovators and Inventors in Improving Socialist Production. Problems of Economics 1:75-78.

Stevens, Timothy T. 1992. The Abandoned Shipwreck Act of 1987: Finding the Proper Ballast for the States. Villanova Law Review 37:573-617.

Stiglitz, Joseph E. 1986. Economics of the Public Sector. New York: W. W. Norton.

Stoebuck, William B., and Dale A. Whitman. 2000. The Law of Property. Third edition. St. Paul, Minn.: West Group.

Swann, Jerre B. 1999. Genericism Rationalized. The Trademark Reporter 89:639-56.

Sweeney, Richard James, Robert D. Tollison, and Thomas D. Willett. 1974. Market Failure, the Common-Pool Problem, and Ocean Resource Exploitation. Journal of Law and Economics 17:179-92.

Thomas, David A. 1994. Thompson on Real Property. Thomas Edition. Charlottesville, Virg.: Michie Company.

Tietenberg, Thomas H. 1996. Environmental and Natural Resource Economics. Fourth edition. New York: Harper Collins.

Tirole, Jean. 1988. The Theory of Industrial Organization. Cambridge, Mass.: MIT Press.

Tritton, Guy, Richard Davis, Michael Edenborough, James Graham, Simon Malynicz, and Ashley Roughton. 2002. Intellectual Property in Europe. Second edition. London: Sweet and Maxwell.

Tullock, Gordon. 1971. Inheritance Justified. Journal of Law and Economics 14:465-74.

Tyerman, Barry W. 1971. The Economic Rationale for Copyright Protection for Published Books: A Reply to Professor Breyer. UCLA Law Review 18:1100-25.

Umbeck, John R. 1981. A Theory of Property Rights with Application to the California Gold Rush. Ames: Iowa State University Press.

U.N. Convention on the Law of the Sea.1982. United Nations Treaty Series (1998), 1833:397-581.

Van der Walt, A. J. 1999. Constitutional Property Clauses: A Comparative Analysis. Cambridge, Mass.: Kluwer Law International.

Van Zandt, David E. 1993. The Lessons of the Lighthouse: "Government" or "Private" Provision of Goods. Journal of Legal Studies 22:47-72. 
Viscusi, W. Kip, John M. Vernon, and Joseph E. Harrington, Jr. 2000. Economics of Regulation and Antitrust. Third edition. Cambridge, Mass.: MIT Press.

Waggoner, Lawrence W., Richard V. Wellman, Gregory S. Alexander, and Mary Louise Fellows. 1991. Family Property Law. Westbury, N.Y.: Foundation Press.

Weinberg, Harold R. 1980. Sales Law, Economics, and the Negotiability of Goods. Journal of Legal Studies 9:569-92.

Weitzman, Martin L. 1974. Prices vs. Quantities. Review of Economic Studies 41:477-91.

White, C. Michael. 1956. Why a Seventeen Year Patent? Journal of the Patent Office Society 38:839-60.

Williams, Howard R., and Charles J. Meyers. 2001. Oil and Gas Law. Volume 6, release no. 36. New York: Matthew Bender.

Wineburg, Arthur, editor. 1999. Intellectual Property Protection in Asia. Second edition (updated). Charlottesville, Virg.: LexisNexis.

Wittman, Donald. 1977. Prior Regulation versus Post Liability: The Choice Between Input and Output Monitoring. Journal of Legal Studies 6:193-211.

Wiygul, Robert B. 1992. The Structure of Environmental Regulation on the Outer Continental Shelf: Sources, Problems, and the Opportunity for Change. Journal of Energy, Natural Resources \& Environmental Law 12:75-180.

Wright, Brian D. 1983. The Economics of Invention Incentives: Patents, Prizes, and Research Contracts. American Economic Review 73:691-707.

Yaari, Menahem E. 1965. Uncertain Lifetime, Life Insurance, and the Theory of the Consumer. Review of Economic Studies 32:137-50.

Zakolski, Lisa A. 1997. Boats and Boating. In American Jurisprudence, second edition, 12:273-364. Rochester: Lawyers Cooperative Publishing. 